\title{
Improving the Exfoliation of Layered Silicate in a Poly(ethylene terephthalate) Matrix Using Supercritical Carbon Dioxide
}

\author{
Joseph Reese Samaniuk
}

Thesis submitted to the faculty of Virginia Polytechnic Institute and State

University in partial fulfillment of the requirements for the degree of

\author{
Master of Science \\ in \\ Chemical Engineering
}

Advisory Committee:

Dr. Donald G. Baird, Committee Chair

Dr. Richey M. Davis

Dr. John Y. Walz

April 29, 2008

Blacksburg, VA

Keywords: Poly(ethylene terephthalate), Polymer-layered silicate nanocomposite, PLSN, supercritical carbon dioxide, nanoclay 


\title{
Improving the Exfoliation of Layered Silicate in a Poly(ethylene terephthalate) Matrix Using Supercritical Carbon Dioxide
}

\author{
Joseph Reese Samaniuk
}

\begin{abstract}
Supercritical carbon dioxide $(\mathrm{scCO} 2)$ was used as a processing aid to improve the level of exfoliation achievable in a PET-layered silicate nanocomposite produced from melt compounding. Layered silicate and $\mathrm{scCO} 2$ were allowed to mix for a period of time before being released into the second stage of a single screw extruder. The rapid expansion forced silicate particles into a modified hopper containing neat PET pellets. The mixture of layered silicate and PET was immediately melt mixed in a single screw extruder, cooled in a water bath and pelletized. Two sets of samples each containing layered silicate with different surface chemistries were produced with this method at 1,3 and $5 \mathrm{wt} \%$ silicate. For comparison, samples of the same weight fraction and type of silicate were produced from a traditional melt compounding method. Wide angle x-ray diffraction (WAXD), mechanical testing and rheological analysis were used in order to characterize the silicate morphology, the composite mechanical properties and the relative amount of degradation between the various samples. Results show that scCO2 processed samples contain a higher degree of layered silicate exfoliation than samples produced with traditional melt compounding. Mechanical property improvements are shown to be dependent on the type of silicate surface modification employed. Finally, degradation of the PET matrix appears to be far less extensive in the scCO2 processed samples as shown from rheological data.
\end{abstract}




\section{Acknowledgements}

I would first like to thank the entire faculty and staff of the Chemical Engineering Department at Virginia Tech. Through my undergraduate and graduate work the department has given me support both financially and academically. The faculty have inspired me to excel by their encouragement, dedication and example. I cannot possibly express how grateful I am for the opportunities this place has given me. Whatever success I may find in the future, its origins come from the teaching and guidance of the people of this department. For that I am forever indebted.

I would like to individually thank Dr. Baird for his academic and financial support. His guidance has allowed me to make the most of my time in graduate school and create work that I am proud of. His sound advice has also helped me to shape my future career path.

Thanks also must to go to David Litchfield for obtaining all of the rheological data found in this research. The advice and practical knowledge he shared with me made it possible for me to complete this work.

In addition, I need to thank Dr. Davis, Dr. Walz, Dr. Liu, Dr. Goldstein and Dr. Durrill. You have all been particularly inspiring in my time at Virginia Tech and I thank you for that.

Finally, I'd like to thank my family. First my mom, Kathleen Samaniuk-Hayes for making sure that no matter how long I've been away I've felt loved. Bob, Jen, Jenny, Amy, Robert, John, Rosemarie, Michael, my grandparents and many other close family members have always supported me. I also need to acknowledge my pole vaulting family as they have been my closest friends in all of my years at Virginia Tech. Thank you. 


\section{Attribution}

The co-authors on the work done in chapter 3 of this thesis are Dr. Donald G. Baird and David Litchfield. Dr. Baird is the Henry C. Wyatt professor of chemical engineering at Virginia Tech and gave tremendous direction and guidance to the work that was completed. David is completing his $\mathrm{PhD}$ work at Virginia Tech currently. He lent invaluable experience and practical knowledge to this work in addition to obtaining all of the rheological data presented here. 


\section{Original Contributions}

1. The use of scCO2 to improve the exfoliation of layered silicate in PET based layered silicate nanocomposites was explored. It was shown with the use of WAXD that the level of silicate exfoliation was increased due to $\mathrm{scCO} 2$ treatment. The rapid expansion of $\mathrm{CO} 2$ from a supercritical state to atmospheric conditions is believed to facilitate layered silicate exfoliation. The mechanical response to the improved exfoliation levels was dependant on the type of layered silicate surface modification used in the PLSN.

2. The effect of $\mathrm{scCO} 2$ treatment on the degradation behavior of a PET layered silicate nanocomposite is examined in this study. Nanocomposites produced using scCO2 showed less extensive matrix degradation than those produced from the traditional melt compounding technique. It is proposed that $\mathrm{scCO} 2$ molecules acting as polar, organic solvents may displace water molecules from the gallery spacings of layered silicates that react hydrolytically with PET chains. Removing water molecules from layered silicate using traditional drying techniques requires drying temperatures in excess of the degradation temperature of the surfactant molecules used as silicate surface modifiers. 
Table of Contents

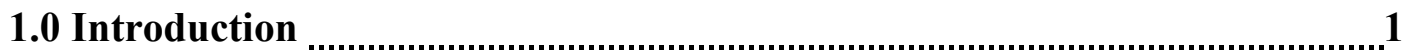

1.1 References

2.0 Literature Review ..................................................................................11

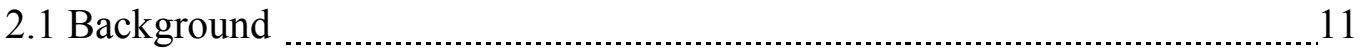

2.1.1 Polymer/Layered Silicate Nanocomposites _................................ 11

2.1.2 Nanosilicate Types and Structures ……........................................... 12

2.1.3 Organoclay Formation Using Ion Exchange …….......................... 14

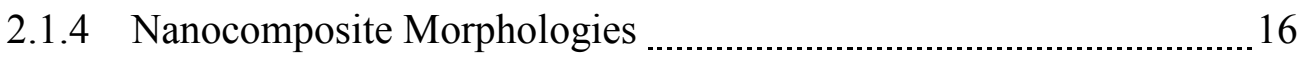

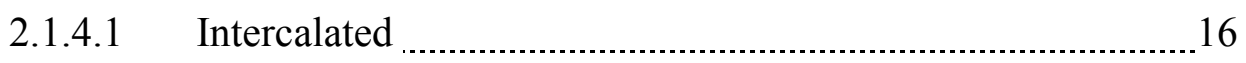

2.1.4.2 Exfoliated _...................................................................... 18

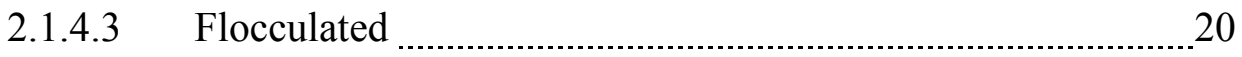

2.1.4.4 Intercalated-Exfoliated Mix _.......................................... 21

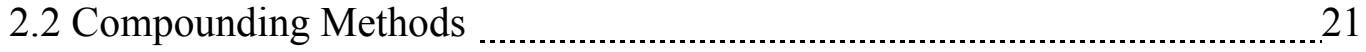

2.2.1 In-situ polymerization

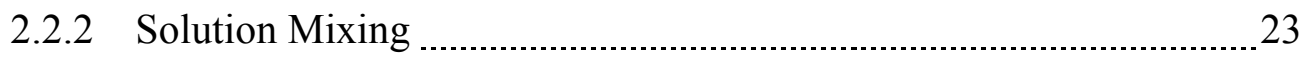

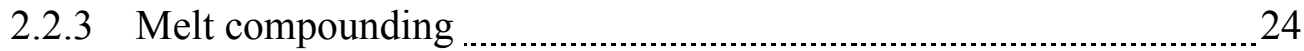

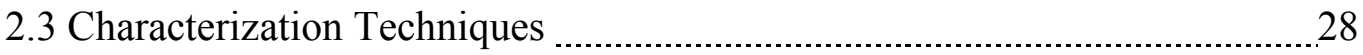

2.3.1 Wide Angle X-ray Diffraction (WAXD) ………............................. 29

2.3.2 Transmission Electron Microscopy (TEM) …................................. 31

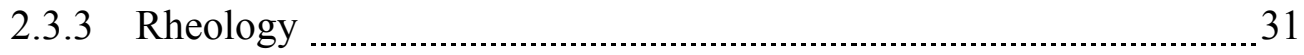

2.4 Material Property Enhancements ……………………………...... 33

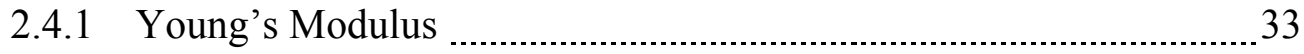

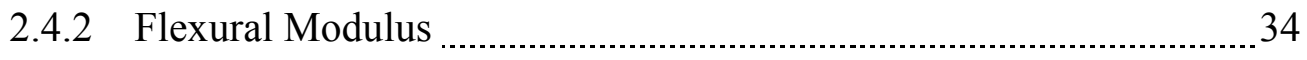

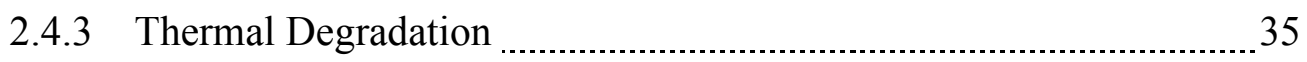

2.4.4 Heat Distortion Temperature …_........... 36

2.4.5 Barrier Property Improvements ………………........................... 36

2.5 Theoretical Modeling of PLSN Tensile Modulus _................................... 37

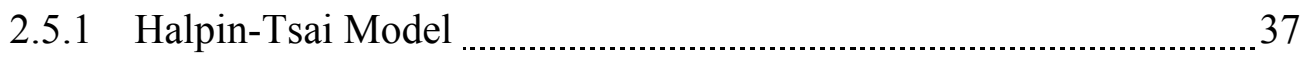

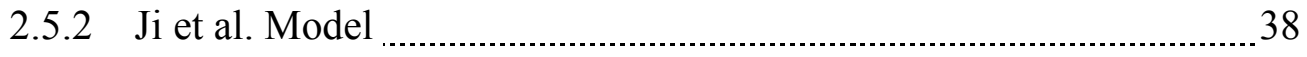

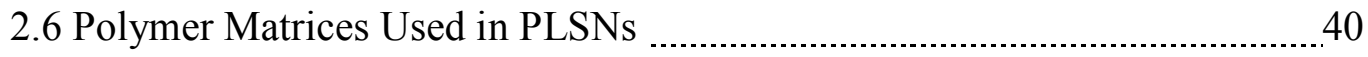


2.6.1 Poly(ethylene terephthalate) (PET) Based PLSNs ........................... 41

2.7 Supercritical Carbon Dioxide in Nanocomposite Compounding ................... 46

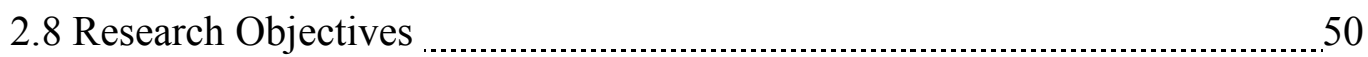

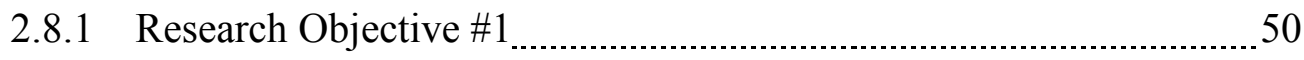

2.8.2 Research Objective \#2

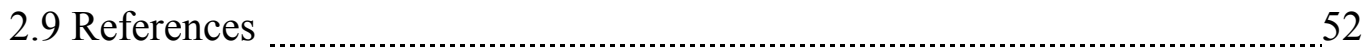

3.0 Improving the Exfoliation of Layered Silicate in a Poly(ethylene terephthalate) Matrix Using Supercritical Carbon Dioxide ................................................57

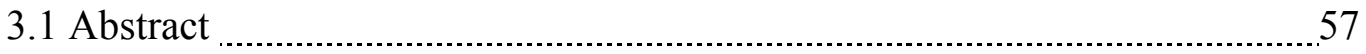

3.2 Introduction

3.3 Experimental

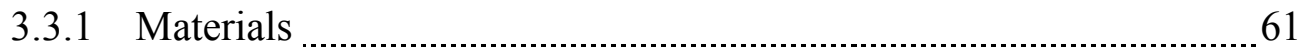

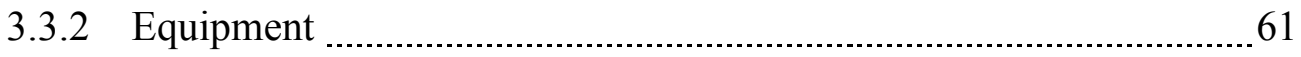

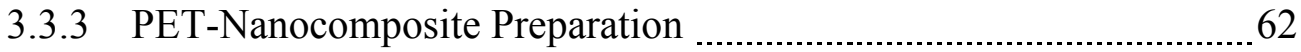

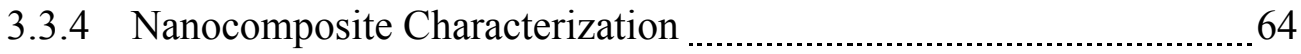

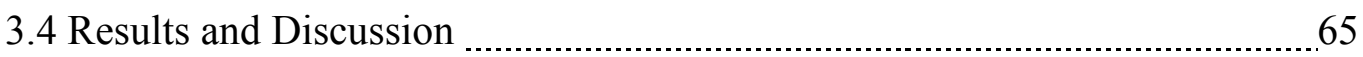

3.4.1 X-ray Diffraction Analysis ……….............................................

3.4.2 Mechanical Testing Analysis ……........................................... 72

3.4.3 Comparison of Modulus Values with Composite Theory _................ 74

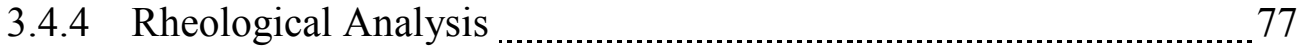

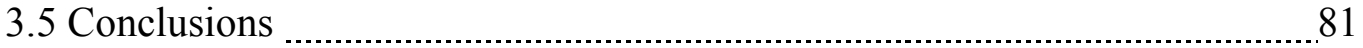

3.6 References

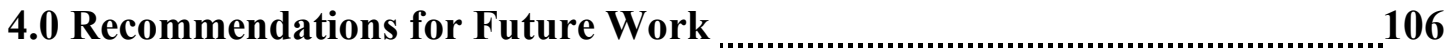

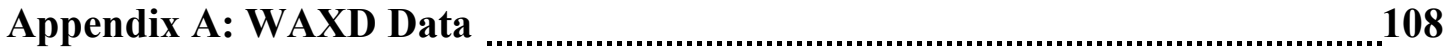

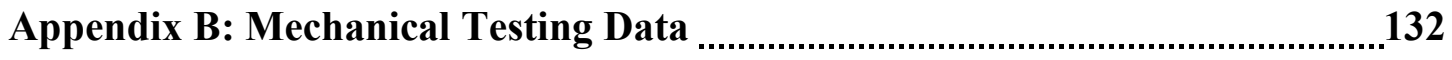

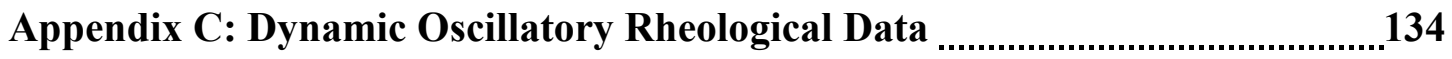

Appendix D: Actual Silicate Loading Calculations ............................................. 


\section{List of Figures}

Figure 2.1: Basic structure of a 2:1 phyllosilicate 13

Figure 2.2: Cation exchange reaction using alkyl ammonium ions 15

Figure 2.3: Intercalated silicate morphology. Straight lines represent silicate layers while curved lines represent polymer chains

Figure 2.4: Exfoliated silicate morphology. Straight lines represent silicate layers while curved lines represent polymer chains

Figure 2.5: Flocculated silicate morphology. Straight lines represent silicate layers while curved lines represent polymer chains 20

Figure 2.6: Schematic of in-situ polymerization. Dots represent monomers 22

Figure 2.7: Schematic of solution mixing. Dots represent solvent molecules 23

Figure 2.8: Schematic of melt compounding 24

Figure 3.1: Schematic of the $\mathrm{scCO} 2$ processing equipment 92

Figure 3.1: WAXD results of PLSN samples containing Cloisite 20A and produced using melt compounding 93

Figure 3.2: WAXD results of PLSN samples containing Cloisite 20A and produced using the scCO2 method 94

Figure 3.3: WAXD results of Cloisite 30B/PET nanocomposites produced from the scCO2 process and melt compounding 95

Figure 3.4: Young's modulus values for all Cloisite 20A samples produced from both the $\mathrm{scCO} 2$ process and the melt compounding process 96

Figure 3.5: Young's modulus values for all Cloisite 30B samples produced from both the $\mathrm{scCO} 2$ process and the melt compounding process 
Figure 3.6: Halpin-Tsai model predictions of tensile modulus compared to experimentally obtained values 98

Figure 3.7: Ji et al. model predictions of tensile modulus compared to experimentally obtained values 99

Figure 3.8: Complex viscosity measured during a time sweep of the 5-30B-MC sample

Figure 3.9: Complex viscosity data of (a) 1-20A samples, (b) 3-20A samples and (c) 5-20A samples 101

Figure 3.10: Complex viscosity data of (a) 1-20A samples, (b) 3-20A samples and (c) 5-20A samples 102

Figure 3.11: G' and G', of 20A-MC PLSNs 103

Figure 3.12: G' and G', of 20A-scCO2 PLSNs 104

Figure 3.13: Complex viscosity data for 3-20A-scCO2 and 3-30B-scCO2 samples 


\section{List of Tables}

Table 3.1: Sample descriptions, abbreviations and the actual clay loadings calculated from burn off testing 86

Table 3.2: WAXD results and average basal spacing values calculated from the Bragg equation (1) on PLSNs containing Cloisite 20A 87

Table 3.3: WAXD results and average tactoid size calculated from the Scherer equation

(2) on PLSNs containing Cloisite 20A 88

Table 3.4: WAXD results and average basal spacing values calculated from the Bragg equation (1) on PLSNs containing Cloisite 30B 89

Table 3.5: WAXD results and average tactoid size calculated from the Scherer equation (2) on PLSNs containing Cloisite 30B 90

Table 3.6: Results of mechanical testing done on all Cloisite 20A samples 91

Table A1: WAXD data for all samples containing Cloisite 20A 109

Table A2: WAXD data for all samples containing Cloisite 30B 120

Table B1: Mechanical Properties for all PLSNs produced 133

Table C1: Rheological Data: Neat PET 135

Table C2: Rheological Data: Extruded PET 135

Table C3: Rheological Data: $1 \mathrm{wt} \% 20 \mathrm{~A}-\mathrm{PET}$ using scCO2 136

Table C4: Rheological Data: 3wt $\% 20 \mathrm{~A}-\mathrm{PET}$ using scCO2 136

Table C5: Rheological Data: 5wt\%20A-PET using scCO2 136

Table C6: Rheological Data: 1wt\%20A-PET using direct melt compounding 137

Table C7: Rheological Data: 3wt\%20A-PET using direct melt compounding 137

Table C8: Rheological Data: $5 \mathrm{wt} \% 20 \mathrm{~A}-\mathrm{PET}$ using direct melt compounding 138 
Table C9: Rheological Data: 1wt\%30B-PET using scCO2

Table C10: Rheological Data: 3wt\%30B-PET using scCO2

Table C11: Rheological Data: 5wt\%30B-PET using scCO2

Table C12: Rheological Data: 1wt\%30B-PET using direct melt compounding ...... 140

Table C13: Rheological Data: 3wt\%30B-PET using direct melt compounding 140

Table C14: Rheological Data: 5wt\%30B-PET using direct melt compounding 140

Table C15: Time Sweep of 5wt\%30B-PET using direct melt compounding 141

Table D1: Actual silicate loadings in weight and volume percent 145 


\subsection{Introduction}

In 1990 a Toyota research group produced and characterized the first polymer/layered silicate nanocomposite (PLSN) material using Nylon-6 [1]. The unprecedented improvements that were achieved in a number of material properties showed tremendous promise for layered silicate material as a filler. In the years since, a flood of research has been carried out on nanocomposites using different polymer matrices, different layered silicates and multiple forms of compatibilizer.

The layered silicates employed in this technology are most commonly phyllosilicates. Phyllosilicates make up a large family of naturally occurring clays whose basic layer structure is comprised of individual sheets of tetrahedral, oxygen rich layers and octagonal layers with silicon atoms at their core [2]. In the case of the most commonly used layered silicate in this family (montmorillonite), $\mathrm{Mg}^{+}$and $\mathrm{Al}^{+3}$ cations occupy the spaces at the center of the tetrahedral sheets [2]. Each silicate layer has a thickness of roughly a single nanometer and individual layers in their natural state are spaced approximately one nanometer apart [3]. Although there are a wide variety of silicate types, all layered silicates share the physical trait of high aspect ratio with length dimensions varying from $30 \mathrm{~nm}$ to several microns [3]. The high aspect ratio and nanometer scale dimensions give layered silicates a large surface area for interaction between silicate surface and polymer matrix. This large surface area is the primary difference between nanosilicate and traditional filler materials. Nanosilicate combined with polymer in only small quantities has been shown to dramatically increase the Young's modulus [1, 4], flexural modulus [1, 5] and impact strength [6] of a polymer matrix. Increases in thermal degradation temperature [7], decreases in thermal 
deformation [5] and improvements in barrier properties from neat polymer materials have all been recorded [8]. Each of these property improvements have been investigated in order to obtain a better understanding of how layered silicate causes these enhancements. Results of past research have shown that there are a number of variables involved in determining the characteristics of a layered silicate nanocomposite including the compatibility of the polymer matrix and the silicate, the processing method used and the resulting morphology of the nanocomposite.

The Toyota research group that first produced PLSNs chose to use Nylon-6 for their polymer matrix. The group found a $68 \%$ increase in tensile modulus, a $224 \%$ increase in flexural modulus and an $87^{\circ} \mathrm{C}$ increase in the heat distortion temperature [1]. Since that time many different polymer matrices have been used to form nanocomposite but all of them have failed to meet the impressive increases obtained in polyamide nanocomposite systems. There is a wealth of research that has attempted to mimic the strong compatibility between polymer and clay that is found in polyamide layered silicate nanocomposites. Multiple types of polyamides [9-18], polyolefins [19-26], polyesters $[27,28]$ and polycarbonates [29] have been combined with layered silicates modified to obtain maximum compatibility with the polymer matrix. It is well known that obtaining successful layered silicate nanocomposites requires excellent compatibility between the polymer matrix and the nanosilicate. A number of silicate surface modifications as well as a variety of compatibilizing compounds have been used for this purpose $[30,31]$. Although considerable improvements in physical properties of nanocomposites have been realized with these techniques there is still ongoing research focused specifically on the enhancement of polymer/layered silicate compatibility. 
A large portion of the research carried out to date on PLSNs has been aimed at overcoming a number of challenges that are encountered when they are compounded. The two most critical challenges that need to be overcome in the production of a valuable PLSN are the inherent incompatibility of polymer and layered silicate as well as the tendency of layered silicates to assemble into ordered, layered domains. Natural layered silicate is highly hydrophilic due to the presence of interlayer cations that balance the negative charge generated by multiple surface oxygen atoms [3]. To make layered silicates compatible with many naturally hydrophobic polymer matrices, an ion exchange reaction can be carried out. In this way, highly hydrophilic layered silicates can be made miscible with polymer matrices. In addition to polymer/clay interactions that allow for miscibility, strong interactions between polymer and clay have been found to be a vital part of improving PLSN mechanical properties $[26,32]$. Research has been heavily focused on a variety of techniques aimed to improve the interaction of polymer matrices and layered silicates. The development of oligomeric compatibilizers [26], novel reactive compatibilizers [28] and custom layered silicate surface modifications [30] has been an ongoing effort. In addition to promoting polymer/layered silicate compatibility, much attention has been focused on controlling the morphology of PLSNs. Layered silicates are naturally held together in sheets by strong Van der Waals forces [33]. Multiple layers of silicate stacked together are referred to as tactoids and can contain hundreds of individual layers. The tactoids themselves interact and can form large agglomerates within a polymer matrix. The advantage of high aspect ratio that layered silicates possess over traditional filler materials is lost when PLSN materials contain this type of large agglomerate. The presence of tactoids causes the effective aspect ratio of the silicates to 
decrease [34]. It has been shown that increasing the level of exfoliation in a PLSN results in improved mechanical, barrier and thermal properties $[35,36]$.

A number of processing techniques have been developed and implemented in an attempt to achieve PLSN systems with desired morphologies. Three compounding methods that have been used in the past are in-situ polymerization [30, 37], solution mixing [38] and melt compounding [39, 40]. In-situ polymerization and solution mixing have the disadvantage of requiring a suitable solvent. In addition, the logistics of each technique put a limit on what type of polymer matrix can be employed. Melt compounding has emerged as the most suitable industrial technique for the production of nanocomposites on a large, environmentally friendly scale. The difficulty associated with melt compounding is the inability of the technique to generate nanocomposites with a well exfoliated morphology. Many studies have shown that although high shear environments can increase exfoliation levels, complete exfoliation in certain polymer matrices cannot be achieved with melt compounding alone $[16,22,31,39,40]$. It has also been shown that extreme shear environments can decrease exfoliation levels as well as reduce nanosilicate aspect ratio by causing silicate fracture [31]. Efforts to expose PLSNs to an optimum amount of shear and back mixing have resulted in nanocomposite morphologies that still fall short of the desired exfoliated silicate state $[20,40]$.

A small number of studies using poly(ethylene terephthalate) (PET) as a matrix in PLSN composites have shown that obtaining quality PET based PLSNs is an especially difficult task. Although PET based PLSNs have potential value to both the packaging industry as well as the fiber industry, producing highly exfoliated PLSNs at an industrial scale has proved difficult. The use of in-situ polymerization to produce this particular 
type of PLSN $[4,30]$ has resulted in mechanical property improvements over neat PET despite the inability of in-situ polymerization to generate exfoliated silicate morphologies. The more industrially compatible technique of melt compounding has resulted in improved levels of silicate exfoliation with limited mechanical property improvements $[5,41]$. The modest mechanical property improvements are attributed primarily to PET matrix degradation occurring during melt processing in the presence of the layered silicate [42]. The high temperatures needed for the melt processing of PET based PLSNs makes using this polymer matrix especially difficult. A technique that takes advantage of the simplicity of melt compounding while maximizing silicate exfoliation and minimizing polymer matrix degradation is necessary to make PET based PLSNs a valuable product.

Recent work using supercritical carbon dioxide $(\mathrm{scCO} 2)$ as a processing aid has shown that improving silicate exfoliation in melt compounding processes beyond the capability of high shear environments is possible. Work carried out by Manke et al. [43] revealed that a supercritical mixture of carbon dioxide and layered silicate that is rapidly depressurized has the capability to exfoliate silicate layers. In addition, the treatment of layered silicate with $\mathrm{scCO} 2$ may have a significant effect on decreasing the amount of degradation that occurs in the melt processing of PET based PLSNs. Carbon dioxide acts as a weakly polar, organic solvent at supercritical conditions [44] which may displace the tightly bound water molecules from silicate surfaces that are responsible for matrix degradation during melt processing [2]. A technique developed by Nguyen et al. [45], combines the exfoliating capability of $\mathrm{scCO} 2$ treatment with melt compounding in order to produce highly exfoliated PLSNs. Use of the technique on polymer matrices such as 
PET may result in higher quality PLSNs with improved exfoliation and decreased degradation.

It is the purpose of this work to evaluate the effectiveness of combining the benefits of scCO2 with melt compounding to produce a poly(ethylene terephthalate) layered silicate nanocomposite with a more highly exfoliated morphology. Previous work has show that $\mathrm{scCO} 2$ can be an effective tool for altering the structure of pure nanosilicate [43]. The unique combination of $\mathrm{scCO} 2$ and a low shear processing environment will allow for a better understanding of the effect $\mathrm{scCO} 2$ has on the morphology of PLSNs. 


\subsection{References}

[1] Y. Kojima, A. Usuki, M. Kawasumi, A. Okada, Y. Fukushima, T. Kurauchi, O. Kamigaito, J. Mater. Res. 8 (1993) 1185-1189.

[2] M. Zanetti, S. Lomakin, G. Camino, Macromol. Mater. Eng. 279 (2000) 1-9.

[3] S.S. Ray, M. Okamoto, Prog. Polym. Sci. 28 (2003) 1539-1641.

[4] Y. Ke, C. Long, Z. Qi, J. Appl. Polym. Sci. 71 (1999) 1139-1146.

[5] Y. Wang, J. Gao, Y. Ma, U.S. Agarwal, Composites: Part B 37 (2006) 399-407.

[6] K. Wang, S. Liang, R. Du, Q. Zhang, Q. Fu, Polym. J. 45 (2004) 7953-7960.

[7] K.P. Pramoda, T. Liu, Z. Liu, C. He, H.-J. Sue, Polym. Degrad. Stab. 81 (2003) 4756.

[8] P.B. Messersmith, E.P. Giannelis, J. Polym. Sci., Part A: Polym. Chem. 33 (1995) 1047.

[9] T. Liu, K.P. Lim, W.C. Tjiu, K.P. Pramoda, Z. Chen, Polym. J. 44 (2003) 35293535.

[10] K. Masenilli-Varlot, E. Reynaud, G. Vigier, J. Varlet, J. Polym. Sci., Part B: Polym. Phys. 40 (2002) 272-283.

[11] X. Liu, Q. Wu, Eur. Polym. J. 38 (2002) 1383-1389.

[12] X. Liu, Q. Wu, Polym. J. 43 (2002) 1933-1936.

[13] F.J. Medellin-Rodriquez, C. Burger, B.S. Hsiao, B. Chu, R.A. Vaia, S. Phillips, Polym. J. 42 (2001) 9015-9023.

[14] D.M. Lincoln, R.A. Vaia, Z.G. Wang, B.S. Hsiao, Polym. J. 42 (2001) 1621-1631.

[15] T.D. Fornes, P.J. Yoon, H. Keskkula, D.R. Paul, Polym. J. 42 (2001) 9929-9940.

[16] J.W. Cho, D.R. Paul, Polym. J. 42 (2001) 1083-1094. 
[17] T. Liu, W.C. Tjiu, C. He, S.S. Na, T.-S. Chung, Polymer International 53 (2004) 392-399.

[18] Z. Liu, D. Yan, Polymer Engineering and Science 44 (2004) 861-867.

[19] A. Usuki, M. Kato, A. Okada, T. Kurauchi, Appl. Polym. Sci. 63 (1997).

[20] P. Peltola, E. Valipakka, J. Vuorinen, S. Syrjala, K. Hanhi, Polym. Eng. Sci. (2006) 995-1000.

[21] J. Li, C. Zhou, G. Wang, D. Zhao, J. Appl. Polym. Sci. 89 (2003) 3609-3617.

[22] D. Marchant, K. Jayaraman, Ind. Eng. Chem. Res. 41 (2002) 6402-6408.

[23] A. Lele, M. Mackley, G. Galgali, C. Ramesh, J. Rheol. 46 (2002) 1091-1110.

[24] M.J. Solomon, A.S. Almusallam, K.F. Seefeldt, A. Somwangthanaroj, P. Varadan, Macromolecules 34 (2001) 1864-1872.

[25] P.H. Nam, P. Maiti, M. Okamoto, T. Kotaka, N. Hasegawa, A. Usuki, Polym. J. 42 (2001) 9633-9640.

[26] M. Kato, A. Usuki, A. Okada, J. Appl. Polym. Sci. 66 (1997) 1781-1785.

[27] D. Wu, C. Zhou, W. Yu, X. Fan, J. Polym. Sci., Part B: Polym. Phys. 43 (2005) $2807-2818$

[28] C.H. Davis, L.J. Mathias, J.W. Gilman, D.A. Schiraldi, J.R. Shields, P. Trulove, T.E. Sutto, H.C. Delong, J. Polym. Sci., Part B: Polym. Phys. 40 (2002) 2661-2666.

[29] X. Huang, S. Lewis, W.J. Brittain, Macromolecules 33 (2000) 2000-2004.

[30] Y. Imai, S. Nishimura, E. Abe, H. Tateyama, A. Abiko, A. Yamaguchi, T. Aoyama, H. Taguchi, Chem. Mater. 14 (2002) 477-479.

[31] H.R. Dennis, D.L. Hunter, D. Chang, S. Kim, J.L. White, J.W. Cho, D.R. Paul, Polym. J. 42 (2001) 9513-9522. 
[32] H. Shi, T. Lan, T.J. Pinnavaia, Chem. Mater. 8 (1996) 1584-1587.

[33] E.P. Giannelis, R. Krishnamoorti, Adv. Polym. Sci. 138 (1999) 107-147.

[34] N. Sheng, M.C. Boyce, D.M. Parks, G.C. Rutledge, J.I. Abes, R.E. Cohen, Polymer 45 (2004) 487-506.

[35] W.J. Boo, L. Sun, J. Liu, E. Moghbelli, A. Clearfield, H.-J. Sue, H. Pham, N. Verghese, J. Polym. Sci., Part B: Polym. Phys. 45 (2007) 1459-1469.

[36] S.S. Ray, K. Okamoto, M. Okamoto, Macromolecules 36 (2003) 2355-2367.

[37] J.-T. Xu, Q. Wang, Z.-Q. Fan, Eur. Polym. J. 41 (2005) 3011-3017.

[38] R. Krishnamoori, J. Ren, A.S. Silva, J. Chem. Phys. 114 (2001) 4968-4973.

[39] V.E. Yudin, G.M. Divoux, J.U. Otaigbe, V.M. Svetlichnyi, Polym. J. 46 (2005) 10866-10872.

[40] M. Modesti, A. Lorenzetti, D. Bon, S. Besco, Polym. J. 46 (2005) 10237-10245.

[41] A. Sanchez-Solis, I. Romero-Ibarra, M.R. Estrada, F. Calderas, O. Manero, Polym. Eng. Sci. 44 (2004) 1094-1102.

[42] T.J. Pinnavaia, G.W. Beall (Eds.), Polymer-Clay Nanocomposites, John Wiley \& Sons Ltd., Chichester, 2000.

[43] C.W. Manke, E. Gulari, D.F. Mielewski, E.C. Lee, System and Method of Delaminating a Layered Silicate Material by Supercritical Fluid Treatment, in: U.S.P. Office (Ed.), Ford Global Technologies, Inc.; Wayne State University, United States, 2002.

[44] D.L. Tomasko, H. Li, D. Liu, X. Han, M.J. Wingert, L.J. Lee, K.W. Koelling, Ind. Eng. Chem. Res. 42 (2003) 6431-6456. 
[45] Q.T. Nguyen, Process for Improving the Exfoliation and Dispersion of Nanoclay Particles into Polymer Matrices Using Supercritical Carbon Dioxide, Chemical Engineering, Virginia Tech, Blacksburg, 2007, p. 195. 


\subsection{Literature Review}

A review of polymer/layered silicate nanocomposites (PLSNs) is presented here with particular emphasis on the ability of various compounding techniques to produce nanocomposite material with desirable properties. Nanosilicate structure and properties as well as the technique employed to generate organophilic silicates are reviewed. The various silicate morphologies that have been found to occur in PLSN systems are explored in detail. The primary compounding methods used in the formation of PLSNs and their effect on silicate morphology are examined. PLSNs characterization techniques, material properties that have seen improvements due to PLSN technology and a number of theoretical models that have been employed to estimate mechanical properties are also discussed in detail. The wide variety of polymer matrices employed in past literature is examined with a particular focus on the difficulties that have been encountered with PET used as the polymer matrix. Finally, studies done using supercritical Carbon Dioxide $(\mathrm{scCO} 2)$ as a tool for generating nanocomposites with highly desirable characteristics are reviewed.

\subsection{Background}

\subsubsection{Polymer/Layered Silicate Nanocomposites}

PLSN materials are unique among composites because of the unusual physical characteristics of the filler material used. The filler is naturally occurring clay that is comprised of high aspect ratio silicate sheets. These silicate sheets have thickness dimensions of approximately a single nanometer with lengths up to $1000 \mathrm{~nm}$ [1]. The nanometer scale of the silicates combined with their high aspect ratio and large surface area make them exceptionally well suited to be filler for composite materials. A Toyota 
research group in 1990 was the first to produce composites using layered silicates as filler. Using $4.5 \mathrm{wt} \%$ clay in Nylon-6, the authors found a $68 \%$ increase in tensile modulus, a $224 \%$ increase in flexural modulus and an $87^{\circ} \mathrm{C}$ increase in the heat distortion temperature over the neat polymer material [2]. The unprecedented improvements in mechanical and thermal properties that were achieved at this low level of filler loading generated massive interest. Since that time hundreds of publications have been dedicated to advancements in PLSN technology. Layered silicates have been compounded into a wide variety of polymer matrices where multiple physical property enhancements in mechanical, thermal and boundary properties have been reported. Silicate morphology, polymer-clay compatibility and the techniques used to compound PLSNs have been of particular interest in developing this field of study. It has been found that extending this technology to some polymer systems can be difficult for a variety of reasons including the tendency of certain polymer matrices to degrade in the presence of layered silicate.

\subsubsection{Nanosilicate Types and Structures}

A wide variety of nanosilicates with different structures, cations and surface charges have been recorded in literature [3]. Layered silicates naturally occurring in the form of clay are part of a large family named phyllosilicates. The basic layer structure of these clays is composed of two types of two dimensional sheets. The first sheet is comprised of tetrahedral structures where the corners of the tetrahedron are occupied by oxygen molecules while the center of the tetrahedron is occupied by a cation that is typically $\mathrm{Si}, \mathrm{Al}$ or $\mathrm{Fe}^{+3}$. The individual tetrahedral structures are joined together on three sides to form a continuous two dimensional sheet. The second layer structure present in layered silicates is comprised of octahedral formations. The corners of the octahedral 
structures are comprised of oxygen molecules while the centers contain cations such as $\mathrm{Mg}, \mathrm{Al}, \mathrm{Fe}^{+2}, \mathrm{Fe}^{+3}$. Both the tetrahedral and octahedral layers combine to share the apical oxygen atoms from the tetrahedral sheets as seen in Fig. 2.1. 1:1 layered structures are formed when a single tetrahedral sheet is combined with a single octahedral sheet. A 2:1 layered structure is seen in Fig. 1 and occurs when a single octahedral sheet is bound on both sides by tetrahedral sheets.

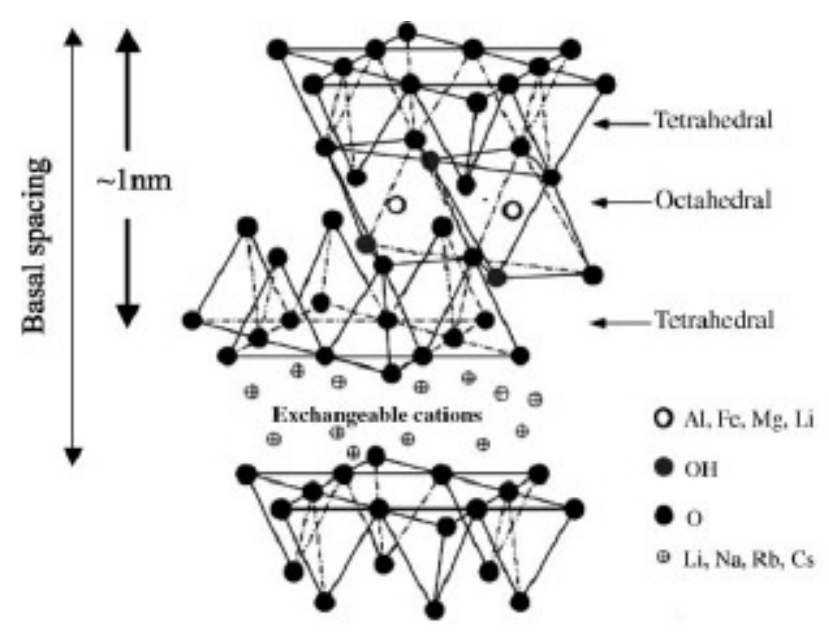

Fig. 2.1: Basic structure of a 2:1 phyllosilicate [4]

The individual layers of silicate formed by the two types of sheet described above are attracted to each other by Van der Waals forces. These layers stack in an orderly fashion to form larger structures called tactoids. The space between the layers is referred to as the interlayer or gallery spacing and it is roughly $1 \mathrm{~nm}$ in its natural state. Inside the gallery spacing small, hydrated cations as well as free water molecules are also present in the silicate's natural state. The most commonly used layered silicates in PLSNs are smectite clays. Among this group the most common type of clay used is montmorillonite (MMT). This sub-group of clay has a 2:1 layer structure with Si cations in the tetrahedral sheets and $\mathrm{Al}$ and $\mathrm{Mg}$ cations in the octahedral sheet. The interlayer spacing of MMT 
contains primarily hydrated $\mathrm{Na}^{+}$cations. The natural abundance of this silicate as well as its tendency for excellent crystalline order has made it the layered silicate of choice for PLSNs.

The physical dimensions of MMT give it unique properties as a filler material. The basic 2:1 sheet structure results in high aspect ratio sheets with a thickness of $1 \mathrm{~nm}$ and lengths of up to $300 \mathrm{~nm}$. A consequence of this high aspect ratio is that small amounts of silicate have very large surface areas. The presence of a large surface area for interaction is a valuable characteristic in fillers. The tremendous surface area available for polymer-clay interaction allows polymer chains to effectively transfer stress into filler particles [5]. In addition, high aspect ratio particles can be used to improve the barrier properties of polymer membranes by increasing the tortuosity of the material [6].

\subsubsection{Organoclay Formation Using Ion Exchange}

The 2:1 layer structure of the MMT sub-group of layered silicates results in a highly hydrophilic surface due to the presence of surface oxygen molecules as well as hydroxyl groups. The hydrophilic nature of the layered silicates is incompatible with many engineering polymers that are primarily hydrophobic in nature. To obtain a miscible system of polymer and clay the surface of the silicate must be altered in some way.

One technique used to promote mixing and increase interactions between polymer and clay is an ion exchange reaction. By removing the natural interlayer cations and replacing them with a surfactant molecule containing both hydrophilic and hydrophobic groups, it is possible to control the silicate surface chemistry. The most commonly used surfactant molecule for this purpose is a quaternary ammonium. Four different groups 
can be added to the ammonium salt to control the surface chemistry of the modified clays. It is common to utilize alkyl ammonium ions with long chain hydrocarbons attached to the positively charged nitrogen atom. The positively charged portion of the ion interacts favorably with the hydrophilic surface of the silicate sheets while the alkyl groups extend into the gallery spacing making interactions with hydrophobic polymer matrices much more favorable. Usuki et al. [7] detailed the steps involved in executing a successful cation exchange reaction using 12-aminolauric acid. The results of a cation exchange reaction using an alkyl ammonium salt are shown in Fig. 2.2.

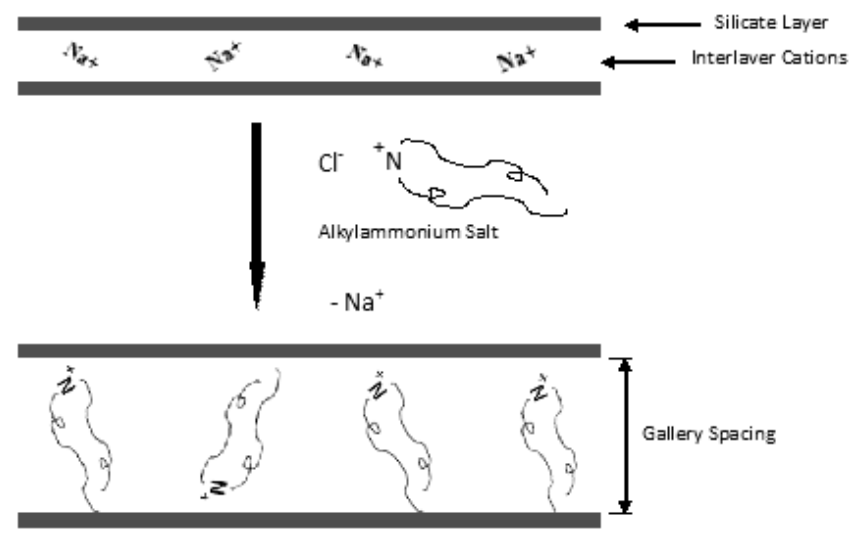

Fig. 2.2: Cation exchange reaction using alkyl ammonium ions A number of cation exchanged clays with a wide variety of surfactant types and concentrations are now available from multiple commercial sources.

In addition to improving polymer/clay interaction, cation exchange reactions carried out with long chain surfactant molecules increase the gallery spacing between silicate layers [8]. The change in gallery spacing due to the insertion of surfactant molecules is shown diagrammatically in Fig. 2.2. This spacing increase plays an important role in the final morphology of PLSNs that are produced using cation exchanged clays. The creation of a well dispersed system of nanosilicate in a polymer 
matrix involves the diffusion of polymer chains between the silicate layers. Small gallery spacings make the diffusion process more difficult since narrow gallery thicknesses are on the order of the diameter of a single polymer chain. Increasing the gallery spacing of the silicate from its natural state by cation exchange reaction facilitates the diffusion of polymer chains between silicate layers in larger tactoids.

\subsubsection{Nanocomposite Morphologies}

Silicate morphology refers to the way in which silicate layers are ordered in a PLSN system. A number of distinct silicate morphologies and the effect these structures have on the final PLSNs have been identified in literature. The two most common clay morphologies are intercalated and exfoliated. Additional clay structures include a flocculated morphology and a mixture of both exfoliation and intercalation in the same nanocomposite. As a result of the fact that each silicate morphology type has a significant impact on PLSN properties, tremendous efforts have been made to understand how these structures form and how they can be controlled.

\subsubsection{Intercalated}

Intercalated clay morphology occurs when polymer chains diffuse into the gallery spacings of layered silicate. The ordered, layered structure of individual tactoids remains, but the presence of polymer chains within gallery spacings forces the silicate layers farther apart. The gallery spacings in intercalated structures are on the order of a few nanometers. An example of intercalated silicate morphology is shown in Fig. 2.3. 


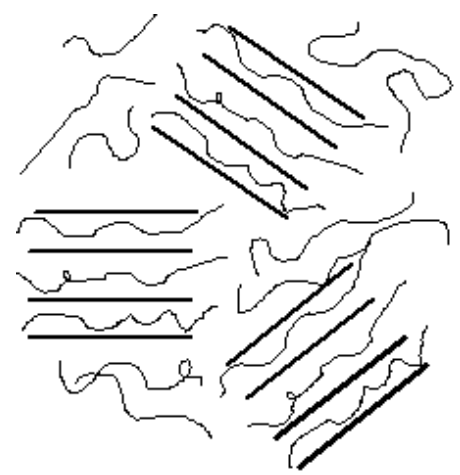

Fig. 2.3: Intercalated silicate morphology. Straight lines represent silicate layers while curved lines represent polymer chains.

Confining polymer chains in the narrow gallery spacing between layers of silicate results in an entropic loss. In order to make intercalation thermodynamically favorable either an increase in entropy in the surfactants used as surface modifiers must occur, or enthalpic gains must be made. Vaia et al. [9] proposed that the entropic loss due to the confinement of polymer chains must be offset by large numbers of polymer-clay interactions thus making intercalation an enthalpically driven process. The enthalpic change involved with the interaction of polymer chain segments with the surfactant molecules and clay surface is small. To make intercalation favorable a large number of these interactions are necessary.

The kinetics governing the diffusion of polymer chains between silicate layers are an important topic that have the most relevance when polymer and clay are combined using melt processing techniques. Vaia et al. [10] used in-situ x-ray diffraction to monitor the direct intercalation of polystyrene into organoclay galleries. The authors found that the activation energy for polymer diffusion between silicate layers was similar to that measured for polystyrene self diffusion. The implication is that the amount of chain mobility between clay layers is similar to that of chain mobility in the bulk polymer. Prior 
to this it was thought that the extreme confinement of polymer chains in gallery spacings would limit chain mobility and their rate of diffusion. The knowledge that diffusion leading to intercalation is on the same order of magnitude as polymer self diffusion means that a fully intercalated morphology can be achieved using traditional melt compounding methods.

\subsubsection{Exfoliated}

An exfoliated structure occurs when silicate layers are separated by regions of polymer matrix at distances on the order of the radius of gyration of the polymer chains [11]. Compared to intercalation the silicate layers are separated by much greater distances. An example of exfoliated silicate morphology is shown in Fig. 2.4.

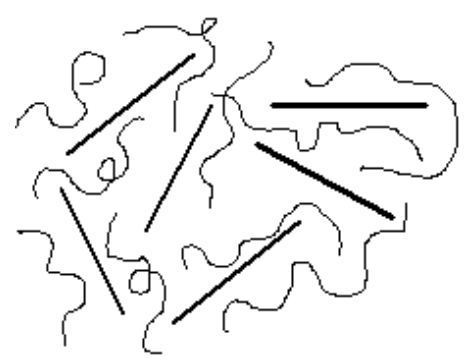

Fig. 2.4: Exfoliated silicate morphology. Straight lines represent silicate layers while curved lines represent polymer chains.

An exfoliated structure can maintain a partially oriented state called an ordered exfoliate where layers have localized order despite their separation, or the silicate layers can be in an entirely disordered state called a disordered exfoliate. The benefit of an exfoliated structure is the ability to take advantage of the high aspect ratio of individual silicate layers. An intercalated system can be represented by effective clay particles made up of multiple clay layers resulting in an effective aspect ratio lower than that of a single 
clay layer [12]. Exfoliated morphologies maximize polymer/clay contact by obtaining the highest aspect ratio and surface area possible.

Boo et al. [13] used alpha zirconium phosphate ( $\alpha-\mathrm{ZrP})$ nanoparticles to examine the effect that exfoliation has on the mechanical properties of nanocomposites. $\alpha-\mathrm{ZrP}$ particles are well suited to form model systems for layered silicate nanocomposites since their geometry is highly controllable. The length and width of these particles can be controlled to produce particles with a very small distribution of sizes. With thickness dimensions on the order of a single nanometer, $\alpha-\mathrm{ZrP}$ is an ideal analog to layered silicate nanoparticles. As a result of the narrow particle size distributions and the relative ease in attaining an exfoliated state, $\alpha-\mathrm{ZrP}$ nanocomposites are useful to examine the effect of morphology on layered nanocomposite materials while eliminating a host of other variables. The authors formed nanocomposites with varying levels of exfoliation of $\alpha-\mathrm{ZrP}$ and found that the nanocomposite with excellent exfoliation had a $40 \%$ improvement in Young's modulus over nanocomposite with poor exfoliation. The model system of $\alpha-Z r P$ particles showed that exfoliation has a large impact on nanocomposites formed using high aspect ratio particles.

Hbaieb et al. [14] also found that mechanical properties of PLSNs are dependent on the morphology of the final composite. The authors compare a 2D and 3D finite element model of PLSNs to the Mori-Tanaka and Halpin-Tsai models developed from composite theory. The results show that as clay volume and weight fraction increase, clay layers collapse to form ordered exfoliates and regions of intercalation. The Mori-Tanaka and Halpin-Tsai models assume complete layer exfoliation. The finite element models incorporate the potential for clay layer collapse. As a result, the 3D finite element 
estimates for composite modulus fall below those of the composite theory models at increasing clay content.

Sheng et al. [12] found with the use of a multi-scale micromechanical model that the advantages of exfoliation may not be as great as expected. The model results show that there is no abrupt stiffness increase due to the formation of exfoliated silicate layers from stacked, intercalated layers. Instead the model predicts a steady, gradual increase in stiffness up to a fully exfoliated state.

\subsubsection{Flocculated}

A less commonly found clay morphology is flocculation. Flocculation occurs when the edges of silicate layers are attracted to one another end to end. An example of flocculated silicate layers is shown in Fig. 2.5.

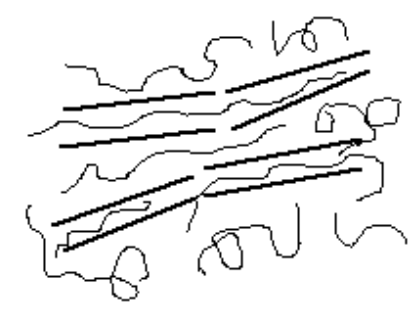

Fig. 2.5: Flocculated silicate morphology. Straight lines represent silicate layers while curved lines represent polymer chains.

Wu et al. [15] proposed that this structure forms because the edges of layered silicates have unshielded hydroxyl groups that tend to interact with one another. The authors report that the formation of flocculation increases the chance of particle-particle interaction under flow conditions. This behavior is consistent with what one would expect from an increase in effective particle aspect ratio resulting from the combination of layers in an end to end fashion. It has been reported that flocculation results in a large 
increase in the aspect ratio of the layered silicate due to the combination of clay layers through end to end hydrogen bonding [4].

\subsubsection{Intercalated-Exfoliated mix}

The most common silicate morphology is a mixture of both intercalated clay layers and exfoliation. Clay loading, strength of polymer-clay interaction and the compounding technique used all have an effect on the resulting clay morphology. More often than not, clay morphology is characterized as a point in-between the extremes of intercalation and exfoliation. The various processing methods employed to compound PLSNs including in-situ polymerization, solution mixing and melt compounding have been found to generate composites with varying degrees of exfoliation and intercalation.

\subsection{Compounding Methods}

The method used to compound PLSNs has a significant effect on silicate morphology and the resulting composite properties. In addition to property concerns, the processing method employed puts limits on both the type of polymer that can be used and the volume of PLSN material that can be produced. Three compounding methods that have been used successfully in producing PLSNs are in-situ polymerization, solution mixing and melt compounding. Each method has advantages as well as disadvantages and much research has been devoted to understanding each of them.

\subsubsection{In-situ polymerization}

The first compounding method employed to generate a PLSN was in-situ polymerization. This compounding method involves the mixing of monomer and layered silicate followed by the initiation of polymerization. A schematic of the technique is shown in Fig. 2.6. 


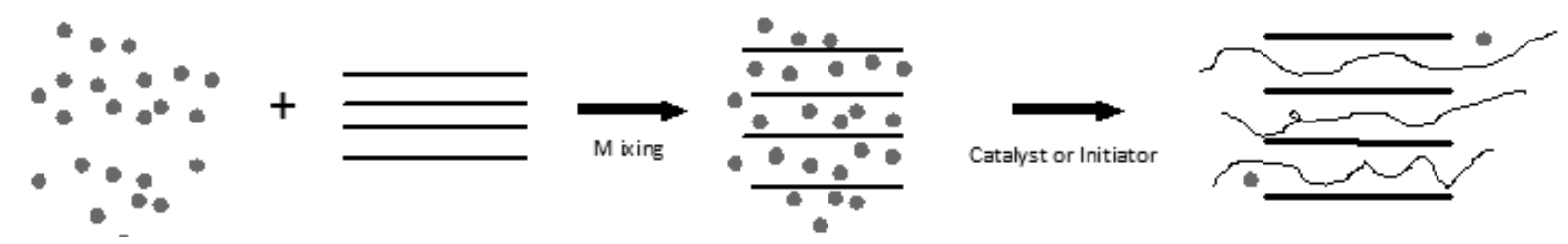

Fig. 2.6: Schematic of in-situ polymerization. Dots represent monomers.

To produce the first Nylon-6 based PLSN, Usuki et al. [7] used a ring opening polymerization with caprolactam. Caprolactam and organoclay were mixed, heated and maintained at the polymerization temperature for $48 \mathrm{hr}$. X-ray diffraction analysis as well as TEM imaging showed that below $15 \mathrm{wt} \%$ silicate the morphology was primarily exfoliated. Above $15 \mathrm{wt} \%$ a mixture of intercalated and exfoliated silicate layers were apparent.

Imai et al. [16] applied in-situ polymerization to the formation of PET based PLSNs. The authors polymerize a novel reactive compatibilizer with BHET in the presence of nanosilicate. The results of mechanical testing on the PLSNs produced showed an $85 \%$ increase in the flexural modulus of the composites over neat PET. The PLSNs that were produced were primarily intercalated and very poorly dispersed. The authors make the conclusion that the strong polymer/clay interaction due to the novel reactive compatibilizer employed must be more important to improving mechanical properties than exfoliation.

Lan et al. [17] used epoxy to determine the effect that extent of polymerization has on silicate morphology. The authors showed that the extent of intercalation and exfoliation in a PLSN can be controlled while using in-situ polymerization by controlling the extent of polymerization. X-ray diffraction results taken at different times in the 
polymerization step show a steady decrease in the amount of intercalated material present and a steady increase in exfoliation.

In-situ polymerization is an effective way to generate PLSNs while controlling the silicate morphology that results. Many different types of polymer matrices can be used to generate PLSNs in this way. The greatest disadvantage to this technique is the extended processing time as well as the necessity for a solvent while polymerizing certain types of polymer. In order to utilize in-situ polymerization at an industrial scale both of these concerns would have to be addressed.

\subsubsection{Solution Mixing}

Another compounding method used to produce PLSNs is solution mixing. This technique involves dissolving the polymer in a solvent, adding the nanosilicate to the mixture and removing the solvent once the composite has formed. The process relies on having a solvent that will swell the clay gallery spacings as well as dissolve the polymer chains. The extent to which the solvent swells and exfoliates the silicate layers controls the final morphology of the composite. Fig. 2.7 shows a schematic of the process.

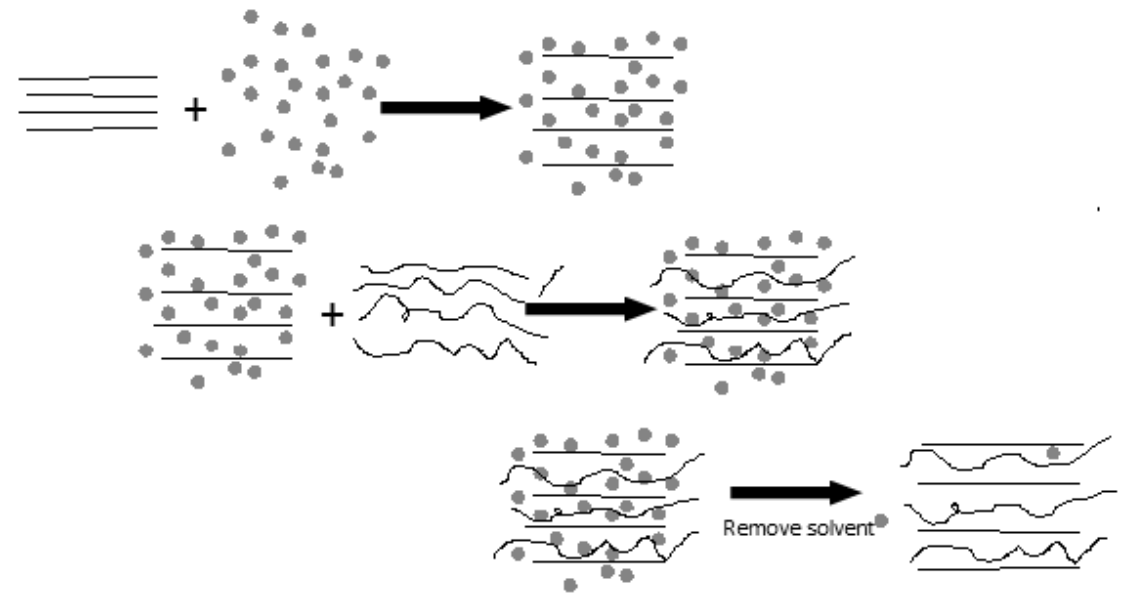

Fig. 2.7: Schematic of solution mixing. Dots represent solvent molecules. 
Krishnamoorti et al. [18] used solution mixing with a polystyrene-polyisoprene block copolymer in toluene as the solvent. The toluene used as a solvent had to be removed with extensive drying in a vacuum oven at $100^{\circ} \mathrm{C}$. The resulting PLSN was comprised of a mixture of intercalated and exfoliated silicate layers as shown by x-ray diffraction.

Solution mixing is a viable compounding method on a small scale but the necessity for large quantities of solvent makes application of this technique at an industrial level impractical. The requirement of finding a suitable solvent that dissolves the polymer matrix while swelling the nanoclays is a challenge for each different polymer-clay system used.

\subsubsection{Melt compounding}

Melt compounding to produce PLSNs involves the combination of layered silicate and polymer at or above the melt temperature of the polymer. When little or no shear history is applied to the PLSN the technique is referred to as direct intercalation [9]. More often the technique is carried out in a mixer or an extruder where shear forces are imparted into the composite material. The combination of mobile polymer chains and shear force facilitates intercalation when suitable levels of polymer-clay compatibility exist. The relative ease in utilizing this technique has made it the most popular compounding method of the three detailed here. Fig. 2.8 shows a simple schematic of melt mixing.

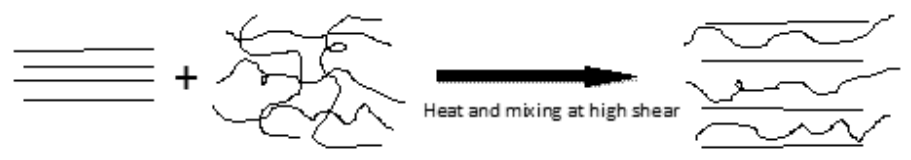

Fig. 2.8: Schematic of melt compounding 
The finding of Vaia et al. [9] that direct intercalation of polymer chains into clay gallery spacings is a viable compounding technique opened up the possibility of melt compounding PLSNs. In a follow up paper, Vaia et al. [10] used in-situ x-ray diffraction to determine that the rate of diffusion of polymer chains between silicate layers was on the same order of magnitude as polymer self diffusion. This work showed that melt compounding was not only possible but it could be carried out under the same conditions as one would melt process a pure polymer material.

Cho et al. [19] carried out one of the first extensive studies on the effects of melt compounding conditions on silicate morphology and PLSN properties. Both a single screw and a twin screw extruder were employed to produce polyamide based PLSNs. Results from samples produced using the single screw extruder at 40rpms showed poor exfoliation. A second pass through the single screw extruder was also attempted but poor exfoliation still existed. PLSNs produced using the twin screw extruder showed considerable property improvements as compared PLSNs processed with the single screw extruder. Exfoliation in the twin screw processed PLSN material was found to be extensive after only a single pass. The young's modulus improved over the single screw PLSNs and a $15 \%$ increase in yield strength was achieved. The authors used a number of different screw speeds and barrel temperatures in the twin screw extruder to consider the effect these conditions might have on the final PLSN properties. Results showed that material properties remained the same over the full range of processing conditions employed. It is important to note that all of the PLSNs produced using the twin screw extruder showed complete exfoliation. The excellent compatibility of polyamide and the 
organoclay used may have made it difficult to consider the effect that barrel temperature and screw speed have on the silicate morphology and PLSN properties.

A more in depth analysis of the effect of extruder conditions on PLSN properties was carried out by Dennis et al. [20]. A single screw extruder as well as a co and counter rotating twin screw extruder were used in their study. Variable screw speeds and multiple screw configurations were used in order to control the amount of shear and backmixing that occurred during the formation of polyamide- 6 based PLSNs. The authors use two commercially available organoclays containing different surfactant modifications in order to obtain the proper degree of polymer/clay compatibility necessary to study the effect of melt processing conditions. Very strong polymer/clay compatibility would dampen the effect of melt processing conditions by resulting in an exfoliated morphology under low shear conditions. In agreement with the findings of Cho et al. [19], PLSN material produced using the single screw extruder showed minimal exfoliation and poor material properties. The twin screw results showed a high degree of variability in exfoliation levels depending on the degree of backmixing and residence time. The results indicate that an optimal level of backmixing exists and that excessive levels of shear lead to reduced exfoliation and dispersion.

The relationship between extruder conditions and silicate morphology is linked by the amount of shear imparted to the PLSN in the melt as well as the transfer of shear throughout the PLSN in the melt. Fornes et al. [21] showed that the molecular weight of the PLSN affects silicate morphology due to the ability of high molecular weight polymers to transfer shear stresses more effectively than low molecular weight polymers. A twin screw extruder was used in the preparation of PLSNs using low, medium and high 
molecular weight polyamide resins. The low molecular weight PLSNs showed incomplete exfoliation and inferior mechanical properties while the medium and high molecular weight PLSNs showed excellent exfoliation. The differences in exfoliation levels are attributed the trend of increasing melt viscosity and stress transfer ability of the polymer melt with increasing molecular weight.

Extruder screw rotational speed is another important melt processing condition. Peltola et al. [22] examined the effect of rotational screw speed on polypropylene based PLSNs. A twin screw extruder was used to produce PLSNs at screw speeds of 200, 500 and 1000rpms. Results show an increase in intercalation and a modest increase in exfoliation with increasing screw speed but no improvement in PLSN mechanical properties are seen. The modest improvements in exfoliation that are seen in TEM images may not have been enough to noticeably alter the mechanical properties of the PLSNs.

Modesti et al. [23] carried out an extensive study of the effect of both temperature and screw speed on the morphology and mechanical properties of polypropylene based PLSNs. Screw speeds of 200 and $350 \mathrm{rpms}$ were used in an intermeshing, co-rotating twin screw extruder. The two different melt temperatures employed were approximately $170^{\circ} \mathrm{C}$ and $200^{\circ} \mathrm{C}$. The results of both the silicate morphology tests and the mechanical property test were conclusive in showing that the most effective melt compounding condition was that of low temperature and high screw speed. The authors conclude that conditions which maximize the shear stress exerted on the polymer are the most effective at forming highly dispersed and exfoliated PLSNs. In addition to the effect of temperature and screw speed on silicate morphology, the authors show that the effect of residence time is far less influential in achieving silicate exfoliation than shear stress 
during processing. This conclusion might be expected since the rate of polymer diffusion into silicate galleries is on the same order as the rate of polymer self diffusion.

The use of melt processing to compound PLSNs can be an effective way to optimize silicate morphology and PLSN mechanical properties. Research has shown that the conditions under which melt compounding is carried out have a considerable effect on the quality of the final composite material. Single screw extrusion alone is insufficient to produce high quality PLSNs. Necessary considerations when producing PLSNs with melt compounding include melt temperature, screw speed and screw geometry. In addition to extruder conditions polymer molecular weight has a measurable effect on silicate morphology. Of the three compounding techniques discussed here, melt compounding has the advantage of being simple, fast and compatible with current industrial techniques. The primary challenge to melt compounding that must be overcome is the inability to disperse and fully exfoliate organoclays in certain polymer matrices such as polypropylene.

\subsection{Characterization Techniques}

Identification of the silicate morphology within a PLSN can be accomplished using a number of analytical techniques. The simplest, most common analysis technique used for this purpose is wide angle x-ray diffraction (WAXD). Gallery spacing values can be determined from diffraction peaks and evidence of silicate exfoliation can be seen from peak intensities. In addition to WAXD, an optical image of the silicate morphology can be generated using transmission electron microscopy (TEM). Finally, multiple studies on the rheological properties of PLSNs have attempted to find qualitative relationships between silicate morphology and rheology with limited success. 


\subsubsection{Wide Angle X-ray Diffraction (WAXD)}

$\mathrm{X}$-ray diffraction is a powerful tool for identifying crystalline structures on the nanoscale. WAXD involves the use of $\mathrm{x}$-ray diffraction at low angles between 1 and 10 degrees where reflections are the result of crystalline structures having length dimension on the order of tens of nanometers. WAXD is particularly useful for the identification of intercalated structures due to their nanometer dimensions and their repetitive crystalline order [1]. Exfoliated structures are not visible as peaks in WAXD curves as the lack of system order prevents the constructive interference necessary for peaks in diffraction curves to form.

Intercalated silicate structures are seen in WAXD curves as distinct peaks rising out of a flat baseline curve. The location of the peak with respect to the angle $2 \Theta$ can be related to the basal spacing of the intercalated silicates using the Bragg equation [24]:

$$
2 d \operatorname{Sin} \Theta=n \lambda
$$

where $\mathrm{d}$ is the average basal spacing of the silicate tactoids, $\Theta$ is one half of the $2 \Theta$ location of the diffraction peak, $\mathrm{n}$ is the wave number taken to be 1 and $\lambda$ is the $\mathrm{x}$-ray wavelength. The Bragg equation is an effective way to measure the changes that occur in basal spacing values due to the formation of an intercalated structure. At angles of $2 \Theta$ between 1 and 10 degrees, basal spacing values calculated from peaks with widths less than 2 degrees of $2 \Theta$ are expected to have less than $2 \%$ error [1].

In addition to reflection peak location relative to $2 \Theta$, peak width with respect to $2 \Theta$ can be a useful characteristic in determining relative silicate tactoid sizes. The full 
width of a reflection peak measured at half of its maximum intensity (FWHM) can be related to the average tactoid size present in the sample by the Scherrer equation [1]:

$$
d^{\prime}=\frac{k \lambda}{L \operatorname{Cos} \Theta}
$$

where d' is the value of the FWHM, $\Theta$ is one half of the peak location at its $2 \Theta$ value, $L$ is the average tactoid size, $\mathrm{k}$ is a proportionality constant equal to approximately $0.93[1$, $25,26]$ and $\lambda$ is the $x$-ray wavelength. Calculation of the average tactoid size combined with basal spacing information attained from the Bragg equation allows for calculation of the average number of silicate layers per tactoid [27]. The accuracy of the Scherrer equation in determining the correct average silicate tactoid size in layered silicates has been shown to be poor in past literature [28]. The nature of this inaccuracy is primarily due to experimental conditions which skew the size results in one direction. By maintaining the same experimental conditions, the precision of tactoid size values calculated from the Scherrer equation allows for semi-quantitative tactoid size comparisons between multiple samples.

In addition to the effect of particle size on the FWHM, crystalline disorder can have a measureable effect on the FWHM [29]. Disorder in silicate layer structure can be in the form of bent silicate layers or irregularities in the chemical structure. The flexible nature of the silicate layers makes it possible to have bends or folds in the layers. The irregular geometry of these bent layers has been shown to increase the FWHM of diffraction peaks. The individual contributions of particle size and crystal structure disorder to FWHM broadening can be isolated if higher orders of the same diffraction peak are present in the WAXD curve [25]. Diffraction peaks that occur from wave 
numbers (n) greater than 1 are higher order peaks that are less intense than primary peaks. These higher order peaks are more sensitive to crystal structure disorder and often cannot be resolved due to high levels of FWHM broadening.

\subsubsection{Transmission Electron Microscopy (TEM)}

Images generated using TEM can be used to confirm results obtained from WAXD. The primary advantage of TEM over WAXD is the ability to confirm the presence of exfoliation in a PLSN sample. WAXD can be strongly affected by particle size, sample preparation, silicate concentration and sample orientation. WAXD curves indicating exfoliation can be the result of low silicate concentration or poor sample preparation. In the case of a WAXD curve indicating exfoliation, TEM can be used to confirm the presence of exfoliation. A severe limitation to the use of TEM is the highly localized nature of the images that are obtained. The extremely high magnification of TEM means the operator must choose a representative image for the entire sample from only a very small portion of the actual sample. For this reason, levels of intercalation and exfoliation can be highly variable if obtained from TEM images.

\subsubsection{Rheology}

The rheology of PLSNs has been studied for a wide variety polymer and filler types. The primary characteristic of interest in rheological studies is the formation of yield stress behavior during dynamic oscillatory rheological testing. Krishnamoorti et al. [30] found increasing yield stress behavior in polyamide-6 PLSNs with increasing silicate loading. This behavior was attributed primarily to the tethering of polyamide chains to the surface of the layered silicate. Lim et al. [31] used dynamic oscillatory shear in the linear viscoelastic regime of three different polymer systems in an attempt to identify the 
behavior of exfoliated and intercalated PLSNs. In agreement with previous studies the authors found an increase in yield behavior with clay loading. It was also found that for exfoliated silicate morphologies yield stress behavior was caused by the formation of a percolated network structure. Intercalated PLSNs showed yield like behavior at low frequencies only when strong interactions between the polymer and silicate existed. Li et al. [32] found similar results in their study of polypropylene based PLSNs. A percolated network structure appeared to form at $3 \mathrm{wt} \%$ silicate loading in polypropylene due to particle-particle interactions among the silicate tactoids. Non-linear rheology using steady shear showed that the percolated network structure can be destroyed when the silicate layers become preferentially aligned in the flow direction. Letwimolnun et al. [33] attempted to use yield stress values to quantify the level of exfoliation present in a PLSN system. The results showed that there is a relationship between yield stress and exfoliation but the models that were implemented in an attempt to quantify this relationship failed to describe the experimental results.

The use of rheology in characterizing PLSN systems has lead to an improved understanding of how silicate layers interact with themselves as well as the polymer matrix. Polymer chains that are highly compatible with the silicate surfaces tether to the silicate layers and create a percolated network structure that is responsible for the yield like behavior seen at low frequencies during dynamic oscillatory rheological testing. At higher clay loadings beyond a percolation threshold, particle-particle interactions between silicate tactoids may also contribute to the formation of a yield stress. Under strong shear forces in the non-linear viscoelastic regime, the preferential orientation of silicate layers has been observed. The alignment of silicate layers destroys any network 
structure that exists and eliminates yield like behavior upon further testing. Efforts to quantify the level of exfoliation in a PLSN using rheology have not been successful. Qualitative conclusions based on previous studies and our current understanding of the formation of percolated networks in PLSNs can be made.

\subsection{Material Property Enhancements}

The tremendous interest in PLSN technology that has been generated in the past two decades is primarily the result of significant property enhancements that can be achieved in PLSNs containing small amounts of layered silicate as filler. A number of material properties where enhancements have been reported in the literature include tensile modulus [2, 27], flexural modulus [2, 23, 24], thermal degradation [11, 34-36], heat distortion temperature $[2,24,37]$ and barrier ability $[6,38,39]$.

\subsubsection{Young's modulus}

Kojima et al. [2] was the first to record significant improvements in the tensile modulus of PLSNs over their neat polymer matrices. A $69 \%$ increase in tensile modulus was realized in a polyamide based PLSN containing $4.7 \mathrm{wt} \%$ layered silicate. The authors also found that the length or aspect ratio of the layered silicate used has a significant effect on the tensile modulus of the final PLSN. The tensile property improvements are attributed to increases in the amount of constrained region in the PLSN due to the presence of the layered silicate. The constrained region includes all portions of the PLSN that are not amorphous and is shown to increase with both silicate loading and length. Estimations of the constrained region correlate well with improvements in physical properties that are realized. 
Galgali et al. [27] studied the effect of silicate orientation as well as polymer/clay compatibility on the tensile modulus of polypropylene based PLSNs. Using 2D x-ray diffraction to quantify the amount of silicate orientation the authors found a strong correlation between the tensile moduli and the average silicate orientation present in the samples. The polymer/clay compatibility was altered in some samples by the addition of an isotactic polypropylene-g-maleic anhydride compatibilizer. It was found that samples containing compatibilizer had average silicate orientations that were dependent on the amount of shear they were exposed to during melt compounding. The tensile modulus of the compatiblized samples correlated very well with the average silicate orientation resulting in large modulus improvements. The uncompatiblized samples had average silicate orientations that were independent of the amount of shear they were exposed to during melt compounding. As a result, no improvement in the tensile modulus of the uncompatiblized samples with increasing shear exposure was found.

\subsubsection{Flexural modulus}

Modesti et al. [23] found that improvements in the flexural modulus were highly dependent on melt compounding conditions. Using a compatiblized polypropylene a $35 \%$ increase in the flexural modulus was realized over the neat polymer matrix. Uncompatiblized polypropylene PLSNs showed a maximum increase of $26 \%$ over the neat polymer matrix. This difference in improvements between the uncompatiblized and compatiblized samples was attributed primarily to improvements in polymer/clay compatibility. The authors propose that improvements in polymer/clay interaction should decrease polymer chain mobility and increase the stiffness of the material. 


\subsubsection{Thermal degradation}

Materials with high moduli and high thermal degradation temperatures are valuable as potential parts in high performance automotive applications. Vaia et al. [35] studied the ablation performance of polyamide- 6 based PLSNs. It was found that the degradation kinetics were unaltered by the presence of layered silicate but the ablation performance increased. The addition of layered silicate in amounts as small at $2 \mathrm{wt} \%$ resulted in over an order of magnitude decrease in the rate of mass loss as compared to neat polyamide. This behavior was attributed to the formation of char on the surface of the PLSN during exposure to high temperature air. The inorganic char is said to be responsible for decreasing degradation by insulating the material beneath it. In addition to having insulating properties, the uniform char formation makes the diffusion of volatile degradation products out of the sample more difficult by increasing the tortuosity of the sample.

Pramoda et al. [34] also used polyamide-6 to examine the thermal degradation behavior of PLSNs. The results showed that the presence of silicate did not affect the type of gas evolved during thermal degradation. The onset temperature for thermal degradation however, was $12^{\circ} \mathrm{C}$ higher for the PLSN containing $2.5 \mathrm{wt} \%$ silicate than the neat polyamide- 6 . The authors also found that the state of exfoliation has a significant effect on the thermal degradation tendency of the PLSNs. Composites only showed an increase in thermal degradation temperature when they contained an exfoliated silicate morphology. Agglomerated clay particles did not alter the thermal stability of the PLSNs. The behavior seen in this study can be attributed to silicate layers acting as barriers to the diffusion of volatile degradation products out of the PLSN samples. 


\subsubsection{Heat Distortion Temperature (HDT)}

Limiting the amount of deformation a material undergoes when exposed to heat is important for many applications that involve high temperatures. Ke et al. [37] found that the addition of $5 \mathrm{wt} \%$ layered silicate to a poly(ethylene terephthalate) (PET) matrix caused a $40^{\circ} \mathrm{C}$ increase in the heat distortion temperature (HDT). This dramatic increase in the HDT is attributed to the confinement of polymer chains between silicate layers. The extreme confinement of the polymer chains decreases their ability to move freely. The authors claim that the observed increase in the HDT is a direct result this reduction in chain mobility.

Wang et al. [24] also found improvements in the HDT of PET PLSNs. At a $1 \mathrm{wt} \%$ silicate loading a $35^{\circ} \mathrm{C}$ increase in the HDT was found. The HDT increased with the addition of layered silicate until a $49^{\circ} \mathrm{C}$ improvement in HDT was realized for a $5 \mathrm{wt} \%$ silicate loading PLSN over the neat polymer matrix. The authors do not point to a single reason for this behavior but instead suggest that it could be the result of both increased crystallinity and a loss of polymer chain mobility due to extreme confinement between silicate layers.

\subsubsection{Barrier property improvements}

Adding high aspect ratio particles to a polymer matrix dramatically increases the tortuosity of a membrane formed from that polymer material. Engineering polymers with improved barrier properties have the potential for use in industrial, military and packaging applications. Ray et al. [38] examined the Oxygen permeability coefficient of poly(butylene succinate) (PBS) based PLSNs as a function of clay loading. The results show a monotonic decrease in the permeability of Oxygen with an increase in silicate 
loading. The decrease in permeability is the result of an increase in tortuosity of the PBS membrane due to the presence of layered silicate. At a silicate loading of $3.6 \mathrm{wt} \%$ there is a steep drop in the Oxygen permeability that the authors attribute to the formation of a flocculated structure. In order to achieve the maximum increase in tortuosity possible, an exfoliated structure must be achieved. Intercalated tactoids are far less effective at limiting the diffusion of small molecules through a PLSN membrane.

\subsection{Theoretical Modeling of PLSN Tensile Modulus}

The use of mathematical models to predict the tensile modulus of PLSN systems is one way to test our understanding of the interactions that exist between layered silicate and the polymer matrix. Simple volume additivity fails to predict modulus values of PLSNs by not accounting for a number of significant factors including silicate aspect ratio, silicate morphology and particle alignment. Adjustments made to the basic equation of volume additivity in an attempt to account for some of these factors have resulted in a number of more accurate models. Other models developed from composite theory take into account multiple phases within PLSN systems and result in highly accurate predictions of modulus.

\subsubsection{Halpin-Tsai Model}

Simple volume additivity grossly under predicts the composite modulus of PLSNs. The under prediction is a result of the failure of the model to incorporate a number of unique characteristics of PLSNs including layered silicate aspect ratio. The Halpin-Tsai equations [40] are the result of the addition of mathematics to simple volume additivity that incorporate the effects of particle aspect ratio on composite modulus. The assumptions of complete exfoliation and full alignment of silicate layers results in a very 
simple model that predicts a best case scenario. The simplicity of the model has led to its widespread use in past literature as a way to make conclusions about the state of silicate morphology and orientation in experimentally produced PLSNs [37]. The assumptions made in the Halpin-Tsai model mean that the modulus values calculated from these equations are expected to be greater than the values obtained from any sample with partial exfoliation or incomplete alignment of silicate particles. The equations are given as:

$$
\begin{gathered}
E_{c}=E_{m}\left[\frac{1+\xi \eta \phi_{f}}{1-\eta \phi_{f}}\right] \\
\eta=\frac{\left[\frac{E_{f}}{E_{m}}-1\right]}{\left[\frac{E_{f}}{E_{m}}+\xi\right]} \\
\xi=2\left[\frac{1}{t}\right]
\end{gathered}
$$

where $E_{f}, E_{m}$ and $E_{c}$ are the filler modulus, matrix modulus and composite modulus, respectively. $\phi_{\mathrm{f}}$ is the filler volume fraction and $[1 / \mathrm{t}]$ is the aspect ratio of the filler particles taken to be approximately 100 . The filler modulus is taken to be $172 \mathrm{GPa}$ [3].

\subsubsection{Ji et al. Model}

The Ji et al. [41] model incorporates three different phases of material within a PLSNs to estimate tensile modulus values. The phases include the filler material, the polymer matrix surrounding the silicate layers and the spacing between the silicate layers. The governing equations in the Ji et al. model are as follows: 


$$
\begin{gathered}
\frac{1}{E_{c}}=\frac{1-\alpha}{E_{m}}+\frac{\alpha-\beta}{(1-\alpha) E_{m}+\frac{\alpha(k-1) E_{m}}{\ln }}+\frac{\beta}{(1-\alpha) E_{m}+\frac{(\alpha-\beta)(k+1) E_{m}}{2}+E_{f} \beta} \\
\alpha=\sqrt{\left[2\left(\frac{\tau}{t_{c}}\right)+1\right] \phi_{f}}
\end{gathered}
$$

where $\tau$ is the thickness of the basal spacing (d-spacing) and $t_{c}$ is the thickness of a single montmorillonite sheet taken to be $1 \mathrm{~nm}$. $\beta$ is defined as the square root of $\phi$ and $\mathrm{k}$ is the ratio of $E_{\mathrm{f}}$ to $\mathrm{E}_{\mathrm{m}}$.

The primary advantage of this model is that the assumption is made that silicate layers are randomly oriented. Galgali et al. [27] showed that the orientation of silicate layers in a PLSN has a major impact on its mechanical properties. The authors also found that while attempting to orient silicate layers with high levels of shear only $30 \%$ alignment of the particles in the flow direction could be achieved. The assumption in the Ji et al. model of randomly aligned silicate layers is much more applicable to actual PLSN systems than the assumption of completely aligned particles as in the Halpin-Tsai model.

The Ji et al. model makes no assumptions as to the exact state of the silicate morphology within a PLSN. The necessity for an estimate of the average basal spacing of the silicate layers in order to use the model means that some level of intercalation is assumed. The vast majority of PLSNs produced in literature are a mixture of exfoliated and intercalated silicate morphologies. By assuming that a mixture of intercalation and exfoliation is always present the Ji et al. model can be applied to a wide variety of PLSN systems. 
Nguyen [42] and Chu et al. [43] used both the Halpin-Tsai and Ji et al. models for comparison with experimental data. Both authors found that the Halpin-Tsai model grossly overestimated the experimentally found Young's modulus values. Incomplete particle alignment and incomplete silicate layer exfoliation were cited as the main reasons the experimental and theoretical values failed to agree. The Ji. et al. model predictions however, were accurate to within $10 \%$ of the experimental modulus values. The partial orientation and incomplete exfoliation of the samples produced in the two papers were the primary reasons that the model and experimental values agreed so well.

\subsection{Polymer Matrices Used in PLSNs}

A wide variety of polymer matrices have been used in the literature to make PLSNs but the most successful and most commonly used polymers are polyamides. Kojima et al. [2] produced the first PLSNs using polyamide-6. The composites they produced were very successful in obtaining superior mechanical properties as compared to neat polyamide- 6 . The outstanding results that have been achieved in polyamide based PLSNs are due primarily to the excellent compatibility that exists between polyamides and layered silicates. Polyamides are capable of hydrogen bonding with surface oxygen atoms and hydroxyl groups on the silicate layers. These strong interactions make it relatively easy for one to achieve an exfoliated silicate morphology using a wide range of processing techniques and conditions. In addition, polymer/clay interactions are preserved in the melt compounding of polyamides as the melt temperatures necessary to produce polyamide based PLSNs are well below the degradation temperature of the layered silicate surfactant modifications used. As a result of the strong compatibility 
between polyamide and clay, a large number of studies on PLSNs have utilized polyamide as a matrix $[2,7,19-21,34,44-53]$.

In addition to polyamides there are a number of polymers that have been investigated extensively in the literature with mediocre success in obtaining desirable silicate morphologies. Polyolefins including polypropylene [54-61], polyethylene [31, 43, 62-64] and polystyrene [10, 30, 31, 65] have been widely investigated as matrices in PLSNs because of their commercial importance. Difficulties in forming PLSNs from these polymers with desirable silicate morphologies have been widespread. The lack of hydrogen bonding ability in the polyolefins severely decreases the intensity of polymer/clay interactions from that seen in polyamide systems. In order to improve the compatibility of polyolefins and layered silicate a number of different compatibilizers have been utilized. The most common compatibilizer that is used extensively with polypropylene based PLSNs is maleic anhydride. A number of papers have shown improvements in polypropylene/clay interaction by adding quantities of maleic anhydride grafted polypropylene to the PLSNs $[27,32,61]$. Other less extensively studied polymer types in PLSNs include epoxy resins [5, 17, 30, 55], poly(ethylene oxide) [10], polycaprolactone [6], polycarbonate [66] and a variety of block copolymers $[31,67,68]$.

\subsubsection{Poly(ethylene terephthalate) (PET) Based PLSNs}

A commercial polymer that stands to gain from improvements in mechanical as well as barrier properties by the addition of layered silicate is PET. PET based PLSNs with improved barrier properties have potential applications in the bottling and packaging industry. Mechanical property improvements can be utilized to spin high performance polyester fibers. These property enhancements are highly dependent on the success of the 
processing method used in producing PLSNs with desired silicate morphologies. In order for PET based PLSNs to be valuable it is necessary to obtain highly dispersed, well exfoliated nanocomposite at an industrial scale. A small number of research efforts focused on PET based PLSNs have found many difficulties in obtaining quality PLSNs. The biggest challenges to producing this type of nanocomposite are the occurrence of polymer matrix degradation during melt processing and a lack of sufficient polymer/clay compatibility leading to poor silicate exfoliation. Attempts to solve these problems have resulted in limited success.

Ke et al. [37] produced five PET based PLSNs containing different amounts of layered silicate filler using in-situ polymerization. At a $5 \mathrm{wt} \%$ loading of silicate a $71 \%$ increase in the tensile modulus was realized over the neat PET. Comparisons between the tensile modulus obtained from experimental results and predictions made from the Halpin-Tsai model however, showed the experimental values to be far less than ideal. The authors attribute this behavior to agglomerates of clay that can be seen in all of the samples that were produced. Although mention is made of the importance of polymer/clay compatibility in the paper, no mention is made of the chemical nature of the layered silicate surfactant modification used. The in-situ polymerization technique utilized additives in addition to PET monomer and layered silicate that the authors did not describe. Although in-situ polymerization in this article produced PLSNs with improved mechanical properties, the level of dispersion and exfoliation was less than desired.

Davis et al. [69] carried out a study on the silicate morphology of PET based PLSNs produced using melt mixing. Two different layered silicate surfactant modifications were tested in the process. The results showed that one of the surfactant 
types degraded at the high temperature necessary for PET melt processing. The other surfactant modification was stable enough at high temperatures to obtain PLSN samples. Despite the well dispersed nature of the layered silicate, WAXD data taken on all of the samples show distinct peaks indicating the presence of an intercalated morphology. The authors use TEM images to claim that the sample produced using the lowest residence time $(2 \mathrm{~min})$ and the slowing mixing rate $(21 \mathrm{rad} / \mathrm{s})$ had the best dispersion and exfoliation. Conventional analysis of the WAXD data however, suggests that the sample with the slightly longer residence time $(5 \mathrm{~min})$ had the best level of exfoliation. The important result of this is that relative to residence time and exposure to shear, an optimum level of exfoliation was achieved. A completely exfoliated morphology could not be achieved with melt mixing alone. Another concern in the production of PET based PLSNs highlighted by this study is the potential for the degradation of layered silicate surfactant molecules during high temperature melt mixing.

Imai et al. [16] attempted to improve the interaction of PET and layered silicate by creating a novel, reactive compatibilizer. The novel compatibilizer shown below:

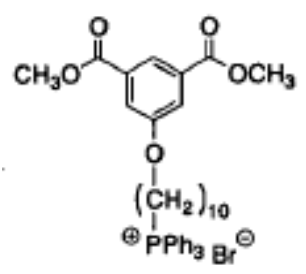

was designed to interact strongly with the surface of silicate layers, increase the silicate basal spacing from that of the untreated silicate and transesterify with the PET chains. PLSN production was carried out by in-situ polymerization using bis-(2hydroxyethyl)terephthalate in the presence of the reactive compatibilizer and layered silicate. WAXD results of the final composite show strong peaks indicating a high level 
of intercalation. Surprisingly, results of mechanical testing show a $170 \%$ increase in the tensile modulus of $8 \mathrm{wt} \%$ silicate composites when a high concentration of compatibilizer was present. The outstanding increase in tensile modulus achieved using the reactive compatibilizer is attributed to improved interaction between PET chains and the layered silicate. Although this technique is successful for dramatically improving PET/clay interaction, the time and resources necessary to produce compatibilizer and carry out insitu polymerization makes it a costly process.

Sanchez-Solis et al. [63] studied the rheological and mechanical response of PET based PLSNs produced from melt compounding. A severe drop in matrix molecular weight due to degradation of the neat PET matrix during extrusion and injection molding was recorded using GPC. Interestingly, when PLSNs were produced with the same thermal history as the neat PET, no additional degradation was recorded due to the presence of layered silicate. Rheological tests show an enhancement of the complex viscosity in the PLSNs over the neat PET with the same thermal history. The authors present no explanation for this behavior as an increase in degradation due to the presence of tightly bound water molecules on the silicate surfaces is expected. The authors claim that the majority of the samples produced contain an exfoliated morphology. This is an unsubstantiated claim as no WAXD or TEM evidence is presented. Mechanical testing results reveal unexpectedly low values for the tensile modulus of all of the samples produced including the neat PET. The neat, extruded PET modulus was recorded at 1091 $\mathrm{MPa}$ which is far below the expected tensile modulus of PET of around $3000 \mathrm{MPa}$. The authors fail to comment on or explain these unusually low values. 
Wang et al. [24] formed PET based PLSNs from twin screw extrusion and examined both the crystallinity of the resulting materials and the mechanical properties. WAXD results showed defined peaks at all clay loadings including the $1 \mathrm{wt} \%$ samples. In addition, TEM images reveal the presence of large, intercalated silicate tactoids in all of the samples. Despite the lack of exfoliation achieved, some of the samples showed improved properties. An increase in the crystallinity of the PLSNs over the neat PET was used to explain the large increase in HDT that was realized in each of the samples. Mechanical testing revealed a $25 \%$ increase in the tensile strength of the $1 \mathrm{wt} \%$ silicate sample but a considerable drop in tensile strength in the 3 and $5 \mathrm{wt} \%$ samples. A similar trend was found with the flexural modulus as a slight increase was detected for the $1 \mathrm{wt} \%$ samples whereas the 3 and $5 \mathrm{wt} \%$ samples showed lower flexural modulus values. The authors attribute the decrease in properties of the 3 and $5 \mathrm{wt} \%$ samples to the presence of large agglomerates of intercalated silicate layers. The dispersion and exfoliation was best at a clay loading of $1 \mathrm{wt} \%$. From this study it is apparent that melt compounding alone is insufficient for the production of highly exfoliated PET based PLSNs.

In addition to concerns about surfactant degradation and poor layered silicate exfoliation, melt compounding techniques used to produce PET based PLSNs have been found to result in PET matrix degradation far beyond that experience by neat PET. In work carried out by Matayabas and Turner [70], it was found that degradation during melt compounding of PET with layered silicate was severe. Attempting to solve this problem, the authors melt compounded additional PLSNs using PET with a much higher initial molecular weight. The results showed even greater degradation in the samples with produced from high molecular weight PET. The study showed that the problem of PET 
matrix degradation in the presence of layered silicate cannot be solved by melt compounding with a higher molecular weight PET matrix.

Although melt compounding of PET based PLSNs is the most industrially compatible technique available, PET matrix degradation and poor layered silicate exfoliation are difficult processing challenges that need to be overcome. Solid stating reactions to increase the molecular weight of melt processed PET based PLSNs can reverse some of the effects of degradation. The solid stating technique is time intensive however, making it costly and inefficient for industrial scale productions. Preventing degradation at the melt compounding step is much more desirable. Finally, silicate exfoliation must be improved in order to obtain high performance PLSNs from melt compounding. Combining melt compounding with additional techniques for exfoliating silicate layers is one potential way to optimize layered silicate morphology.

\subsection{Supercritical Carbon Dioxide in Nanocomposite Compounding}

Supercritical carbon dioxide $(\mathrm{scCO} 2)$ has a number of potential uses in polymer processing. In a review article by Tomasko et al. [71], a wide range of scCO2 applications in polymer processing are detailed. These applications include the use of $\mathrm{scCO} 2$ as a foaming agent, a plasticizer, a processing solvent and a processing aid used for the impregnation of polymer matrices with additives. The interest in using scCO2 as opposed to other supercritical fluids is environmental and economic in nature. $\mathrm{scCO} 2$ is both inexpensive and environmentally benign. It can be used to alter the viscosity of a polymer matrix simply by changing the temperature and pressure conditions.

Carbon dioxide acts as a polar, organic solvent under supercritical conditions making it highly compatible with many types of polymer matrices and layered silicate 
[71]. This behavior of carbon dioxide at supercritical conditions has been used in an attempt to improve the level of silicate exfoliation that can be achieved in PLSNs. A number of different processing techniques using $\mathrm{scCO} 2$ as a processing aid have been investigated for their ability to disrupt the regular, layered order of the nanosilicate both prior to and during PLSN compounding.

Manke et al. [72] was the first to attempt to delaminate silicate layers with the use of scCO2. Layered silicate was mixed with carbon dioxide at $1700 \mathrm{psig}$ and $80^{\circ} \mathrm{C}$ in a high pressure vessel connected by a ball valve to another empty chamber. The mixture remained at rest for a period of 5 hours at which time a ball valve between the pressure vessel and the empty chamber was opened and a catastrophic release of pressure occurred. The silicate was removed from the chamber and dry mixed with polypropylene. Results from WAXD carried out on the treated clay show a considerable decrease in the intensity of the main diffraction peak seen in the untreated clay. No WAXD data was obtained from the polypropylene based PLSN that was produced. TEM images of the treated clay also show what appears to be a noticeable increase in silicate layer disorder. No TEM images were obtained from the PLSN samples that were produced. Although the authors present evidence of delamination in the treated clays, they show no evidence than the treated silicate layers remain in an exfoliated state after they have been processed into a PLSN.

Zerda et al. [73] used $\mathrm{scCO} 2$ as a low viscosity solvent in the in-situ polymerization of poly(methyl methacrylate) (PMMA). The primary purpose of the $\mathrm{scCO} 2$ was to allow methyl methacrylate monomers to readily diffuse and homogeneously disperse within the gallery spacings of the silicate layers. 
Montmorillonite, methyl methactrylate monomer, initiator and $\mathrm{CO} 2$ were combined in a custom high pressure apparatus designed to allow for compressive forces on the mixture. The pressure of the chamber was increased to $14 \mathrm{MPa}$ and the temperature was set to $65^{\circ} \mathrm{C}$ for a period of $4 \mathrm{hr}$. After this period of saturation time the temperature was raised to $110^{\circ} \mathrm{C}$ and maintained for a $6 \mathrm{hr}$ period in order to complete the polymerization step. Once polymerization was complete, the pressure was reduced to atmospheric conditions over a period of $15 \mathrm{hr}$. Removal of trapped $\mathrm{CO} 2$ was accomplished by exposing the samples to temperatures above the glass transition to allow foaming to occur. The foamed material was then pulverized and melt processed. This technique produced highly dispersed, intercalated PLSNs. Highly dispersed composites with clay concentration of $40 \mathrm{wt} \%$ were achieved. Isotropic forms of the $40 \mathrm{wt} \%$ PLSNs showed a $50 \%$ increase in tensile modulus while melt processed samples containing orientation showed an increase in the tensile modulus of $220 \%$. An advantage to this particular technique is the high level of control the operator has over the viscosity of the polymerizing PMMA.

Mielewski et al. [74] added scCO2 to a PLSN melt in an extruder in an attempt to facilitate exfoliation of the layered silicates upon rapid depressurization at the extruder exit. Polymer material and layered silicate were dry blended prior to being loaded into the hopper of an extruder. During extrusion, $\mathrm{scCO} 2$ was added downstream of the melt through an inlet port along the barrel. As the melt exits the extruder die the drop in pressure causes the melt to foam as $\mathrm{CO} 2$ is released. The authors claim that the expanding $\mathrm{CO} 2$ causes the layered silicate to become exfoliated. No evidence that the technique is successful in exfoliating layered silicates is presented. There is no TEM or WAXD data presented on any composites that are produced. Recent work carried out by 
Nguyen [42] on a similar technique shows evidence that the slow expansion of $\mathrm{CO} 2$ at the extruder die is unable to force silicate layers apart.

Nguyen [42] developed a method to combine the benefits of melt compounding with the exfoliating capability of $\mathrm{scCO} 2$. The technique first involved the saturation of layered silicate in $\mathrm{scCO} 2$ at $3000 \mathrm{psig}$ and $80^{\circ} \mathrm{C}$ for a period of $24 \mathrm{hr}$. The saturation was accomplished in a custom pressure chamber designed with an inlet for the addition of $\mathrm{CO} 2$ and an exit with a ball valve for the subsequent release of the mixture. The pressure chamber exit was designed with the ability to release its contents through an inlet in the second stage of a single screw extruder. To make composite material, polymer was loaded into a modified hopper attached to the extruder with the ability to trap released clay. The extruder was brought to melt temperature with the screw turned off. The ball valve on the pressure chamber was opened and the mixture of silicate and $\mathrm{scCO} 2$ rapidly expanded throughout the extruder screw and up into the modified hopper where it immediately mixed with the polymer pellets. The extruder screw was then turned on and the mixture was melt mixed and pelletized. Polypropylene based PLSNs were produced in this way and tested for silicate morphology as well as mechanical property improvements. Results from WAXD showed an increase in the exfoliation levels of the $\mathrm{scCO} 2$ processed material as compared to samples produced with dry mixing of polymer and clay. Mechanical tests showed a $17 \%$ improvement in the Young's modulus of $\mathrm{scCO} 2$ produced PLSNs containing $6.5 \mathrm{wt} \%$ silicate over PLSNs with the same $\mathrm{wt} \%$ silicate produced from dry mixing of the silicate and clay. Visual inspection of injection molded plaques showed a considerable enhancement in the clarity of the $\mathrm{scCO} 2$ processed PLSNs. The combination of $\mathrm{scCO} 2$ facilitated silicate exfoliation with melt 
compounding makes this particular technique ideal for use with polymer matrices that stand to benefit from the addition of layered silicate but are unable to achieve a suitable level of silicate exfoliation with simple melt compounding.

\subsection{Research Objectives}

Recent work with PET based nanocomposites has show that although melt mixing has potential as a compounding method for this type of PLSN, there are a number of processing challenges that need to be overcome. At the high temperatures needed for PET melt mixing, trapped water molecules within nanosilicate galleries react hydrolytically with PET chains. Degradation due to the presence of clay lowers matrix molecular weight and limits silicate exfoliation by decreasing the ability of the polymer to transfer shear forces to silicate tactoids [43]. Previous work with $\mathrm{scCO} 2$ has shown promise for increasing silicate exfoliation without relying on the use of high levels of shear [42, 72]. Implementation of the scCO2 technique developed by Nguyen [42] to process PET nanocomposites holds promise in improving exfoliation levels while taking advantage of the benefits of melt compounding. Therefore, the primary objective is:

\subsubsection{To evaluate the efficacy of the scCO2 technique in producing PET layered silicate nanocomposites with greater levels of exfoliation and improved mechanical properties.}

In addition to achieving an exfoliated morphology in a PET nanocomposite, it is desirable to limit the degradation of PET matrix due to the presence of silicate during melt mixing. Tightly bound water present on the surface of silicate sheets causes additional matrix degradation beyond that experienced while processing neat polymer material $[53,70]$. Polymer matrix degradation has a negative effect on composite 
properties and necessitates a solid state polymerization processing step in order to achieve high molecular weight composites. One way in which degradation could be limited is to remove water molecules that are bound tightly to the surface of silicate sheets through hydrogen bonding. The removal of silicate bound water through conventional drying methods however, requires temperatures in excess of the degradation temperature of many of the commonly used alkyl ammonium surface modifications [44]. Another way to remove bound water from silicate surfaces might be to displace the water molecules using small, polar organic molecules [11]. At supercritical conditions it is known that carbon dioxide acts as a highly volatile organic solvent [71]. The saturation of layered silicates in $\mathrm{scCO} 2$ prior to melt mixing with a PET matrix may decrease the amount of water present on silicate surfaces leading to less degradation. The second objective of this research is:

2.8.2 To investigate the effect that the scCO2 processing method has on the degradation behavior of PET/layered silicate nanocomposites. Conclusions will be based on direct comparisons between the degradation behavior of melt compounded PET nanocomposites and scCO2 processed PET nanocomposites. 


\subsection{References}

[1] G.W. Brindley, G. Brown, Crystal Structures of Clay Minerals and Their X-ray Identification, Mineralogical Society, London, 1980.

[2] Y. Kojima, A. Usuki, M. Kawasumi, A. Okada, Y. Fukushima, T. Kurauchi, O. Kamigaito, J. Mater. Res. 8 (1993) 1185-1189.

[3] J. Lusis, R.T. Woodhams, M. Xanthos, Polym. Eng. Sci. 13 (1973) 139-145.

[4] S.S. Ray, M. Okamoto, Prog. Polym. Sci. 28 (2003) 1539-1641.

[5] H. Shi, T. Lan, T.J. Pinnavaia, Chem. Mater. 8 (1996) 1584-1587.

[6] P.B. Messersmith, E.P. Giannelis, J. Polym. Sci., Part A: Polym. Chem. 33 (1995) 1047.

[7] A. Usuki, Y. Kojima, M. Kawasumi, A. Okada, Y. Fukushima, T. Kurauchi, O. Kamigaito, J. Mater. Res. 8 (1993) 1179-1184.

[8] Southern Clay Products, Technical Dheets, http://www.nanoclay.com/product_bulletins.asp, 2006.

[9] R.A. Vaia, H. Ishii, E.P. Giannelis, Chem. Mater. 5 (1993) 1694-1696.

[10] R.A. Vaia, K.D. Jandt, E.J. Kramer, E.P. Giannelis, Macromolecules 28 (1995) 80808085.

[11] M. Zanetti, S. Lomakin, G. Camino, Macromol. Mater. Eng. 279 (2000) 1-9.

[12] N. Sheng, M.C. Boyce, D.M. Parks, G.C. Rutledge, J.I. Abes, R.E. Cohen, Polymer 45 (2004) 487-506.

[13] W.J. Boo, L. Sun, J. Liu, E. Moghbelli, A. Clearfield, H.-J. Sue, H. Pham, N. Verghese, J. Polym. Sci., Part B: Polym. Phys. 45 (2007) 1459-1469.

[14] K. Hbaieb, Q.X. Wang, Y.H.J. Chia, B. Cotterell, Polym. J. 48 (2007) 901-909.

[15] D. Wu, C. Zhou, W. Yu, X. Fan, J. Polym. Sci., Part B: Polym. Phys. 43 (2005) 28072818. 
[16] Y. Imai, S. Nishimura, E. Abe, H. Tateyama, A. Abiko, A. Yamaguchi, T. Aoyama, H. Taguchi, Chem. Mater. 14 (2002) 477-479.

[17] T. Lan, T.J. Pinnavaia, Chem. Mater. 6 (1994) 2216-2219.

[18] R. Krishnamoorti, J. Ren, A.S. Silva, J. Chem. Phys. 114 (2001) 4968-4973.

[19] J.W. Cho, D.R. Paul, Polym. J. 42 (2001) 1083-1094.

[20] H.R. Dennis, D.L. Hunter, D. Chang, S. Kim, J.L. White, J.W. Cho, D.R. Paul, Polym. J. $42(2001)$ 9513-9522.

[21] T.D. Fornes, P.J. Yoon, H. Keskkula, D.R. Paul, Polym. J. 42 (2001) 9929-9940.

[22] P. Peltola, E. Valipakka, J. Vuorinen, S. Syrjala, K. Hanhi, Polym. Eng. Sci. (2006) 9951000.

[23] M. Modesti, A. Lorenzetti, D. Bon, S. Besco, Polym. J. 46 (2005) 10237-10245.

[24] Y. Wang, J. Gao, Y. Ma, U.S. Agarwal, Composites: Part B 37 (2006) 399-407.

[25] D. Campbell, R.A. Pethrick, J.R. White, Polymer Characterization: Physical Techniques, Stanley Thornes Ltd, Cheltenham, UK, 2000.

[26] V. Singh, T. Singh, A. Chandra, S.K. Bandyopadhyay, P. Sen, K. Witte, A. Srivastava, Nucl. Instrum. Methods Phys. Res., Sect. B 244 (2006) 243-247.

[27] G. Galgali, S. Agarwal, A. Lele, Polym. J. 45 (2004) 6059-6069.

[28] A. Guinier, X-ray Diffraction in Crystals, Imperfect Crystals and Amorphous Bodies, Dover, New York, 1994.

[29] D.M. Moore, J. R. C. Reynolds, X-ray Diffraction and the Identification and Analysis of Clay Minerals, Second ed., Oxford University Press, New York, 1997.

[30] R. Krishnamoorti, R.A. Vaia, E.P. Giannelis, Chem. Mater. 8 (1996) 1728-1734.

[31] Y.T. Lim, O.O. Park, Rheol. Acta 40 (2001) 220-229.

[32] J. Li, C. Zhou, G. Wang, D. Zhao, J. Appl. Polym. Sci. 89 (2003) 3609-3617. 
[33] W. Letwimolnun, B. Vergnes, G. Ausias, P.J. Carreau, J. Non-Newtonian Fluid Mech. 141 (2007) 167-179.

[34] K.P. Pramoda, T. Liu, Z. Liu, C. He, H.-J. Sue, Polym. Degrad. Stab. 81 (2003) 47-56.

[35] R.A. Vaia, G. Price, P.N. Ruth, H.T. Nguyen, J. Lichtenhan, Appl. Clay Sci. 15 (1999) $67-92$.

[36] J.W. Gilman, Appl. Clay Sci. 15 (1999) 31-49.

[37] Y. Ke, C. Long, Z. Qi, J. Appl. Polym. Sci. 71 (1999) 1139-1146.

[38] S.S. Ray, K. Okamoto, M. Okamoto, Macromolecules 36 (2003) 2355-2367.

[39] K. Sall, Eur. Plas. News (2002).

[40] J.C. Halpin, J.L. Kardos, Polym. Eng. Sci. 16 (1976) 344-352.

[41] X.L. Ji, J.K. Jing, W. Jiang, B.Z. Jiang, Polym. Eng. Sci. 42 (2002) 983-993.

[42] Q.T. Nguyen, Process for Improving the Exfoliation and Dispersion of Nanoclay Particles into Polymer Matrices Using Supercritical Carbon Dioxide, Chemical Engineering, Virginia Tech, Blacksburg, 2007, p. 195.

[43] D. Chu, Q. Nguyen, D.G. Baird, Polym. Compos. 28 (2007) 499-511.

[44] O. Monticelli, Z. Musina, A. Frache, F. Bellucci, G. Camino, S. Russo, Polym. Degrad. Stab. 92 (2007) 370-378.

[45] F.J. Medellin-Rodriquez, C. Burger, B.S. Hsiao, B. Chu, R.A. Vaia, S. Phillips, Polym. J. 42 (2001) 9015-9023.

[46] K. Masenilli-Varlot, E. Reynaud, G. Vigier, J. Varlet, J. Polym. Sci., Part B: Polym. Phys. 40 (2002) 272-283.

[47] Z. Liu, D. Yan, Polymer Engineering and Science 44 (2004) 861-867.

[48] X. Liu, Q. Wu, Eur. Polym. J. 38 (2002) 1383-1389.

[49] X. Liu, Q. Wu, Polym. J. 43 (2002) 1933-1936. 
[50] T. Liu, W.C. Tjiu, C. He, S.S. Na, T.-S. Chung, Polymer International 53 (2004) 392399.

[51] T. Liu, K.P. Lim, W.C. Tjiu, K.P. Pramoda, Z. Chen, Polym. J. 44 (2003) 3529-3535.

[52] D.M. Lincoln, R.A. Vaia, Z.G. Wang, B.S. Hsiao, Polym. J. 42 (2001) 1621-1631.

[53] R.D. Davis, J.W. Gilman, D.L. Vanderhart, Polym. Degrad. Stab. 79 (2003) 111-121.

[54] K. Wang, S. Liang, R. Du, Q. Zhang, Q. Fu, Polym. J. 45 (2004) 7953-7960.

[55] A. Usuki, M. Kato, A. Okada, T. Kurauchi, Appl. Polym. Sci. 63 (1997).

[56] M.J. Solomon, A.S. Almusallam, K.F. Seefeldt, A. Somwangthanaroj, P. Varadan, Macromolecules 34 (2001) 1864-1872.

[57] P.H. Nam, P. Maiti, M. Okamoto, T. Kotaka, N. Hasegawa, A. Usuki, Polym. J. 42 (2001) 9633-9640.

[58] D. Marchant, K. Jayaraman, ANTEC 61 (2003) 2200-2204.

[59] D. Marchant, K. Jayaraman, Ind. Eng. Chem. Res. 41 (2002) 6402-6408.

[60] A. Lele, M. Mackley, G. Galgali, C. Ramesh, J. Rheol. 46 (2002) 1091-1110.

[61] M. Kato, A. Usuki, A. Okada, J. Appl. Polym. Sci. 66 (1997) 1781-1785.

[62] J.-T. Xu, Q. Wang, Z.-Q. Fan, Eur. Polym. J. 41 (2005) 3011-3017.

[63] A. Sanchez-Solis, I. Romero-Ibarra, M.R. Estrada, F. Calderas, O. Manero, Polym. Eng. Sci. 44 (2004) 1094-1102.

[64] K. Chrissopoulou, I. Altintzi, S.H. Anastasiadis, E.P. Giannelis, M. Pitsikalis, N. Hadjichristidis, N. Theophilou, Polym. J. 46 (2005) 12440-12451.

[65] X. Hu, W. Zhang, M. Si, M. Gelfer, B. Hsiao, M. Rafailovich, J. Sokolov, V. Zaitsev, S. Schwarz, Macromolecules 36 (2003) 823-829.

[66] X. Huang, S. Lewis, W.J. Brittain, Macromolecules 33 (2000) 2000-2004. 
[67] R.K. Gupta, V. Pasanovic-Zujo, S.N. Bhattacharya, J. Non-Newtonian Fluid Mech. 128 (2005) 116-125.

[68] J. Ren, R. Krishnamoorti, Macromolecules 36 (2003) 4443-4451.

[69] C.H. Davis, L.J. Mathias, J.W. Gilman, D.A. Schiraldi, J.R. Shields, P. Trulove, T.E. Sutto, H.C. Delong, J. Polym. Sci., Part B: Polym. Phys. 40 (2002) 2661-2666.

[70] T.J. Pinnavaia, G.W. Beall (Eds.), Polymer-Clay Nanocomposites, John Wiley \& Sons Ltd., Chichester, 2000.

[71] D.L. Tomasko, H. Li, D. Liu, X. Han, M.J. Wingert, L.J. Lee, K.W. Koelling, Ind. Eng. Chem. Res. 42 (2003) 6431-6456.

[72] C.W. Manke, E. Gulari, D.F. Mielewski, E.C. Lee, System and Method of Delaminating a Layered Silicate Material by Supercritical Fluid Treatment, in: U.S.P. Office (Ed.), Ford Global Technologies, Inc.; Wayne State University, United States, 2002.

[73] A.S. Zerda, T.C. Caskey, A.J. Lesser, Macromolecules 36 (2003) 1603-1608.

[74] D.F. Mielewski, C.W. Manke, E. Gulari, E.C. Lee, System and Method of Preparing a Reinforced Polymer by Supercritical Fluid Treatment, in: U.S.P. Office (Ed.), Ford Global Technologies, Inc., Wayme State Unicersity, United States, 2004. 


\title{
3.0 Improving the Exfoliation of Layered Silicate in a Poly(ethylene terephthalate) Matrix Using Supercritical Carbon Dioxide
}

\author{
Joseph Samaniuk, David Litchfield, Donald Baird, \\ Virginia Polytechnic Institute and State University, Blacksburg, VA
}

\subsection{Abstract}

A technique for improving the exfoliation of organically modified layered silicate (OMLS) in a PET matrix using super critical carbon dioxide ( $\mathrm{scCO} 2)$ is compared to traditional direct melt blending. The process relies on the rapid expansion of a scCO2/OMLS mixture directly into the second stage of a single screw extruder where the clay and scCO2 mixture is subsequently melt blended with the PET matrix. The simple, environmentally benign process results in a more highly exfoliated system than traditional direct melt compounding. X-ray diffraction analysis is used to reveal improved clay exfoliation and the resulting mechanical properties are examined. Rheology is used as a tool to draw conclusions about the effect that $\mathrm{scCO} 2$ has on reducing PET matrix degradation during processing.

\subsection{Introduction}

Polymer/layered silicate nanocomposites (PLSN) have been studied extensively for the potential to lead to outstanding property improvements that can be achieved at relatively low silicate loadings as compared to other types of reinforcing materials such as glass. In 1990 a Toyota research group first produced and characterized a polymer/layered silicate nanocomposite using Nylon-6. The group found a $68 \%$ increase in tensile modulus, a $224 \%$ increase in flexural modulus and an $87^{\circ} \mathrm{C}$ increase in the heat distortion temperature over the neat polymer material [1]. Since the first findings of the 
Toyota group there has been research to show improvements in Young's modulus [2, 3], barrier properties $[4,5]$, heat distortion temperature [1], thermal degradation temperature [6] and decreased flammability $[7,8]$ over the pure polymer matrix.

Multiple works have shown that physical property improvements are highly dependent on the silicate morphology of the final nanocomposite $[9,10]$. The two most common morphologies that are encountered are intercalated and exfoliated. For either morphology to occur the polymer and the nanosilicate must be fully compatible. Layered silicates in their natural state are highly hydrophilic, whereas most engineering polymers are hydrophobic. To allow for mixing and to improve the compatibility between nanosilicate and polymer, an ion exchange reaction must be carried out on the layered silicate to exchange the natural interlayer cations with ions such as alkylammonium cations $[11,12]$. Increased compatibility between silicate and polymer promotes mixing, intercalation of polymer chains between silicate sheets and layer exfoliation.

Research has found that optimizing the level of exfoliation in a PLSN leads to superior material properties [13]. Recently, much effort has been devoted to understanding the effects that processing conditions have on the extent of exfoliation in a PLSN system $[10,14]$. Although various synthesis methods for producing PLSNs have been implemented in research applications, none of the current techniques are sufficient for both large scale production and morphological control of the final nanocomposite. Due primarily to the need for suitable solvents, achieving desired morphologies of clay within PLSNs using in-situ polymerization or solution mixing is impractical for large scale applications. Processing methods that combine high temperature and high shear such as direct melt compounding have greater promise for application on a large scale but 
have found limited success in achieving complete silicate exfoliation in certain polymer matrices $[14,15]$.

Poly(ethylene terephthalate) (PET) is a highly important commercial polymer that stands to gain from improved barrier and mechanical properties that result from the addition of layered silicate to form a nanocomposite. Previous studies have focused heavily on the crystallization properties of PET nanocomposites but rheological studies are very rare. A number of studies have shown that the presence of layered silicate in PET increases the crystallization rate, thermal degradation and tensile strength of the composite material $[16,17]$. Although property enhancements have been achieved, challenges to implementing PET as a polymer matrix in PLSNs have become apparent. A common difficulty in producing PET nanocomposites has been achieving a fully exfoliated silicate state [16]. Imai et al. [18] generated a novel reactive compatibilizer specifically for PET in an attempt to obtain exfoliation of silicate in a PET matrix but obtained only intercalated material. Another large hurdle to generating PLSNs from PET is degradation during processing. Melt processing a PET PLSN is the most attractive industrial synthesis option, but it results in dramatic decreases in molecular weight due to degradation [19]. A melt processing technique that results in a highly exfoliated silicate structure while minimizing PET matrix degradation is needed in order to take full advantage of PET PLSNs.

In an effort to achieve highly exfoliated states of silicate in PLSNs there have been a number of unique applications of scCO2 in traditional processing methods. The reason $\mathrm{scCO} 2$ has become popular in these applications is due to its environmentally friendly nature, low toxicity, low flammability and low cost as compared to other 
supercritical fluids [20]. Zerda et al. [21] used a modified hopper in which polymer and nanosilicate were mixed in $\mathrm{scCO} 2$ for a period of time prior to being melt processed. Exposure to $\mathrm{scCO} 2$ was found to increase the clay basal spacing and allow polymer chains to more easily intercalate the silicate galleries. Mielewski et al. [22] proposed a method of injecting $\mathrm{scCO} 2$ into a molten polymer stream during extrusion in order to cause silicate exfoliation upon foaming at the die exit. Nanocomposite material was produced in this fashion but no TEM or WAXD evidence of improved exfoliation was presented. Finally, Manke et al. [23] saturated layered silicate in $\mathrm{scCO} 2$ for a period of time before releasing it into a separate chamber at a lower pressure. The rapid depressurization was claimed to be responsible for exfoliating individual silicate sheets as seen in WAXD curves. Although exfoliation of clay was observed from TEM analysis, no composite material was produced and the authors make no claim as to the way in which the polymer and the clay are to be combined.

The purpose of the current work is to describe a technique to improve the level of exfoliation achievable in a melt compounding process while implementing industrially compatible and environmentally friendly technology. $\mathrm{scCO} 2$ is used as a processing aid to swell nanosilicate and force layer delamination upon rapid expansion of a clay/scCO2 mixture. The force of the rapid expansion is utilized to directly inject the clay/scCO2 mixture into neat polymer material in a single step. Evidence that the presence of $\mathrm{scCO} 2$ decreases the amount of bound water between silicate galleries is presented. The decrease in bound water among layered silicate is thought to result in less PET molecular weight degradation during both processing and rheological analysis. Improvements in exfoliation through $\mathrm{scCO} 2$ treatment are also achieved. The purpose of this article is to evaluate the 
efficacy of the $\mathrm{scCO} 2$ process in producing PET/layered silicate nanocomposites with greater levels of exfoliation and improved mechanical properties.

\subsection{Experimental}

\subsubsection{Materials}

PET $\left(\mathrm{M}_{\mathrm{W}}=66,000 \mathrm{~g} / \mathrm{mol}, \mathrm{IV}=0.96 \mathrm{dl} / \mathrm{g}\right)$ manufactured by Performance Fibers and in the form of pellets was used as the polymer matrix. The nanosilicates used were an alkyl-modified clay (Cloisite 20A) and hydroxyl-modified clay (Cloisite 30B) that were obtained from Southern Clay Products Inc. (Gonzalez, TX). The alkyl modification consisted of dimethyl, dehydrogenated tallow, quaternary ammonium ions. The hydroxyl modified clay contained methyl, tallow, bis-2-hydroxyethyl, quaternary ammonium ions.

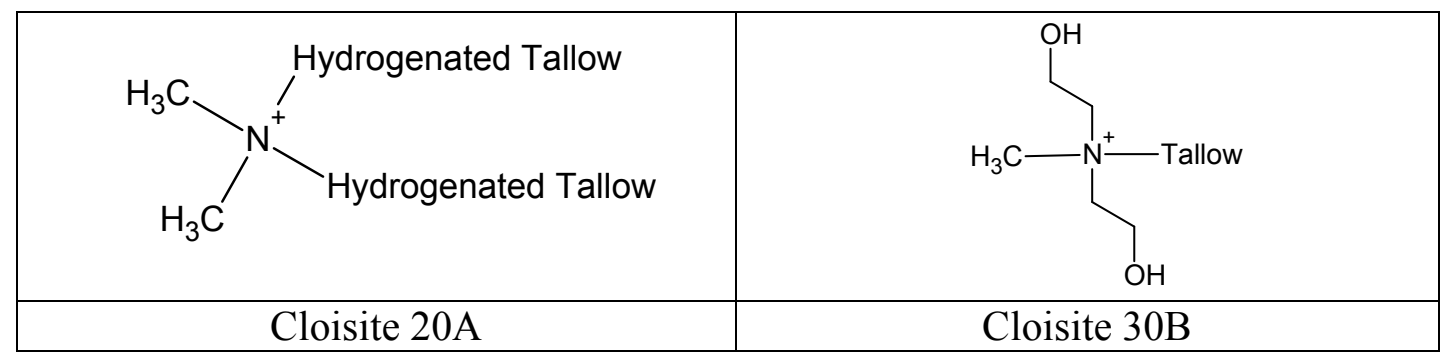

\subsubsection{Equipment}

A two stage, single screw Killion extruder (25.4 mm diameter screw, $\mathrm{L} / \mathrm{D}=30: 1)$ was used during sample preparation. An increase in channel depth in the screw used at the second stage allowed the $\mathrm{scCO} 2$ and clay to be injected more easily. The metering section prior to this increase in channel depth was a high pressure region that acted to increase shear on the polymer melt. A modified hopper held a nitrogen atmosphere during PET extrusion to prevent moisture pickup by the pellets. The chamber used to contain clay/scCO2 was a modified pressure chamber obtained from Parr Instrument Company. The pressure chamber was situated on the feed port at the second stage of the 
extruder where its contents could be injected into the barrel region and into the modified hopper. The chamber consisted of one inlet to allow for $\mathrm{scCO} 2$ filling and one outlet sealed by a ball valve. $\mathrm{scCO} 2$ was generated using a supercritical fluids system obtained from Trexel Inc. (Woburn, MA). A schematic of the scCO2 equipment is shown in Fig. 3.1. Dogbones used for mechanical testing were produced using an Arburg Allrounder injection molder (22 mm diameter barrel, $\mathrm{L} / \mathrm{D}=24)$.

\subsubsection{PET-Nanocomposite Preparation}

Nanocomposites were prepared using the $\mathrm{scCO} 2$ method as well as with traditional direct melt compounding using the same single screw extruder for comparison. Samples containing 1, 3 and $5 \mathrm{wt} \%$ nanosilicate were produced using both Cloisite 20A and Cloisite 30B in both synthesis methods. Actual clay loadings were calculated from burn off testing done at $600^{\circ} \mathrm{C}$ in an ash oven for over 3 hours. All clay loading values calculated from burn off were found by averaging the results of three separate burn offs. Clay loadings are reported as weight percents that include the weight of the surface modifications. Values for the volume fraction of silicate present in the PLSNs were calculated using the method outlined in Chu et al. [24].

Direct melt compounded composite materials were prepared by mixing PET and clay mechanically in a kitchen aid mixer. Clay weakly adhered to the surface of the PET pellets and mixing continued for at least 5 min until the mixture looked thoroughly homogeneous. The PET/clay mixture was then dried in a vacuum oven for $24 \mathrm{hr}$ at $120^{\circ} \mathrm{C}$. The vacuum oven was filled with nitrogen prior to removing the mixture for processing. During processing the material was fed to the extruder under a nitrogen atmosphere. The melt temperature of the extruder was maintained at $270^{\circ} \mathrm{C}$ with zone 
temperatures increasing from $230^{\circ} \mathrm{C}$ in the melting zone to $270^{\circ} \mathrm{C}$ at the die. The low temperatures used in the melt zone were important to maximize the shear stress transferred to the layered silicates as well as to minimize PET matrix degradation. The extrudate was run through a water-bath and pelletized.

To produce composite using the scCO2 method, clay was first dried by itself for $24 \mathrm{hr}$ in a vacuum oven at $120^{\circ} \mathrm{C}$. The dried clay was then mixed with $\mathrm{scCO} 2$ at 20.7 $\mathrm{MPa}(3000 \mathrm{psi})$ and $80^{\circ} \mathrm{C}$ for an additional $12 \mathrm{hr}$ in a pressure chamber modified with the capability to inject its contents into the second stage of the single screw extruder. PET pellets were dried for $24 \mathrm{hr}$ in a vacuum oven at $120^{\circ} \mathrm{C}$. The oven was filled with nitrogen prior to removing the PET pellets and loading then into a nitrogen fed hopper that was closed off to the atmosphere. Prior to turning on the extruder screw, the clay/scCO2 mixture was rapidly released into the second stage of the extruder. The die exit was blocked with solid polymer material forcing the expanding flow of $\mathrm{CO} 2$ and silicate into the barrel region as well as the modified hopper. PET and clay were mixed in this way and were found to result in a consistent concentration of clay throughout the subsequent extrusion process. The material was then extruded (Melt temp: $270^{\circ} \mathrm{C}$, RPM: 20 ), run through a water-bath and pelletized.

Samples produced with both the scCO2 process and traditional melt compounding had actual silicate weight loadings that differed slightly from the desired values. Table 3.1 shows the actual silicate loadings for every sample produced as well as the abbreviations used to refer to individual samples in the rest of the paper. During handling and processing of the melt compounded material small amounts of clay adhered to the 
containers and the walls of the hopper. In attempting to compensate for this loss some of the samples received slightly more clay than expected while other received less.

\subsubsection{Nanocomposite Characterization}

The Young's modulus of the PLSNs was the primary property of interest and was obtained using an Instron model 4204 testing machine with a crosshead speed of 1.27 $\mathrm{mm} / \mathrm{min}$. An extensometer was used to accurately measure Young's modulus and yield strength. Specimens were prepared by injection molding dogbones. The dogbones had a gauge length of $12.7 \mathrm{~mm}$, a thickness of $1.59 \mathrm{~mm}$ and a width of $3.18 \mathrm{~mm}$. At least 6 specimens were tested for each sample to obtain an accurate estimate of the mechanical properties.

The degree of exfoliation, or clay morphology was determined using wide angle X-ray diffraction (WAXD) on a Scintag XDS 2000 diffractometer (wavelength of 1.542 $\AA$ ). The data was obtained in the range of scattering angle, $2 \Theta$ from $1.5^{\circ}$ to $10^{\circ}$ at a scanning rate of $1.20^{\circ}$ per minute. All WAXD data was obtained from samples ground into a powder form using a rotating blade micro grinder. All of the samples were ground into a power after the extrusion process but prior to injection molding. Particle size was controlled by using an ultrafine metal mesh for separation purposes.

Rheological studies were performed on a Rheometrics Mechanical Spectrometer Model 800 (RMS-800). Tests were run under a nitrogen atmosphere to minimize PET matrix degradation due to exposure to atmospheric moisture. Samples were prepared by taking PET pellets prior to injection molding and pressing them between a cone and plate setup above their melt temperature. This preparation method eliminated the need to compression mold disks which would have further degraded the polymer matrix. 
Dynamic frequency sweep tests were performed at $275^{\circ} \mathrm{C}$ in a cone and plate rheometer to obtain storage moduli, loss moduli and complex viscosity. The plate used had a diameter of $25 \mathrm{~mm}$ and a cone angle of $0.1 \mathrm{rad}$.

\subsection{Results and Discussion}

WAXD results are used here to make conclusions about the clay morphology present in the PLSN samples. Mechanical properties are then presented in order to make connections between property improvements and observed levels of silicate intercalation and exfoliation as seen in WAXD. Comparisons to theoretical values of Young's modulus are made in an attempt to clarify the roles that exfoliation and silicate orientation have on experimental values of modulus. Finally, rheology is used to evaluate the level of degradation that occurs in PLSNs produced using the two different processing methods.

\subsubsection{X-ray Diffraction Analysis}

$\mathrm{X}$-ray diffraction was used as the primary method for determining the clay morphology of the nanocomposites that were produced in this study. All WAXD data showing a defined diffraction peak was analyzed using the Bragg equation to evaluate the average basal spacing between intercalated silicate sheets as follows:

$$
2 d \operatorname{Sin} \Theta=n \lambda
$$

where $\mathrm{d}$ represents the average basal spacing between silicate sheets, $\Theta$ represents the diffraction angle, $\mathrm{n}$ is the wave number and $\lambda$ is the $\mathrm{X}$-ray wavelength. Additionally, well defined peaks in the WAXD data were analyzed using the Scherer equation to obtain the average size of the tactoids present in the system as follows: 


$$
d^{\prime}=\frac{k \lambda}{L \operatorname{Cos} \Theta}
$$

where d' represents the full width of a diffraction peak at half maximum (FWHM), $\mathrm{k}$ is a proportionality constant equal to approximately 0.93 [25-27] and $\mathrm{L}$ is the average tactoid thickness. Repeat WAXD measurements on the same sample prepared multiple times reveal that basal spacings and tactoid sizes calculated from $2 \Theta$ values are accurate to within $2 \%$. Although transmission electron microscopy (TEM) is a valuable tool in confirming the presence of complete exfoliation, it was in this case deemed unnecessary as there are no claims of fully exfoliated morphologies.

X-ray data obtained on all PET samples produced with Cloisite 20A show a number of interesting results. Fig. 3.2 contains WAXD diffraction curves for all of the melt compounded PLSNs produced using Cloisite 20A. Fig. 3.3 contains the WAXD results from PLSNs produced using the scCO2 method that contain Cloisite 20A. In both figures there are diffraction peaks that indicate the presence of an ordered, layered system. The peaks for the PLSN materials in both figures are shifted down from the location of the neat PET by the same amount. This result indicates that an intercalated morphology is present in both systems and that the basal spacing increases due to the intercalation of PET chains between silicate galleries is the same for both the $\mathrm{scCO} 2$ processed and melt compounded materials. A visual comparison of the intensity of the peaks in the two figures reveals a difference in exfoliation levels between the melt compounded samples and the $\mathrm{scCO} 2$ processed samples. While keeping clay concentration constant, the intensity of a WAXD peak is proportional to the fraction of silicate that is intercalated in a sample [26]. The decrease in peak intensity seen in the 
$\mathrm{scCO} 2$ processed materials as compared to the melt compounded materials is due to the decreased presence of intercalated silicate. This decrease in intercalated silicate is due to an increase in exfoliated silicate sheets. Additional evidence for improved exfoliation can be seen in peak broadening. The breadth of a diffraction peak at half of its maximum value increases as the average thickness of the particles being examined decreases $[25$, 26, 28]. The increase in the FWHM of the peaks in Fig. 3.3 means that there is a decrease in the average tactoid size in the $\mathrm{scCO} 2$ produced samples. Both processing methods contain intercalated material with the same basal spacing as indicated by their diffraction peak location; therefore, the decrease in particle size must be attributed to the presence of fewer silicate layers per tactoid. This result means that the $\mathrm{scCO} 2$ process must be facilitating the exfoliation of the outermost layers of the silicate tactoids. This layer delamination could be accomplished either by physically forcing the outer layers away from the tactoid during the rapid expansion of $\mathrm{scCO}$, or by causing disorder along the edges of the outermost silicate layers thus facilitating intercalation and subsequent exfoliation.

Quantitative information can be obtained from WAXD curves using the Bragg relationship. Table 3.2 contains the quantitative data obtained from Fig. 3.2 and Fig. 3.3 using the Bragg equation. The basal spacing values calculated show an increase from that of the pure Cloisite 20A for all of the samples produced. Differences in gallery spacing between the samples produced from the two different processing methods fall within the $2 \%$ error expected from WAXD diffraction. Asymmetry in WAXD peak structure increases the error in determining basal spacing values and may have influenced the 
value of the 1-20A-scCO2 PLSN [26]. These results indicate that average basal spacing in the tactoids present is unaffected by the $\mathrm{scCO} 2$ processing method.

Additional quantitative data can be obtained from the Scherrer relationship. Table 3.3 contains quantitative data obtained from Fig. 3.2 and Fig. 3.3 using the Scherer equation. The results in Table 3.3 show a large difference in the average tactoid size between the scCO2 processed PLSNs containing Cloisite 20A and the melt compounded PLSNs containing Cloisite 20A. The tactoids present in the scCO2 samples are 15 to 35 $\AA$ smaller than those in the melt compounded samples. Using the average tactoid size as well as the average basal spacing for each sample the average number of silicate layers per tactoid can be calculated [26]. The result as seen in Table 3.3 is that the $\mathrm{scCO} 2$ processed PLSNs show a considerable decrease in the average number of silicate layers present in each tactoid. This finding confirms that the $\mathrm{scCO} 2$ process is facilitating the peeling of outer silicate layers from individual tactoids. Similar results can be seen in Table 3.5 for the PLSNs containing Cloisite 30B. The scCO2 processed samples show a decrease in both the average tactoid size and the average number of silicate sheets present per tactoid over the melt compounded samples.

The increase in silicate delamination and exfoliation that occurs due to the $\mathrm{scCO} 2$ technique can also be seen in Fig. 3.3 in the increased intensity of interference at low values of $2 \Theta$. Interference due to the presence of well dispersed, highly exfoliated layered silicates is often found as an increase in WAXD curve intensity that occurs at values of $2 \Theta$ below $2^{\circ}$. All of the scCO2 processed materials exhibit this behavior between $2 \Theta$ values of $1.5^{\circ}$ and $2^{\circ}$ whereas the melt compounded materials exhibit none. 
In addition to the presence of intensity increases at low values of $2 \Theta$ and primary peak broadening, the presence of secondary peak broadening is a sign of disorder in the nanocomposite layer structure. Higher order peaks in a WAXD curve are more susceptible to broadening due to layer structure faults [25]. Comparing the WAXD curves between Fig. 3.2 and Fig. 3.3 it is apparent that the secondary peaks of the $\mathrm{scCO} 2$ processed PLSNs have broadened into the baseline curve. This is likely the result of layer disorder caused by nucleated $\mathrm{CO} 2$ bubbles expanding between silicate sheets during the rapid clay/scCO2 release. The increase in layer disorder as indicated by secondary peak broadening means it is likely that the $\mathrm{scCO} 2$ process causes considerable disorder among the outermost silicate layers in each tactoid. This layer disorder would facilitate PET chain intercalation, subsequent exfoliation and explain the occurrence of smaller average tactoids in the $\mathrm{scCO} 2$ processed PLSNs. Using a twin screw extruder instead of a single screw would introduce more shear during processing that might be able to take greater advantage of the layer disorder. Although it has been shown that too much shear during processing has a negative effect on PLSN properties [29], the low shear caused by the single screw extruder implemented here may not be enough to take full advantage of the $\mathrm{scCO} 2$ treatment.

Evaluation of the WAXD data using the Scherrer equation may also reveal information about a relationship between tactoid size and the ability of the silicate sheets within the tactoid to become dispersed under the influence of shear. In Table 3.3 it is clear that the average number of silicate layers per tactoid of the pure Cloisite $20 \mathrm{~A}$ increases after it is processed into a PLSN using a single screw extruder. The apparent increase in the average number of silicate layers per tactoid only makes sense if tactoids 
comprised of very few silicate layers are easily exfoliated during incorporation into the polymer matrix while tactoids with many silicate layers are much more difficult to exfoliate. The delamination of tactoids with fewer layers would skew the average number of silicate layers to a higher value and give the result that is seen in Table 3.3. Although no conclusions have been made about the relationship between tactoid thickness and ease of exfoliation in past literature, similar WAXD patterns where the FWHM of pure silicate peaks decreases after compounding of a PLSN in a single screw extruder have been recorded [30].

WAXD curves produced from the PLSNs containing Cloisite 30B show that there is a considerably different morphological result between PLSNs produced with Cloisite 30B and those produced with Cloisite 20A. Fig. 3.4 shows the WAXD results of PET/Cloisite 30B samples produced from the $\mathrm{scCO} 2$ process and from melt compounding. The most interesting characteristic of all of the samples produced is the small reflection peak located at a higher angle of $2 \Theta$ than the pure clay peak. This is almost certainly due to the degradation of clay surface modification during processing. Monticelli et al.[25] found that after treating Cloisite $30 \mathrm{~B}$ at $250^{\circ} \mathrm{C}$ for $4 \mathrm{hr}$, the surface modification degraded until the basal spacing fell from $18.5 \AA\left(2 \Theta \sim 4.8^{\circ}\right)$ to $12.9 \AA(2 \Theta$ $\sim 6.85^{\circ}$ ) [31]. The peaks seen in Fig. 3.4 correspond to basal spacing values between 14.7 $\AA$ and $13.6 \AA$. Table 3.4 contains the basal spacing values calculated using the Bragg equation with Fig. 3.4. These spacing values indicate that surface modification degradation is occurring during the short time the material is exposed to temperatures in excess of $250^{\circ} \mathrm{C}$ in the extrusion process. The lack of clay surface degradation seen in the Cloisite 20A samples is due to the greater stability of the alkyl modification. Cloisite 30B 
contains hydroxyl groups that are far less stable at the processing temperatures used than the alkyl groups of Cloisite 20A. The diffraction patterns in Fig. 3.4 are indicative of a mixed system of well exfoliated nanosilicate with a small number of intercalated tactoids. As a result of some clay surfactant degradation the PET chains were unable to form sufficient numbers of clay/polymer interactions. Intercalation has been shown to be an enthalpically driven process dependent on high levels of clay/polymer interaction to make it thermodynamically favorable [32]. The weak peaks at high values of $2 \Theta$ combined with a flat baseline at lower values of $2 \Theta$ indicate that despite some lack of intercalation, much of the clay was exfoliated during melt mixing. In addition to WAXD, a visual comparison between the $\mathrm{scCO} 2$ processed PLSNs containing Cloisite $30 \mathrm{~B}$ and the melt compounded PLSNs containing Cloisite 30B reveals that there is a much greater degree of dispersion and continuity in the $\mathrm{scCO} 2$ processed PLSNs. Melt compounded PLSNs with Cloisite 30B contained large agglomerates of clay that are easily visible. The poor mixing of Cloisite 30B with PET during traditional melt compounding as compared to Cloisite 20A during melt compounding is likely due to the much smaller initial basal spacing of Cloisite 30B compared to Cloisite 20A. The small initial basal spacing of Cloisite 30B requires a greater shear force than a single screw extruder can exert. Additionally, the smaller initial basal spacing of Cloisite 30B may account for the superior performance of the $\mathrm{scCO} 2$ method in producing a highly dispersed and exfoliated system. The reason for this is that a nucleating bubble of $\mathrm{CO} 2$ between two silicate sheets would be more effective at exfoliating or disordering layers that are closer together. 


\subsubsection{Mechanical Testing Analysis}

Next we investigate the tensile properties of PLSN materials in order to determine whether the increased exfoliation lead to any improvements of the material performance. Results of mechanical testing carried out on all PLSNs are shown in Table 3.6. Young's modulus values for PLSNs containing Cloisite 20A are plotted in Fig. 3.5 and reveal that there is little or no improvement in modulus for the $\mathrm{scCO} 2$ processed material. For the neat PET, the $1 \mathrm{wt} \%$ PLSNs and the $5 \mathrm{wt} \%$ PLSNs, there is overlap in the error bars indicating that there is no statistical difference between the modulus values of material produced by either process. At $3 \mathrm{wt} \%$ the melt compounded samples had a slightly higher modulus than the $\mathrm{scCO} 2$ samples which may be the result of a discrepancy in actual clay loading from the desired $3 \mathrm{wt} \%$. From Table 3.1 it can be seen that the $3-20 \mathrm{~A}-$ $\mathrm{MC}$ material has approximately $0.72 \mathrm{wt} \%$ more clay than the $3-20 \mathrm{~A}-\mathrm{scCO} 2$ material. It is well known that small quantities of layered silicate can have large impacts on material properties for some polymers such as nylon 6 [30]. Despite improved exfoliation in the $\mathrm{scCO} 2$ processed samples, there is no improvement in Young's modulus over the melt compounded material. This finding is likely due to two factors: poor compatibility between the alkyl modified Cloisite 20A and the PET matrix, and small variations in actual clay loading that exist between the PLSNs produced in the two processing methods. It is known that a strong attraction between nanosilicate and the polymer matrix is necessary to achieve improvements in mechanical properties [18]. Weak attractions between polymer and clay limit the stress transfer between the polymer and clay surface. Increasing the surface area of contact between polymer and clay by increasing clay exfoliation will have only a modest effect on material modulus when strong polymer/clay 
interactions are not present. The lack of modulus improvement in PLSNs containing Cloisite 20A may also be attributed to variations in actual clay content. The $\mathrm{scCO} 2$ processed PLSNs all have slightly lower concentrations of silicate than the melt compounded samples as seen in Table 3.1. This small difference is a product of the difficulty that exists in accurately controlling silicate concentration during the $\mathrm{scCO} 2$ process.

Mechanical testing carried out on all PLSNs containing Cloisite 30B revealed better results for improved Young's modulus between the two processing methods relative to those observed for the PLSNs with Cloisite 20A. Fig. 3.6 contains Young's modulus values for all PLSNs containing Cloisite 30B. At a clay loading of $3 \mathrm{wt} \%$ there is slightly over a $10 \%$ increase in modulus in the $\mathrm{scCO} 2$ PLSN over the melt compounded PLSN. This increase is attributed to improvements in dispersion and exfoliation in the 3-30B-scCO2 sample over the 3-30B-MC sample as seen in WAXD analysis. Stronger polymer/clay interactions due to improved compatibility of Cloisite 30B in PET over Cloisite 20A also facilitate modulus improvements. The 1 and $5 \mathrm{wt} \%$ samples in Fig. 3.6 show a similar trend as the $3 \mathrm{wt} \%$ PLSNs, but there is error bar overlap. The small amount of overlap may again be a product of deviations in actual clay content from the desired amount as both the 1-30B-scCO2 and 5-30B-scCO2 samples have slightly less silicate than the melt compounded samples.

Improvements in tensile strength and elongation at break are not affected by the $\mathrm{scCO} 2$ treatment but there are interesting differences between PLSNs containing different clay surface modifications. Both tensile strength and elongation at break are shown in Table 3.6. The results reveal that tensile strength increases with clay loading through 5 
$\mathrm{wt} \%$ clay in all of the Cloisite 20A PLSNs but appears to reach a plateau at $3 \mathrm{wt} \%$ clay in the Cloisite 30B PLSNs. In addition, the tensile strength values of the Cloisite 30B PLSNs tend to be greater and have lower experimental standard deviation. The high plateau that Cloisite 30B PLSNs reach at low clay concentration can be explained by better polymer/clay interaction in the Cloisite 30B PLSNs over the Cloisite 20A PLSNs. Elongation at break decreases with clay loading in all of the samples while the Cloisite 20A PLSNs show more elongation than Cloisite 30B PLSNs of equal silicate loading. The decrease in elongation seen for the Cloisite 30B samples over the Cloisite 20A samples is likely due to large differences in matrix molecular weight as seen in the rheological data to be presented.

\subsubsection{Comparison of Modulus Values with Composite Theory}

We next compare the measured modulus values with those predicted by means of composite theory in order to determine whether we are at least reaching the theoretically expected values. Deviations in experimental values from model predictions can be used to make conclusions about the nature of the material produced. Two models that are commonly applied to PLSNs are the Halpin-Tsai model [33] and the Ji et al. model [34]. Both models give estimates of the PLSN Young's modulus based on the modulus of the filler, the modulus of the polymer matrix and the filler volume fraction. Each model is based on different assumptions about silicate exfoliation as well as particle orientation.

The Halpin-Tsai model is often used because of its simplicity despite the existence of more accurate theoretical models. The equations are based on the assumption

that the layered silicate filler is completely exfoliated. It is also assumed that the silicate layers are fully aligned in the polymer matrix in the direction of applied force. 
Combining both of these assumptions means that the values calculated from the HalpinTsai equations are expected to be greater than the values obtained from any sample with partial exfoliation or incomplete alignment of silicate particles. The equations are given as:

$$
\begin{gathered}
E_{c}=E_{m}\left[\frac{1+\xi \eta \phi_{f}}{1-\eta \phi_{f}}\right] \\
\eta=\frac{\left[\frac{E_{f}}{E_{m}}-1\right]}{\left[\frac{E_{f}}{E_{m}}+\xi\right]} \\
\xi=2\left[\frac{1}{t}\right]
\end{gathered}
$$

where $E_{f}, E_{m}$ and $E_{c}$ are the filler modulus, matrix modulus and composite modulus, respectively. $\phi_{\mathrm{f}}$ is the filler volume fraction and $[1 / \mathrm{t}]$ is the aspect ratio of the filler particles taken to be approximately 100 . The filler modulus is taken to be $172 \mathrm{GPa}$ [35]. The theoretical modulus values calculated using the above equations are compared graphically with experimentally obtained values in Fig. 3.7. The theoretical values are much greater than the experimentally obtained values. The higher values predicted from Halpin-Tsai are based on the assumptions that all the filler present is in a fully exfoliated state and completely aligned in the direction of the tensile forces applied. WAXD curves show the assumption of complete exfoliation is not applicable in the PLSNs that were tested. In addition, a saturation point where alignment of clay particles is limited while under strong shear force has been shown to occur [36]. During injection molding the highest values for orientation have been recorded at roughly $30 \%$ [37]. Both the lack of 
particle alignment and the absence of complete exfoliation explain why experimentally obtained values of modulus are considerably lower than Halpin-Tsai model estimates.

The model developed by $\mathrm{Ji}$ et al. makes more realistic assumptions about the morphological state of a PLSN than the Halpin-Tsai equations. The first assumption is that incomplete exfoliation exists in the PLSN and that the extent of intercalation based on basal spacing increase has a measurable effect on the modulus of the PLSN. The second assumption is that the silicate particles are in a randomly oriented state. Both of these assumptions result in predicted modulus values that are much closer to actual experimental values than those predicted by the Halpin-Tsai equations. The governing equations in the Ji et al. model are as follows:

$$
\begin{gathered}
\frac{1}{E_{c}}=\frac{1-\alpha}{E_{m}}+\frac{\alpha-\beta}{(1-\alpha) E_{m}+\frac{\alpha(k-1) E_{m}}{l n k}}+\frac{\beta}{(1-\alpha) E_{m}+\frac{(\alpha-\beta)(k+1) E_{m}}{2}+E_{f} \beta} \\
\alpha=\sqrt{\left[2\left(\frac{\tau}{t_{c}}\right)+1\right] \phi_{f}}
\end{gathered}
$$

where $\tau$ is the thickness of the interlayer spacing (d-spacing) and $t_{c}$ is the thickness of a single montmorillonite sheet taken to be $1 \mathrm{~nm}$. $\beta$ is defined as the square root of $\phi$ and $\mathrm{k}$ is the ratio of $E_{f}$ to $E_{m}$. The results of calculating modulus values from the Ji et al. equations using WAXD data on the PLSNs produced in this study are shown in Fig. 3.8. The model predictions for both the Cloisite 20A and Cloisite 30B PLSNs are much closer to the experimental values than the predictions from Halpin-Tsai theory. The predictions for Cloisite 30B material produced using $\mathrm{scCO} 2$ fall within one standard deviation of the experimentally obtained values whereas the predictions for the Cloisite $30 \mathrm{~B}$ material produced with melt compounding are greater than the experimentally obtained values. 
The $\mathrm{Ji}$ et al. model makes no assumption as to the exact state of intercalation and exfoliation in a PLSN system which may explain this result. It is expected that while keeping all else the same, greater amounts of exfoliation lead to higher modulus values. Additionally, the d-spacing used in the model cannot account for the effects of the average tactoid size present in a PLSN. The Ji et al. model also neglects to take into account the aspect ratio of the filler particles. Aspect ratio is an important variable in the resulting mechanical properties of PLSNs $[35,38]$ and might have a considerable effect on the theoretical values of modulus.

\subsubsection{Rheological Analysis}

Rheological data is primarily used in this study as a tool for quantifying the amount of degradation that occurs in the PLSNs. Knowing that viscosity scales to the 3.4 power with molecular weight it is possible to obtain relative measures of PET matrix degradation using rheology. Although many attempts have been made in the past literature to obtain reliable relationships between PLSN rheology and morphology, only qualitative relationships based on comparisons between sets of rheological data have been reported $[9,11,39]$. Without a strong relationship between PLSN rheology and morphology to base conclusions on, the rheological analysis here will focus solely on matrix degradation. The rheological measurements will show that matrix molecular weight loss in the PLSNs due to degradation during processing may be a factor in limiting Young's modulus to below theoretical values calculated by the Ji et al. model.

The complex viscosity data obtained on the PLSNs shows a trend where the scCO2 processed PLSNs have higher viscosity values at all frequencies than the melt compounded PLSNs. Fig. 3.10 contains all the complex viscosity data for the Cloisite 
20A PLSNs as well as data for neat and extruded PET material. From the difference in the neat and extruded PET it is apparent that some degradation due to the extrusion process is occurring. The data from all material containing nanosilicate shows that the presence of clay leads to further degradation during melt mixing. This behavior is due to the presence of interlayer water molecules held tightly to the surface of the nanosilicate despite the drying technique that was used $[40,41]$. The trend apparent in the complex viscosity data in Fig. 3.10 where there are greater viscosity values at all frequencies for the scCO2 processed PLSNs over the melt compounded PLSNs is the result of less degradation during processing. Although the effect is far less pronounced, a similar result is seen in the Cloisite 30B samples shown in Fig. 3.11. It is known that organic molecules with partial negative charges are capable of displacing water molecules present in silicate galleries [32]. It is conceivable that scCO2 molecules which contain weak dipoles could displace water molecules that are held by strong hydrogen forces to the surface of the nanosilicates. The decreased presence of water in the PLSNs due to scCO2 treatment should be beneficial for all processing steps including injection molding and solid stating. The effect scCO2 processing has on the building of molecular weight by means of solid state polymerization and subsequent injection molding is the focus of a paper to be published in the future.

After degradation occurs in the melt processing of the PLSNs there is the potential for additional molecular weight degradation due to the presence of water molecules in and around silicate layers that have remained unreacted. This additional degradation can take place in a rheometer while a sample is maintained at melt temperature and be used to qualitatively asses how much water is still present after melt 
processing. Small amounts of water reacting with PET in the rheometer cause the complex viscosity to decrease gradually at low, increasing frequencies. The amount of degradation in the matrix is a function of both the presence of water and the amount of time the sample is held at the melt temperature. Fig. 3.9 is a plot of complex viscosity measured during a time sweep of the 5-30B-MC sample. It is apparent from Fig. 3.9 that rapid degradation occurs in the first 200s of the sweep after which time degradation slows. During a frequency sweep, it takes about one half of the run time, i.e $200 \mathrm{~s}$, to cover frequencies from 0.1 to $0.2 \mathrm{rad} / \mathrm{s}$ and then the rest of the frequencies are covered in the remaining 200s. The consequence of this extended period of time at low frequency is matrix degradation in addition to that seen during melt mixing of the PLSNs. Matrix degradation that occurs in the rheometer manifests itself as a gradual decrease in complex viscosity seen at low but increasing frequencies whereas degradation occurring during melt processing is apparent from the lower average values of viscosity that are found at every frequency relative to the other samples. Behavior indicating the existence of degradation occurring in the rheometer is seen in Fig. 3.10 in all of the samples containing clay. In this study the decrease in complex viscosity at low, increasing frequency is attributed to matrix degradation rather than the presence of a network formation. Additional evidence that this behavior is due to degradation rather than the formation of a percolated network structure is the presence of this behavior in the 1-20AMC sample. A $1 \mathrm{wt} \%$ loading of nanosilicate is far below the concentration where one would expect a percolated network to form [39, 42]. The presence of such a strong decrease in complex viscosity at low, increasing frequency and low silicate loading must be due to polymer degradation. The effect of clay aggregation and network formation 
may play a role in the low frequency response of the 3 and $5 \mathrm{wt} \%$ PLSNs, but the intense viscosity decrease seen at low, increasing frequency in the $1 \mathrm{wt} \%$ sample makes it difficult to determine the individual contribution of network effects to this behavior.

The decrease in complex viscosity at low frequency present in the PLSNs in Fig. 3.10 can be used to make qualitative statements based on the amount of water present in the PLSN system. An increased presence of water would result in greater decreases in viscosity at low frequency. In Fig. 3.10 it is apparent that all of the $\mathrm{scCO} 2$ processed samples show considerably less of a decrease in viscosity at low frequency than the melt compounded samples. This behavior at low clay loading is not attributed to the improvements in exfoliation that are achieved in the $\mathrm{scCO} 2$ processed PLSNs as the same behavior is seen in the $1 \mathrm{wt} \%$ PLSNs where low concentrations of silicate make network formation highly unlikely. Less decrease in the viscosity at low frequency is taken as strong evidence that the $\mathrm{scCO} 2$ treatment facilitates the removal of water from the interlayer galleries of the nanosilicate.

The effect of clay loading on matrix degradation can also be seen in rheological measurements. Fig. 3.12 and Fig. 3.13 show storage and loss moduli for all PLSNs produced with Cloisite 20A. As the clay loading increases, both the storage and loss moduli decrease. The decrease in moduli and complex viscosity with clay loading is a result of molecular weight degradation due to the presence of nanosilicate. Increasing the amount of silicate introduces more water into the system which causes chain scission during processing. Plateau like behavior at low frequency in G' also increases with clay loading and is attributed primarily to polymer degradation during testing as previously discussed. Increases in G' at low, decreasing frequency may also be attributed to clay 
aggregation and network formation in the PLSNs containing 3 and $5 \mathrm{wt} \%$ silicate. However, the contribution of clay aggregation to this behavior is unknown due to the presence of degradation. Further inspection of $G^{\prime}$ data shows less prominent plateau behavior at low frequency for the scCO2 processed samples. This find is in accordance with the decreases seen in the complex viscosity data at low frequency and is attributed to less water content between silicate layers in the scCO2 samples. Although the contribution of clay aggregation to plateau behavior in the $G^{\prime}$ data is unknown, it is interesting to note that one would expect to see a decrease in this behavior like that seen in Fig. 3.12 and Fig. 3.13 for the scCO2 processed PLSNs with improvements in exfoliation.

In addition to clay loading, clay surface modification type can have a significant effect on the level of matrix degradation. Fig. 3.14 shows a comparison of the complex viscosity data obtained from both 3-20A-scCO2 and 3-30B-scCO2 samples. The 3-30BscCO2 sample has a considerably lower complex viscosity than the 3-20A-scCO2 sample. It is possible that because of the hydroxyl groups associated with the surface modification in Cloisite 30B more water is bound tightly within the silicate galleries due to hydrogen bonding [40]. The additional water found in the galleries of Cloisite 30B over Cloisite 20A would explain why Cloisite 30B samples have far lower viscosity and, hence, molecular weights than Cloisite 20A samples of comparable silicate loading.

\subsection{Conclusions}

The scCO2 technique is an effective way to increase dispersion and exfoliation in a process using high temperature and shear to generate a PLSN. The disordering effect that $\mathrm{scCO} 2$ has on the layered silicate structure facilitates intercalation and subsequent 
exfoliation. This work has shown that improvements in the tensile moduli of PLSNs due to increased nanosilicate exfoliation may not be realized if poor compatibility between layered silicate and the polymer matrix exists. In addition to facilitating exfoliation, rheological measurements have shown that $\mathrm{scCO} 2$ treatment may decrease the amount of polymer degradation that occurs during all processing steps. It has been proposed that this decrease in degradation is due to the removal of water molecules from silicate galleries after displacement by $\mathrm{scCO} 2$ molecules. Rheological results from this study show that the amount of silicate and the type of clay surface modification used has a considerable effect on the extent of polymer matrix molecular weight degradation. Processing degradation due to the presence of nanosilicate may contribute to the inability of mechanical properties to meet or exceed the theoretical models used to make modulus value predictions. It is recommended for future work that solid state polymerization be used to build back the lost molecular weight which should lead to an improvement in mechanical properties. 


\subsection{References}

[1] Y. Kojima, A. Usuki, M. Kawasumi, A. Okada, Y. Fukushima, T. Kurauchi, O. Kamigaito, J. Mater. Res. 8 (1993) 1185-1189.

[2] R.A. Vaia, G. Price, P.N. Ruth, H.T. Nguyen, J. Lichtenhan, Appl. Clay Sci. 15 (1999) 67-92.

[3] E.P. Giannelis, R. Krishnamoorti, Adv. Polym. Sci. 138 (1999) 107-147.

[4] K. Sall, Eur. Plas. News (2002).

[5] P.B. Messersmith, E.P. Giannelis, J. Polym. Sci., Part A: Polym. Chem. 33 (1995) 1047.

[6] K.P. Pramoda, T. Liu, Z. Liu, C. He, H.-J. Sue, Polym. Degrad. Stab. 81 (2003) 4756.

[7] J.W. Gilman, T. Kashiwagi, J.D. Lichtenhan, SAMPE J. 34 (1997) 40-46.

[8] J.W. Gilman, Appl. Clay Sci. 15 (1999) 31-49.

[9] F. He, J. Yang, L. Zhu, B. Wang, G. Sun, P. Lv, I.Y. Phang, T. Liu, Appl. Polym. Sci. 102 (2006) 542-549.

[10]T. Liu, W.C. Tjiu, C. He, S.S. Na, T.-S. Chung, Polymer International 53 (2004) 392-399.

[11] R. Krishnamoorti, R.A. Vaia, E.P. Giannelis, Chem. Mater. 8 (1996) 1728-1734.

[12]T. Lan, T.J. Pinnavaia, Chem. Mater. 6 (1994) 2216-2219.

[13] W.J. Boo, L. Sun, J. Liu, E. Moghbelli, A. Clearfield, H.-J. Sue, H. Pham, N. Verghese, J. Polym. Sci., Part B: Polym. Phys. 45 (2007) 1459-1469.

[14] M. Modesti, A. Lorenzetti, D. Bon, S. Besco, Polym. J. 46 (2005) 10237-10245.

[15] S.S. Ray, K. Okamoto, M. Okamoto, Macromolecules 36 (2003) 2355-2367. 
[16]Y. Ke, C. Long, Z. Qi, J. Appl. Polym. Sci. 71 (1999) 1139-1146.

[17] Y. Wang, J. Gao, Y. Ma, U.S. Agarwal, Composites: Part B 37 (2006) 399-407.

[18] Y. Imai, S. Nishimura, E. Abe, H. Tateyama, A. Abiko, A. Yamaguchi, T. Aoyama, H. Taguchi, Chem. Mater. 14 (2002) 477-479.

[19] A. Sanchez-Solis, I. Romero-Ibarra, M.R. Estrada, F. Calderas, O. Manero, Polym. Eng. Sci. 44 (2004) 1094-1102.

[20]D.L. Tomasko, H. Li, D. Liu, X. Han, M.J. Wingert, L.J. Lee, K.W. Koelling, Ind. Eng. Chem. Res. 42 (2003) 6431-6456.

[21] A.S. Zerda, T.C. Caskey, A.J. Lesser, Macromolecules 36 (2003) 1603-1608.

[22]D.F. Mielewski, C.W. Manke, E. Gulari, E.C. Lee, System and Method of Preparing a Reinforced Polymer by Supercritical Fluid Treatment, in: U.S.P. Office (Ed.), Ford Global Technologies, Inc., Wayme State Unicersity, United States, 2004.

[23] C.W. Manke, E. Gulari, D.F. Mielewski, E.C. Lee, System and Method of Delaminating a Layered Silicate Material by Supercritical Fluid Treatment, in: U.S.P. Office (Ed.), Ford Global Technologies, Inc.; Wayne State University, United States, 2002.

[24]D. Chu, Q. Nguyen, D.G. Baird, Polym. Compos. 28 (2007) 499-511.

[25]D. Campbell, R.A. Pethrick, J.R. White, Polymer Characterization: Physical Techniques, Stanley Thornes Ltd, Cheltenham, UK, 2000.

[26] G.W. Brindley, G. Brown, Crystal Structures of Clay Minerals and Their X-ray Identification, Mineralogical Society, London, 1980.

[27] V. Singh, T. Singh, A. Chandra, S.K. Bandyopadhyay, P. Sen, K. Witte, A. Srivastava, Nucl. Instrum. Methods Phys. Res., Sect. B 244 (2006) 243-247. 
[28]D.M. Moore, J. R. C. Reynolds, X-ray Diffraction and the Identification and Analysis of Clay Minerals, Second ed., Oxford University Press, New York, 1997.

[29] H.R. Dennis, D.L. Hunter, D. Chang, S. Kim, J.L. White, J.W. Cho, D.R. Paul, Polym. J. 42 (2001) 9513-9522.

[30] J.W. Cho, D.R. Paul, Polym. J. 42 (2001) 1083-1094.

[31] O. Monticelli, Z. Musina, A. Frache, F. Bellucci, G. Camino, A. Russo, Polym. Degrad. Stab. 92 (2007) 370-378.

[32] M. Zanetti, S. Lomakin, G. Camino, Macromol. Mater. Eng. 279 (2000) 1-9.

[33] J.C. Halpin, J.L. Kardos, Polym. Eng. Sci. 16 (1976) 344-352.

[34] X.L. Ji, J.K. Jing, W. Jiang, B.Z. Jiang, Polym. Eng. Sci. 42 (2002) 983-993.

[35] J. Lusis, R.T. Woodhams, M. Xanthos, Polym. Eng. Sci. 13 (1973) 139-145.

[36] A. Lele, M. Mackley, G. Galgali, C. Ramesh, J. Rheol. 46 (2002) 1091-1110.

[37] G. Galgali, S. Agarwal, A. Lele, Polym. J. 45 (2004) 6059-6069.

[38] N. Sheng, M.C. Boyce, D.M. Parks, G.C. Rutledge, J.I. Abes, R.E. Cohen, Polymer 45 (2004) 487-506.

[39] Y.T. Lim, O.O. Park, Rheol. Acta 40 (2001) 220-229.

[40] O. Monticelli, Z. Musina, A. Frache, F. Bellucci, G. Camino, S. Russo, Polym. Degrad. Stab. 92 (2007) 370-378.

[41] R.D. Davis, J.W. Gilman, D.L. Vanderhart, Polym. Degrad. Stab. 79 (2003) 111121.

[42] J. Li, C. Zhou, G. Wang, D. Zhao, J. Appl. Polym. Sci. 89 (2003) 3609-3617. 


\begin{tabular}{|c|c|c|c|}
\hline Material Description & Abbreviation & $\begin{array}{c}\text { Silicate } \\
\text { Loading }(w t \%)\end{array}$ & $\begin{array}{l}\text { Silicate } \\
\text { Loading } \\
\text { (vol\%) }\end{array}$ \\
\hline Neat PET & PET & 0 & 0 \\
\hline $\begin{array}{c}1 \mathrm{wt} \% \text { Cloisite 20A/PET Melt } \\
\text { Compounded }\end{array}$ & 1-20A-MC & 1.27 & 0.99 \\
\hline $\begin{array}{c}3 \mathrm{wt} \% \text { Cloisite } 20 \mathrm{~A} / \mathrm{PET} \text { Melt } \\
\text { Compounded }\end{array}$ & $3-20 \mathrm{~A}-\mathrm{MC}$ & 3.32 & 2.59 \\
\hline $\begin{array}{c}5 \mathrm{wt} \% \text { Cloisite 20A/PET Melt } \\
\text { Compounded }\end{array}$ & 5-20A-MC & 5.80 & 4.55 \\
\hline $1 \mathrm{wt} \%$ Cloisite $20 \mathrm{~A} / \mathrm{PET} \mathrm{scCO} 2$ & $1-20 \mathrm{~A}-\mathrm{scCO} 2$ & 1.09 & 0.85 \\
\hline $3 \mathrm{wt} \%$ Cloisite $20 \mathrm{~A} /$ PET scCO2 & $3-20 \mathrm{~A}-\mathrm{scCO} 2$ & 2.60 & 2.02 \\
\hline $5 \mathrm{wt} \%$ Cloisite 20A/PET scCO2 & $5-20 \mathrm{~A}-\mathrm{scCO} 2$ & 4.78 & 3.74 \\
\hline $\begin{array}{c}1 \mathrm{wt} \% \text { Cloisite 30B/PET Melt } \\
\text { Compounded }\end{array}$ & 1-30B-MC & 1.21 & 0.84 \\
\hline $\begin{array}{c}3 \mathrm{wt} \% \text { Cloisite 30B/PET Melt } \\
\text { Compounded }\end{array}$ & 3-30B-MC & 2.85 & 1.99 \\
\hline $\begin{array}{c}5 \mathrm{wt} \% \text { Cloisite 30B/PET Melt } \\
\text { Compounded }\end{array}$ & 5-30B-MC & 5.21 & 3.66 \\
\hline $1 \mathrm{wt} \%$ Cloisite 30B/PET scCO2 & $1-30 \mathrm{~B}-\mathrm{scCO} 2$ & 1.14 & 0.79 \\
\hline $3 \mathrm{wt} \%$ Cloisite $30 \mathrm{~B} / \mathrm{PET} \mathrm{scCO} 2$ & 3-30B-scCO2 & 2.84 & 1.98 \\
\hline $5 \mathrm{wt} \%$ Cloisite 30B/PET scCO2 & $5-30 \mathrm{~B}-\mathrm{scCO} 2$ & 4.93 & 3.46 \\
\hline
\end{tabular}

Table 3.1: Sample descriptions, abbreviations and the actual clay loadings calculated from burn off testing. 


\begin{tabular}{|c|c|c|c|}
\hline Sample & $\begin{array}{c}\mathbf{2 \Theta} \\
\mathbf{(}^{\mathbf{}}\end{array}$ & $\begin{array}{c}\mathbf{d}_{001} \\
(\AA)\end{array}$ & \% Increase \\
\hline Pure 20A & 3.65 & 24.18 & - \\
\hline 1-20A-MC & 2.85 & 30.96 & 28.1 \\
\hline 3-20A-MC & 2.85 & 30.96 & 28.1 \\
\hline 5-20A-MC & 2.70 & 32.68 & 35.2 \\
\hline 1-20A-scCO2 & 2.65 & 33.30 & 37.8 \\
\hline 3-20A-scCO2 & 2.75 & 32.09 & 32.7 \\
\hline 5-20A-scCO2 & 2.85 & 30.96 & 28.1 \\
\hline
\end{tabular}

Table 3.2: WAXD results and average basal spacing values calculated from the Bragg equation (1) on PLSNs containing Cloisite 20A 


\begin{tabular}{|c|c|c|c|}
\hline Sample & $\begin{array}{c}\text { FWHM } \\
\mathbf{(}^{\mathbf{}}\end{array}$ & $\begin{array}{c}\text { Avg. Tactoid Size } \\
(\mathbf{\AA})\end{array}$ & $\begin{array}{c}\text { Avg. \# of Layers } \\
\text { per Tactoid }\end{array}$ \\
\hline Pure 20A & 1.25 & 65.7 & 2.72 \\
\hline 1-20A-MC & 0.6 & 136.8 & 4.42 \\
\hline 3-20A-MC & 0.7 & 117.3 & 3.79 \\
\hline 5-20A-MC & 0.65 & 126.3 & 3.86 \\
\hline 1-20A-scCO2 & 0.8 & 102.6 & 3.08 \\
\hline 3-20A-scCO2 & 0.8 & 102.6 & 3.20 \\
\hline 5-20A-scCO2 & 0.75 & 109.4 & 3.53 \\
\hline
\end{tabular}

Table 3.3: WAXD results and average tactoid size calculated from the Scherer equation (2) on PLSNs containing Cloisite 20A 


\begin{tabular}{|c|c|c|c|}
\hline Sample & $\begin{array}{c}\mathbf{2 \Theta} \\
\mathbf{(}^{\mathbf{}}\end{array}$ & $\begin{array}{c}\mathbf{d}_{\mathbf{0 0 1}} \\
(\mathbf{\AA})\end{array}$ & \% Increase \\
\hline Pure 30B & 4.72 & 18.72 & - \\
\hline 1-30B-MC & 6.40 & 13.81 & -26.2 \\
\hline 3-30B-MC & 6.35 & 13.92 & -25.6 \\
\hline 5-30B-MC & 6.30 & 14.03 & -25.0 \\
\hline 1-30B-scCO2 & 6.40 & 13.81 & -26.2 \\
\hline 3-30B-scCO2 & 6.10 & 14.49 & -22.6 \\
\hline 5-30B-scCO2 & 6.50 & 13.60 & -27.4 \\
\hline
\end{tabular}

Table 3.4: WAXD results and average basal spacing values calculated from the Bragg equation (1) on PLSNs containing Cloisite 30B 


\begin{tabular}{|c|c|c|c|}
\hline Sample & $\begin{array}{c}\text { FWHM } \\
\mathbf{(}^{\mathbf{}}\end{array}$ & $\begin{array}{c}\text { Avg. Tactoid Size } \\
(\mathbf{\AA})\end{array}$ & $\begin{array}{c}\text { Avg. \# of Layers } \\
\text { per Tactoid }\end{array}$ \\
\hline Pure 30B & 0.90 & 91.2 & 4.87 \\
\hline 1-30B-MC & - & - & - \\
\hline 3-30B-MC & 1.31 & 62.74 & 4.51 \\
\hline 5-30B-MC & 1.08 & 76.10 & 5.42 \\
\hline 1-30B-scCO2 & - & - & - \\
\hline 3-30B-scCO2 & 1.35 & 60.87 & 4.20 \\
\hline 5-30B-scCO2 & 1.13 & 72.74 & 5.35 \\
\hline
\end{tabular}

Table 3.5: WAXD results and average tactoid size calculated from the Scherer equation (2) on PLSNs containing Cloisite 30B 


\begin{tabular}{|c|c|c|c|c|c|c|c|}
\hline Materials & $\begin{array}{c}\text { Young's } \\
\text { Modulus } \\
\text { (MPa) }\end{array}$ & S.D. & $\begin{array}{c}\text { \% } \\
\text { Increase }\end{array}$ & $\begin{array}{c}\text { Tensile } \\
\text { Strength } \\
\text { (MPa) }\end{array}$ & S.D. & $\begin{array}{c}\text { \% } \\
\text { Elongation }\end{array}$ & S.D. \\
\hline \hline Neat PET & 2698 & 96 & - & 29.49 & 9.00 & 91.31 & 49.60 \\
\hline 1-20A-MC & 3010 & 154 & 12 & 38.96 & 5.88 & 47.77 & 19.31 \\
\hline 3-20A-MC & 3814 & 349 & 41 & 39.98 & 7.44 & 47.60 & 10.87 \\
\hline 5-20A-MC & 3553 & 200 & 32 & 57.88 & 13.80 & 4.91 & 0.66 \\
\hline 1-20A-scCO2 & 3228 & 159 & 20 & 24.35 & 2.90 & 13.46 & 9.78 \\
\hline 3-20A-scCO2 & 3061 & 168 & 13 & 41.14 & 13.31 & 6.11 & 2.04 \\
\hline 5-20A-scCO2 & 3282 & 231 & 22 & 54.10 & 2.04 & 3.22 & 0.31 \\
\hline 1-30B-MC & 3165 & 121 & 17 & 25.53 & 1.77 & 12.28 & 3.88 \\
\hline 3-30B-MC & 3074 & 155 & 14 & 64.64 & 1.29 & 2.95 & 0.158 \\
\hline 5-30B-MC & 3584 & 219 & 33 & 57.63 & 4.71 & 2.11 & 0.247 \\
\hline 1-30B-scCO2 & 3370 & 151 & 25 & 27.13 & 5.13 & 11.70 & 2.51 \\
\hline 3-30B-scCO2 & 3395 & 176 & 26 & 62.33 & 0.66 & 3.72 & 0.420 \\
\hline 5-30B-scCO2 & 3818 & 363 & 42 & 59.00 & 2.28 & 2.22 & 0.095 \\
\hline
\end{tabular}

Table 3.6: Results of mechanical testing done on all Cloisite 20A samples 


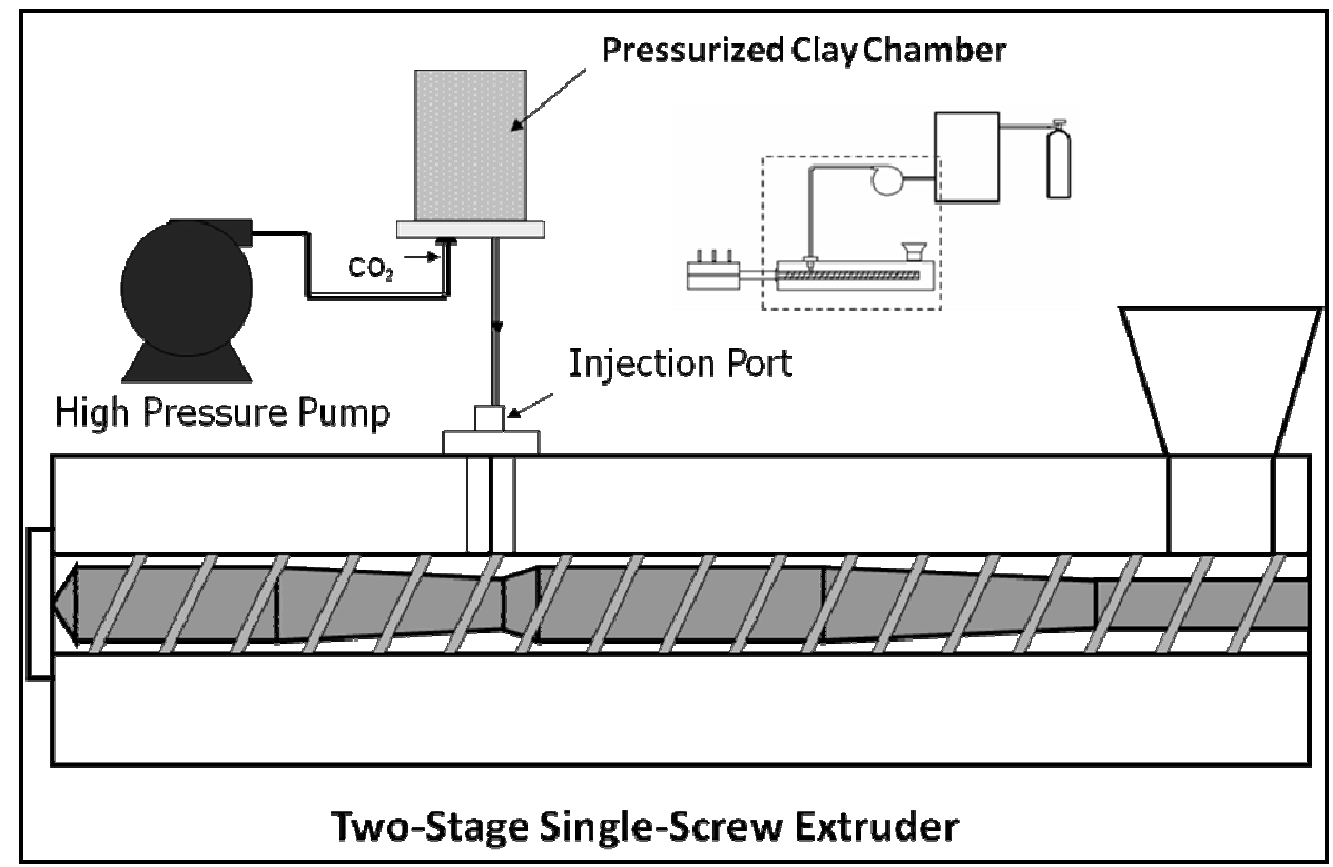

Figure 3.1: Schematic of the $\mathrm{scCO} 2$ processing equipment 


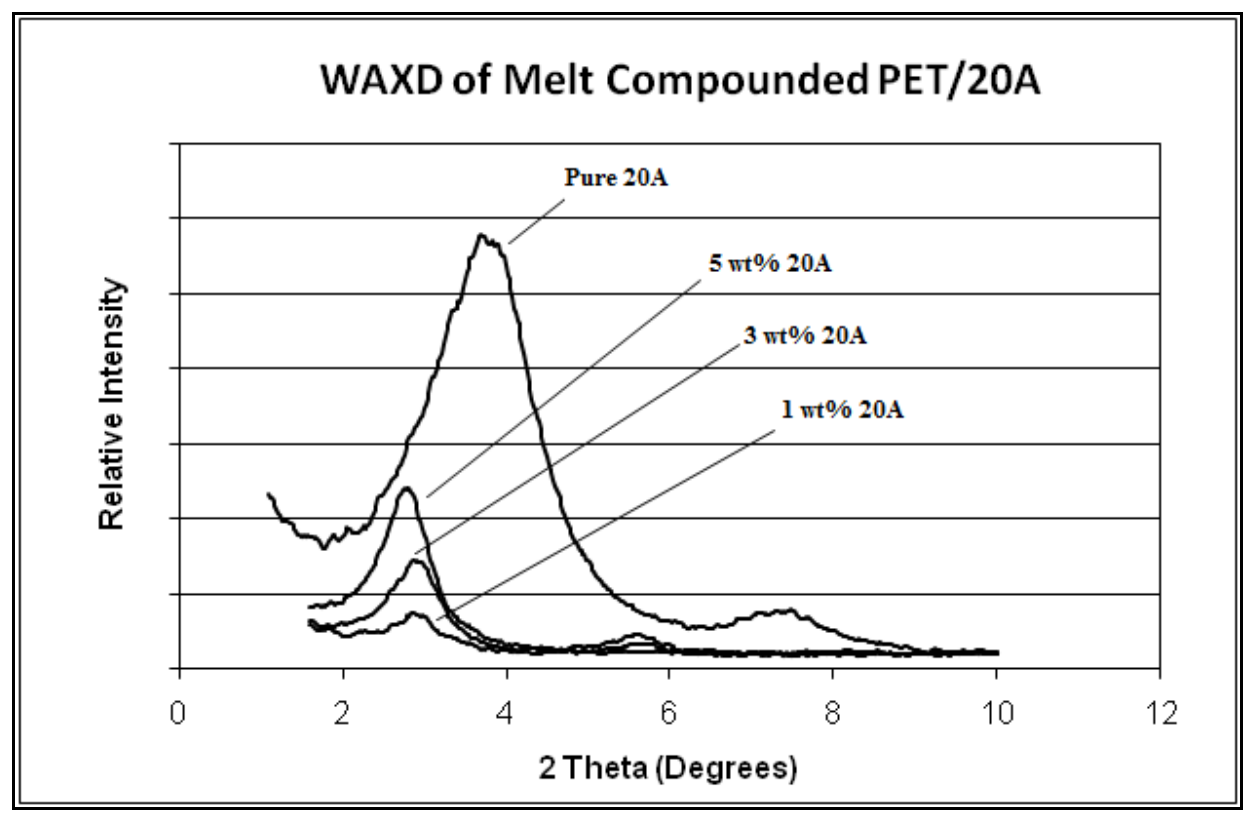

Figure 3.2: WAXD results of PLSN samples containing Cloisite 20A and produced using melt compounding 


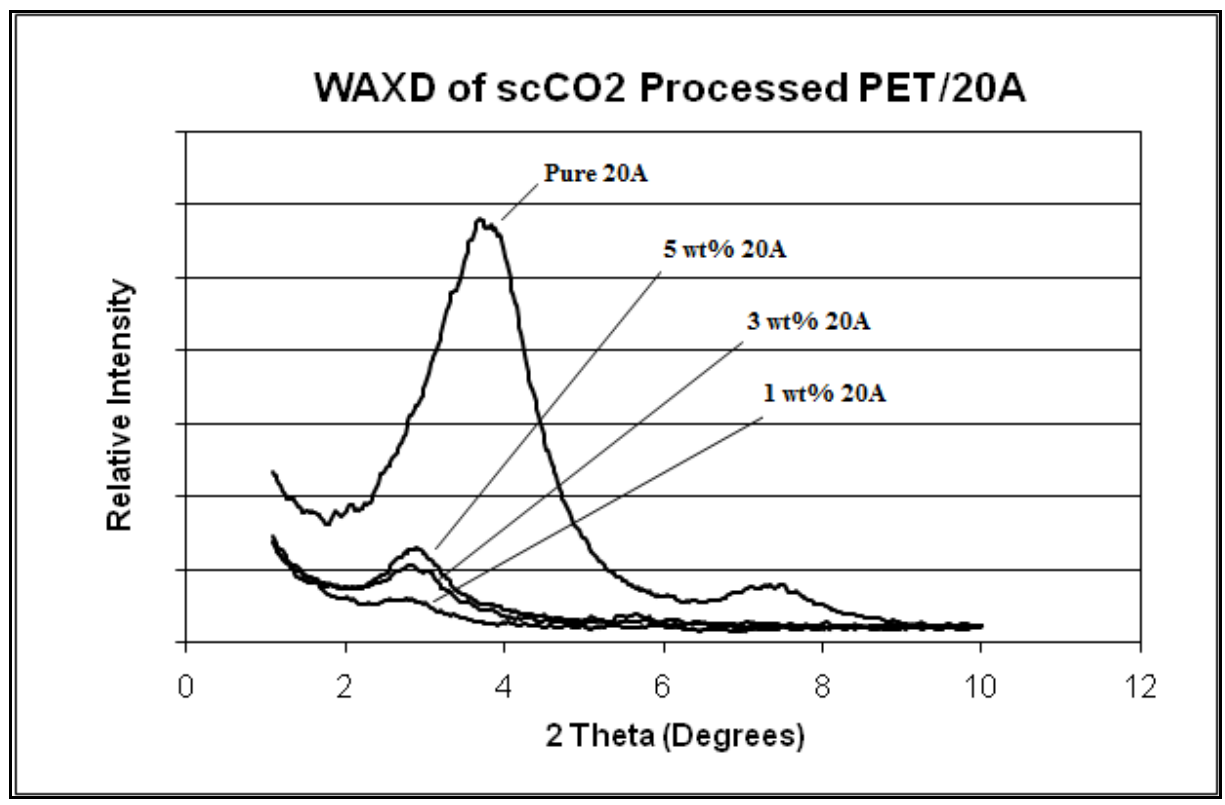

Figure 3.3: WAXD results of PLSN samples containing Cloisite 20A and produced using the scCO2 method 


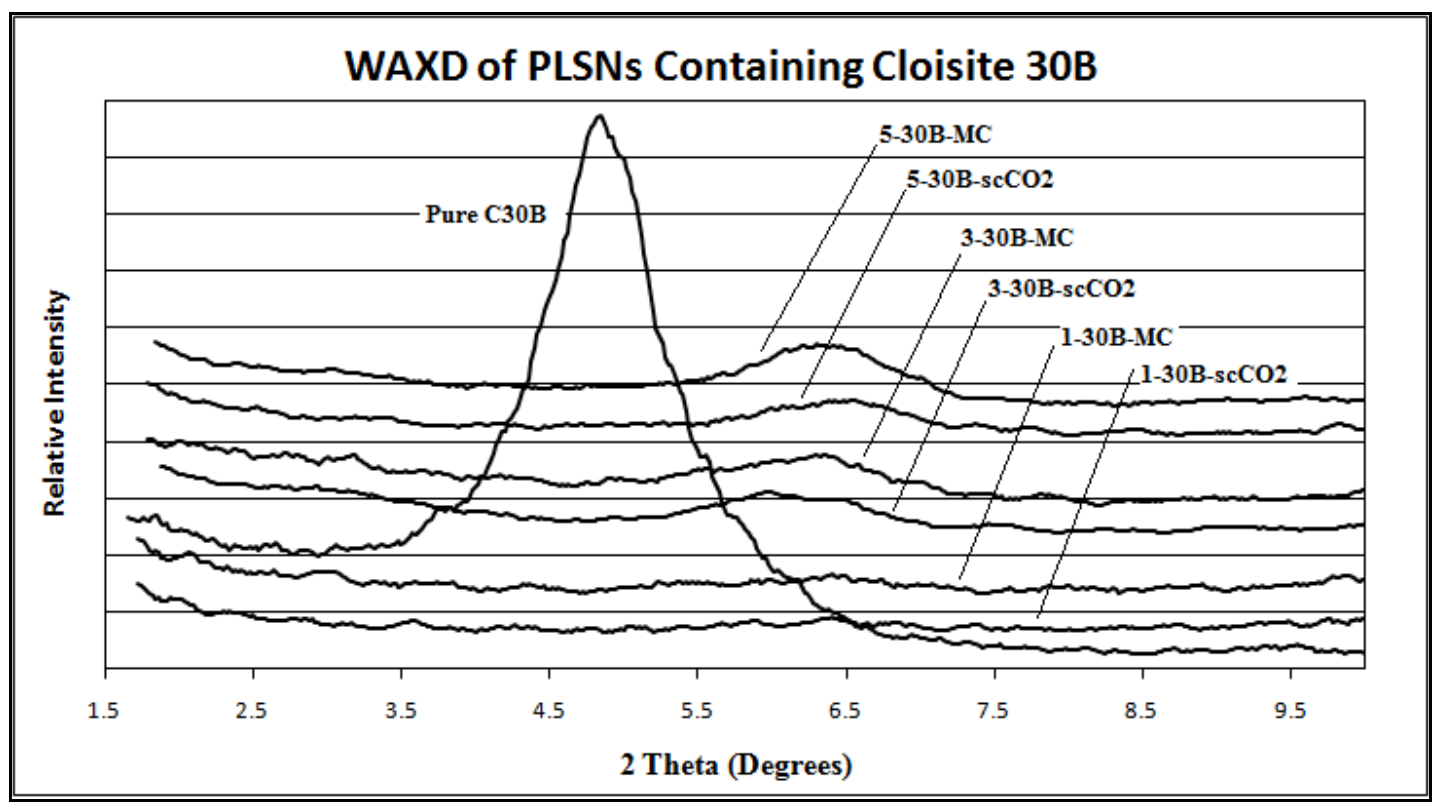

Figure 3.4: WAXD results of Cloisite 30B/PET nanocomposites produced from the $\mathrm{scCO} 2$ process and melt compounding 


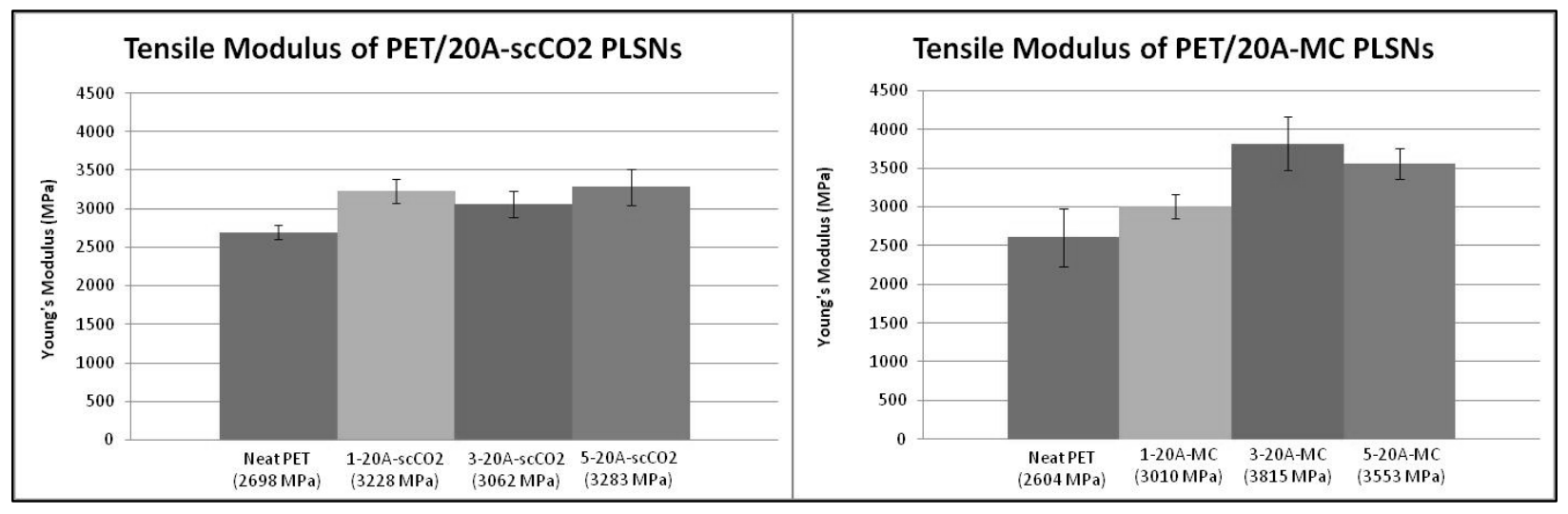

Figure 3.5: Young's modulus values for all Cloisite 20A samples produced from both the $\mathrm{scCO} 2$ process and the melt compounding process 


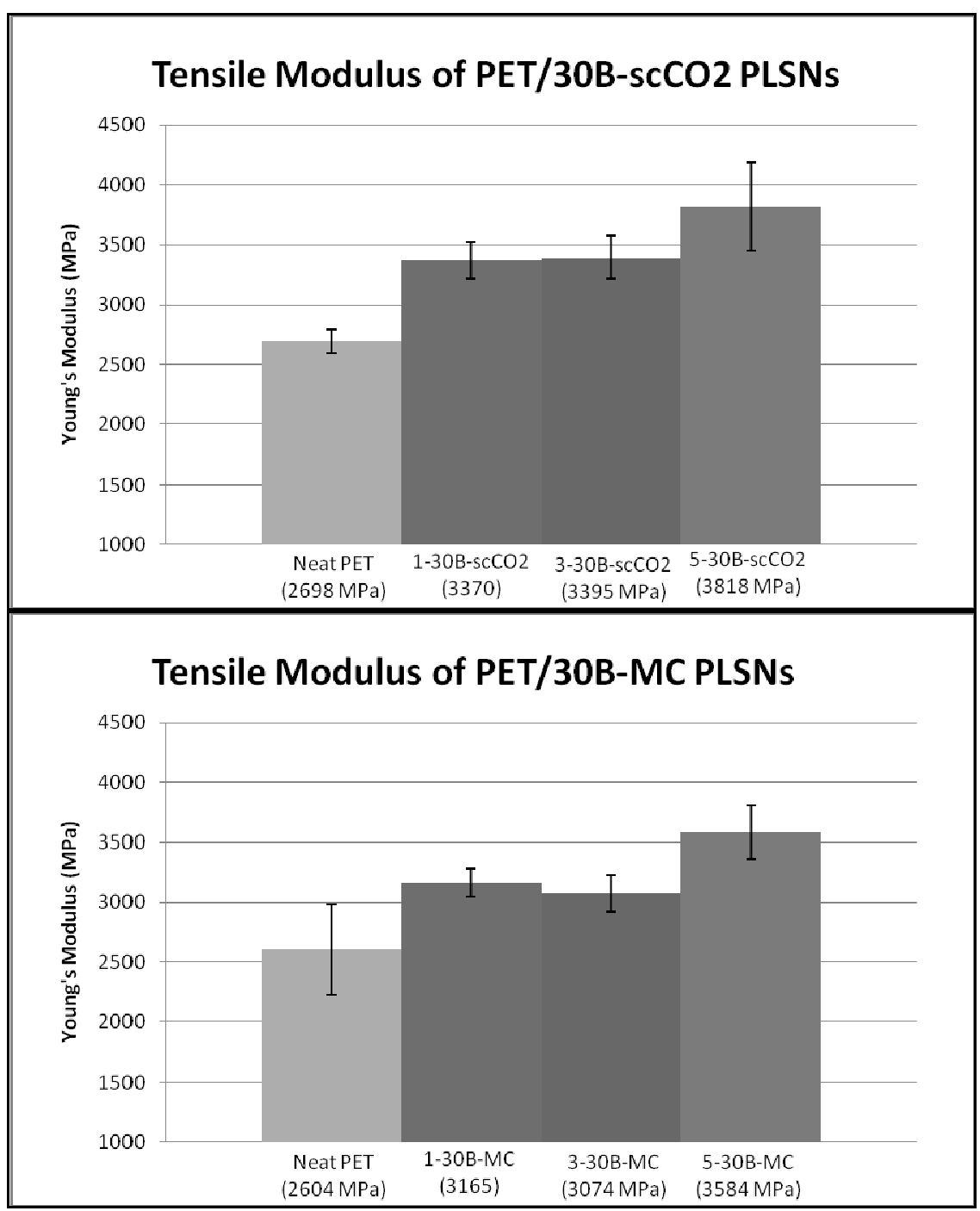

Figure 3.6: Young's modulus values for all Cloisite 30B samples produced from both the $\mathrm{scCO} 2$ process and the melt compounding process 


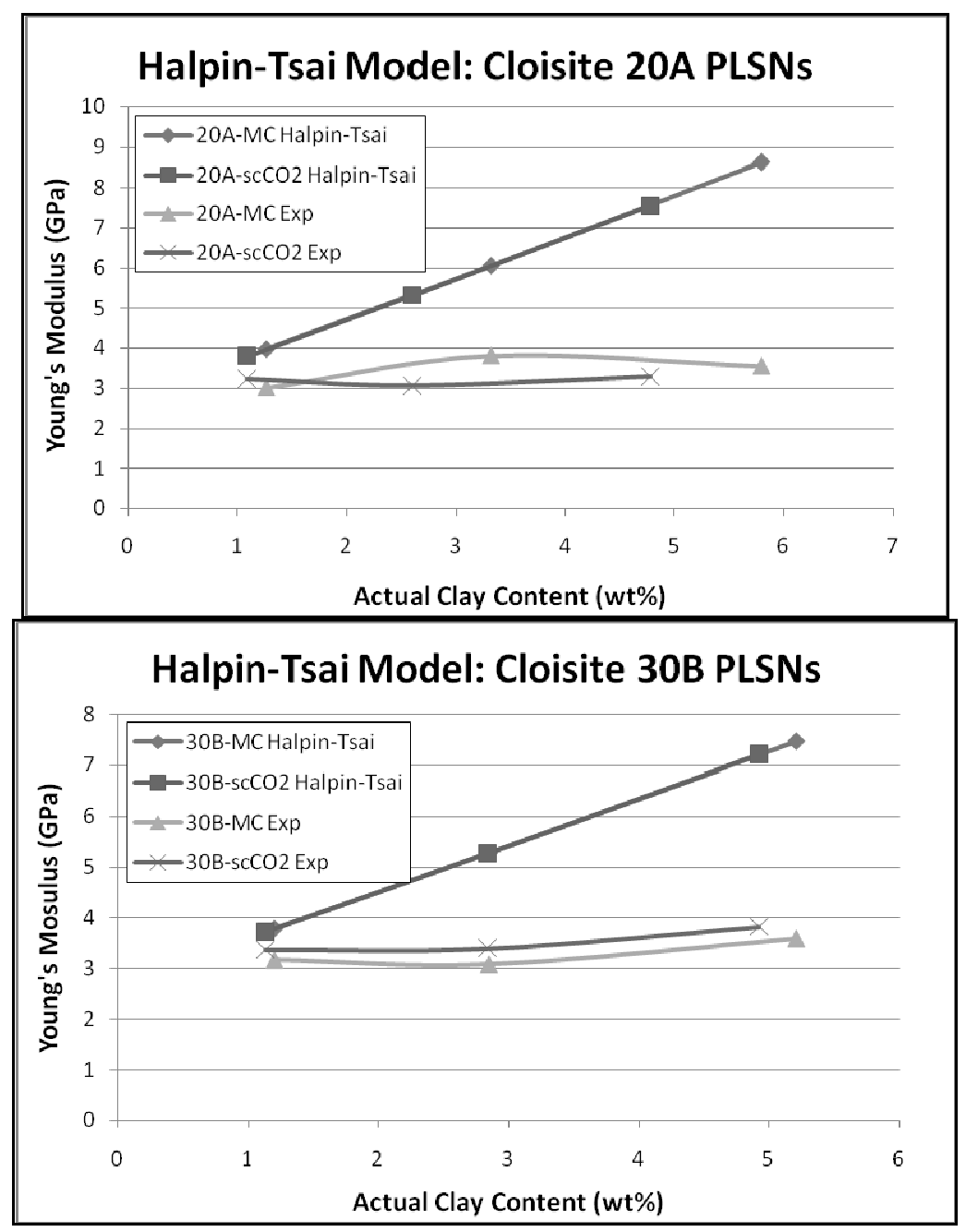

Figure 3.7: Halpin-Tsai model predictions of tensile modulus compared to experimentally obtained values 


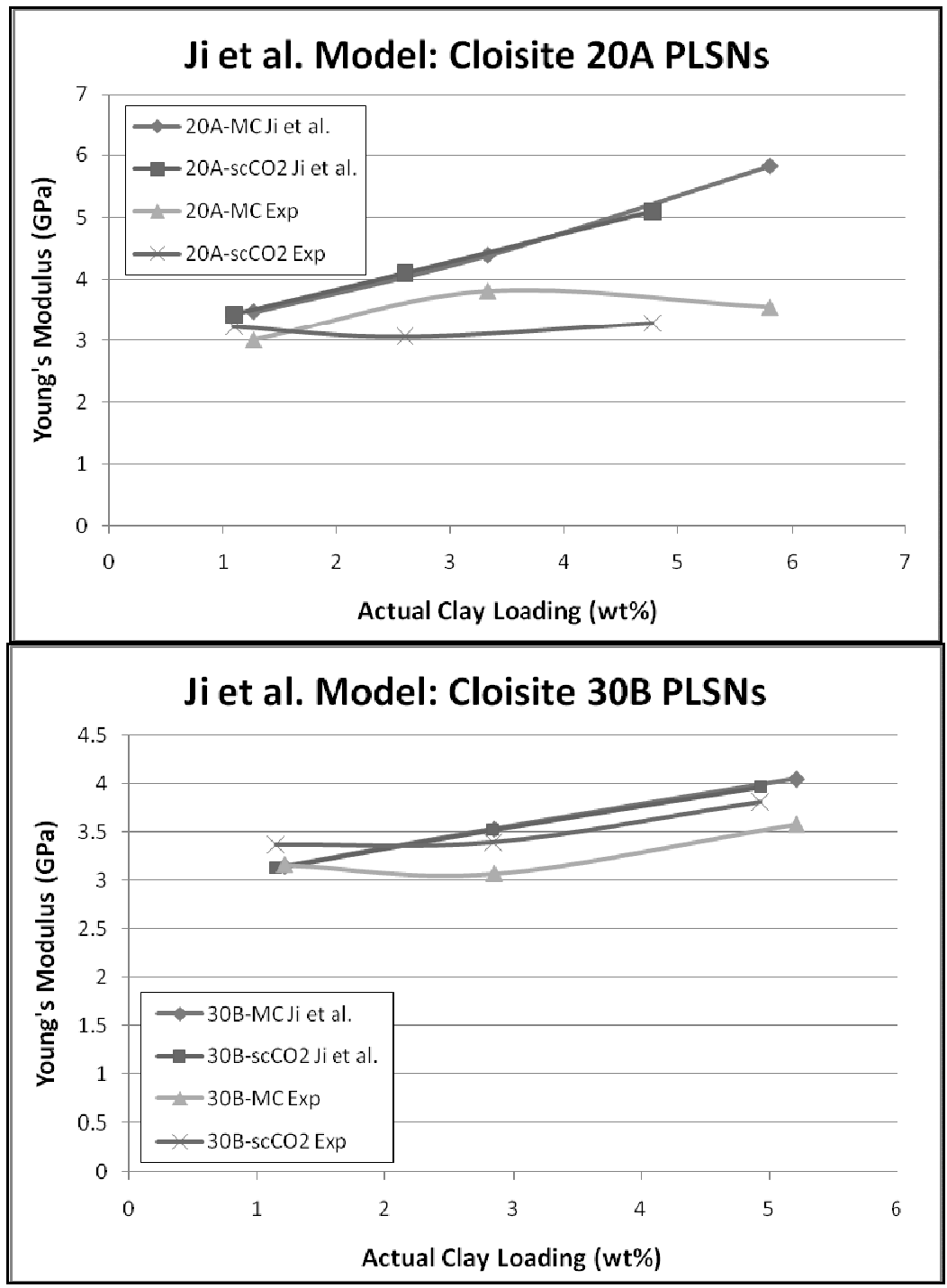

Figure 3.8: Ji et al. model predictions of tensile modulus compared to experimentally obtained values 


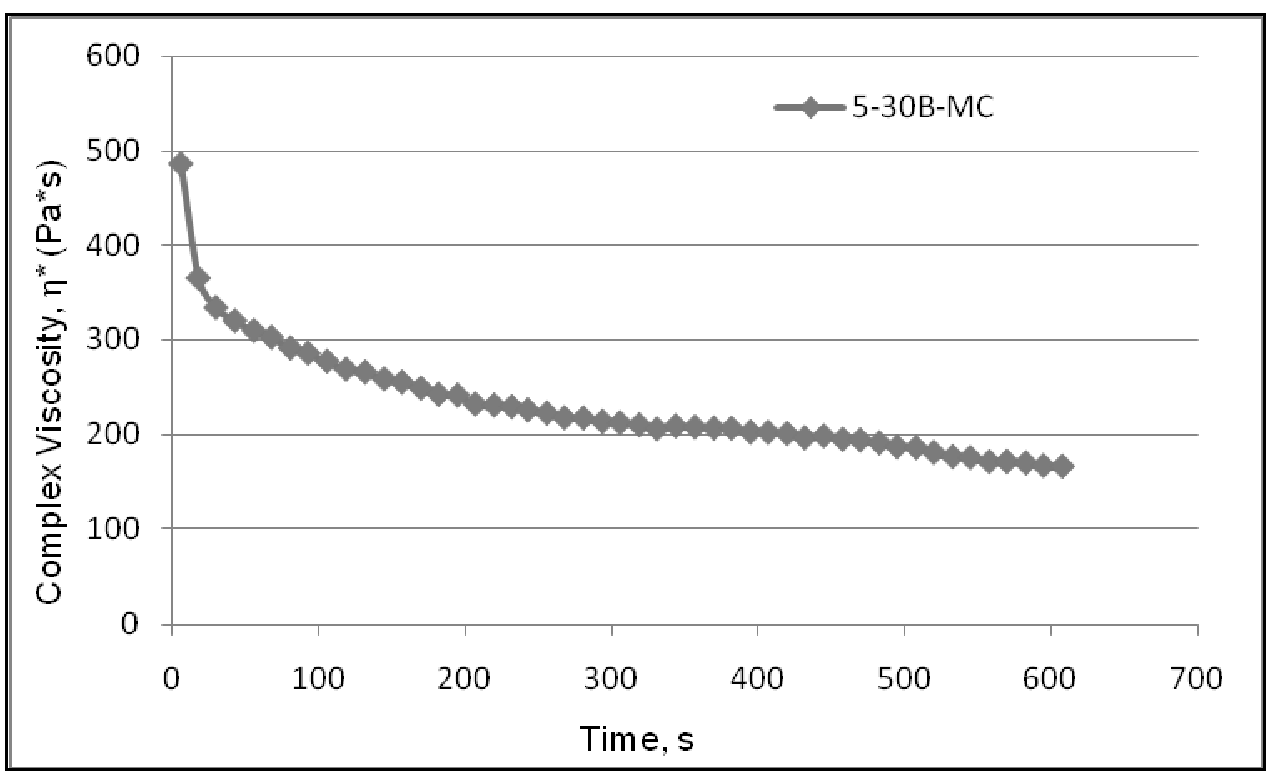

Figure 3.9: Complex viscosity measured during a time sweep of the 5-30B-MC sample 
(a)

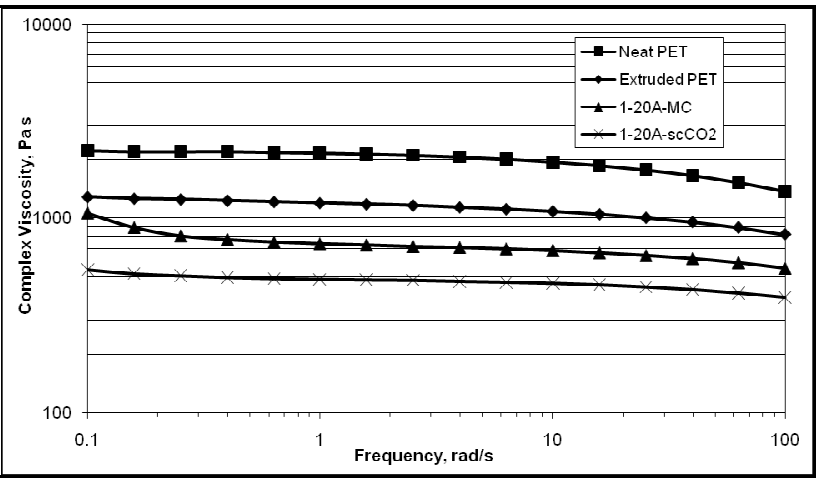

(b)

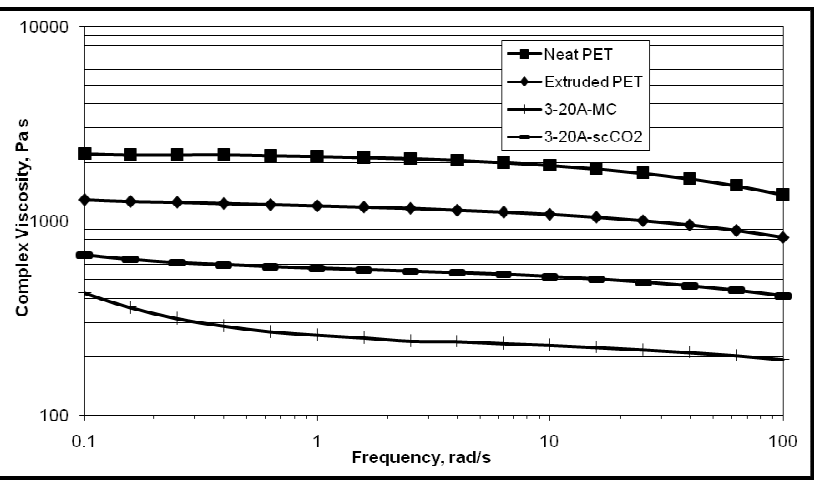

(c)

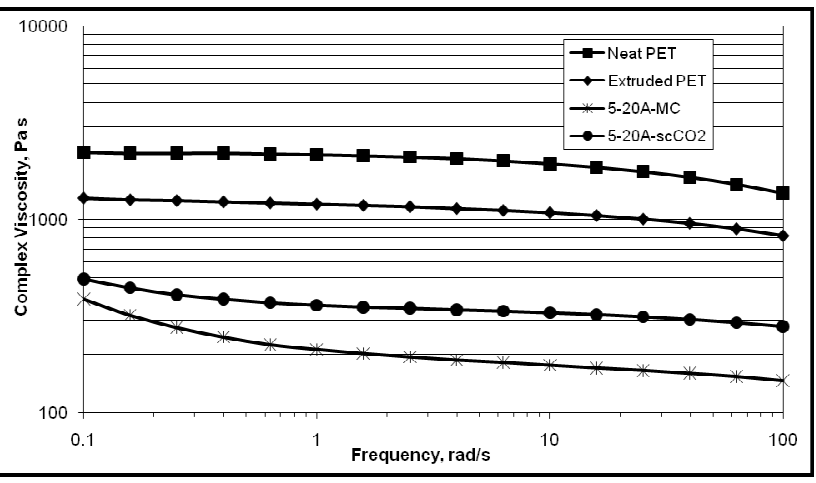

Figure 3.10: Complex viscosity data of (a) 1-20A samples, (b) 3-20A samples and (c) 520A samples 
(a)

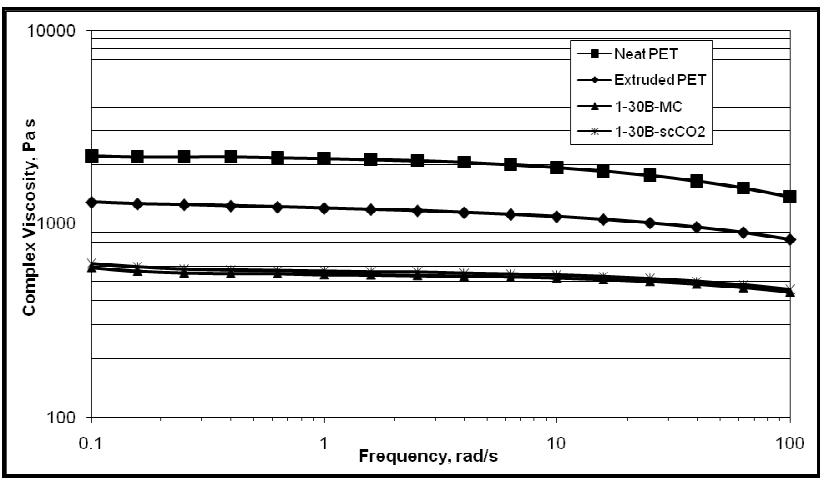

(b)
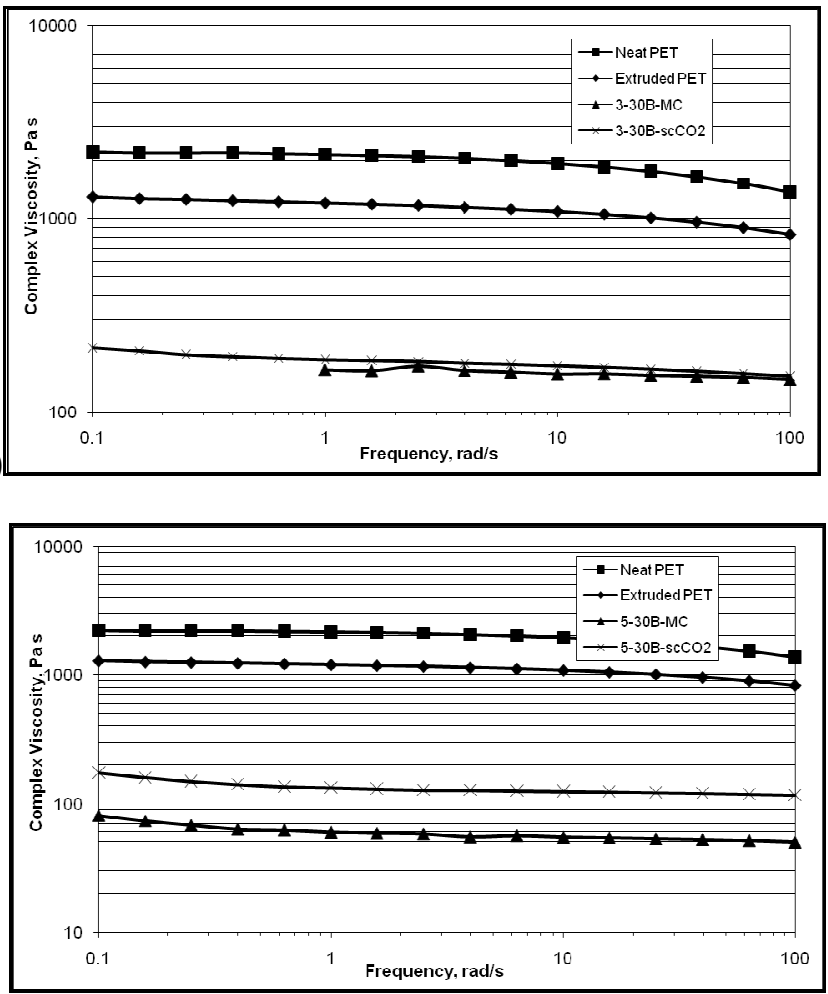

Figure 3.11: Complex viscosity data of (a) 1-30B samples, (b) 3-30B samples and (c) 530B samples 


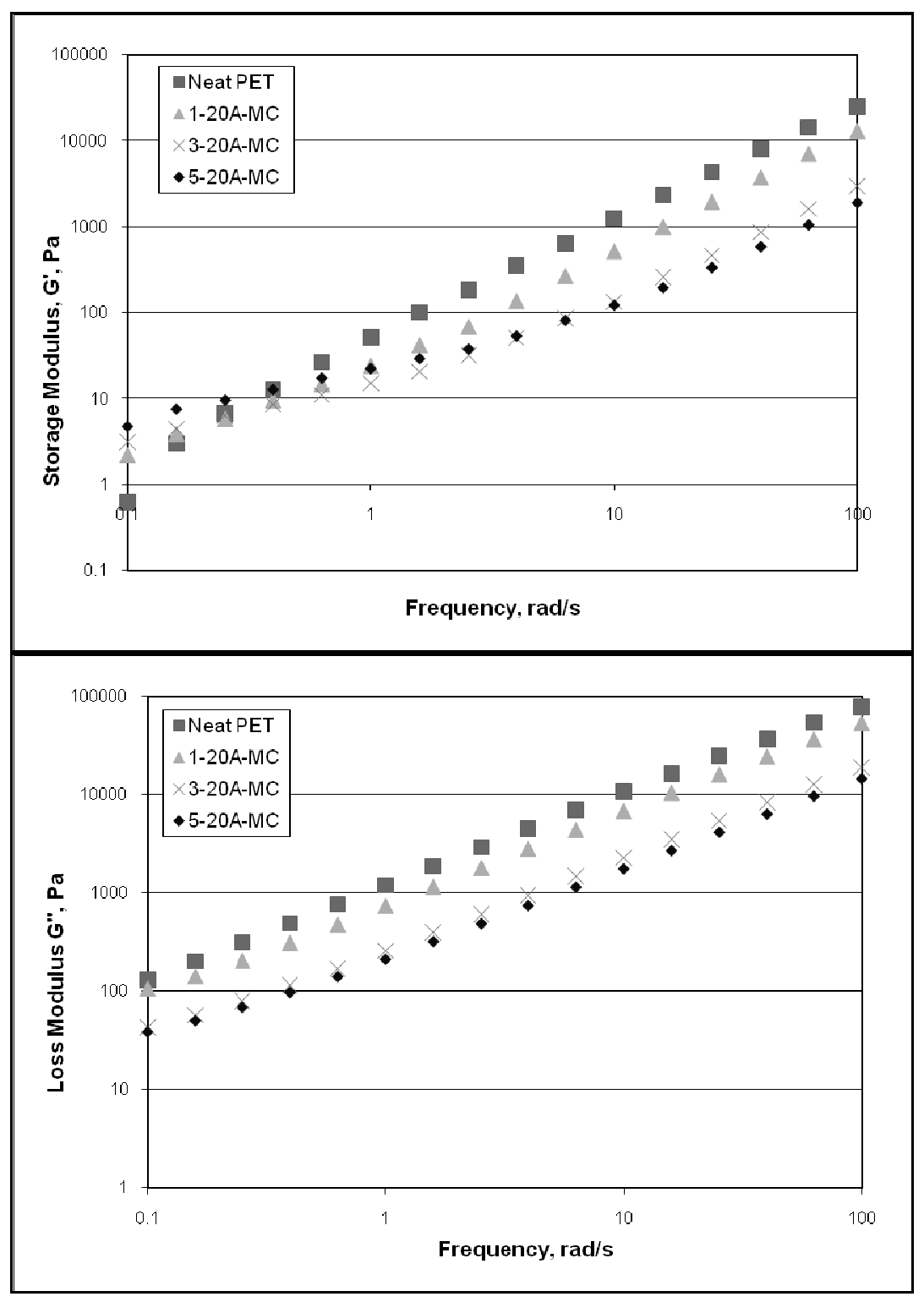

Figure 3.12: G' and G', of 20A-MC PLSNs 


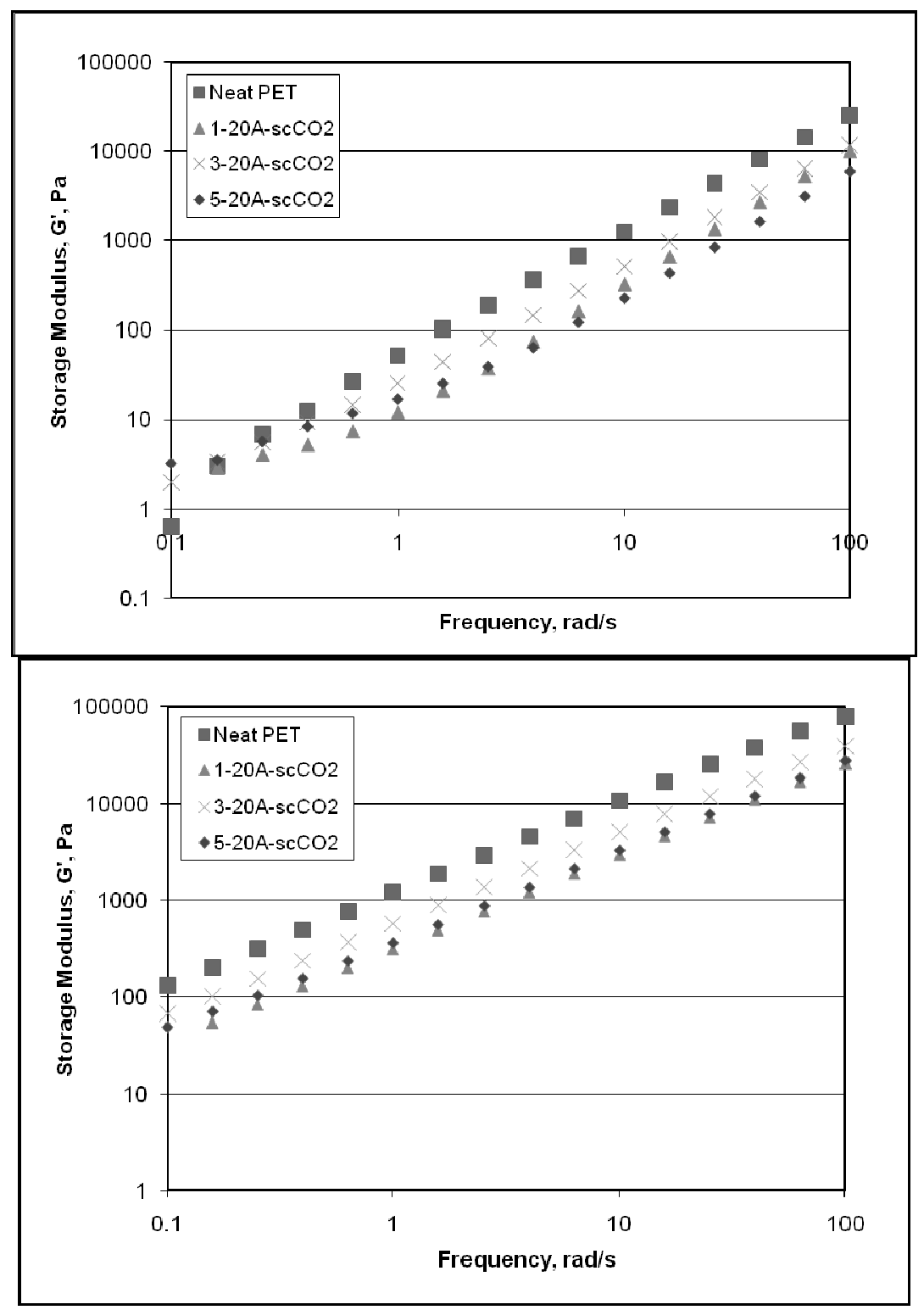

Figure 3.13: G' and G', of 20A-scCO2 PLSNs 


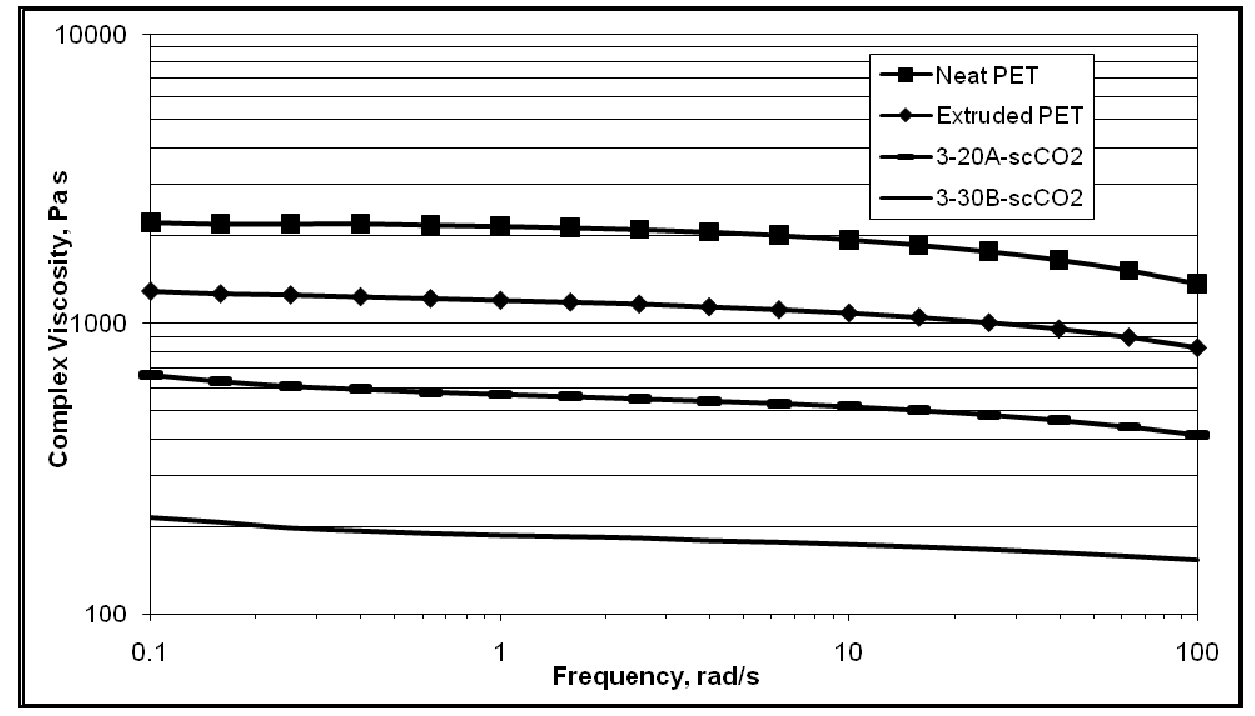

Figure 3.14: Complex viscosity data for 3-20A-scCO2 and 3-30B-scCO2 samples 


\subsection{Recommendations for Future Work}

1) To test the ability of the $\mathrm{scCO} 2$ technique to improve silicate exfoliation beyond the capability of shear and mixing, a twin screw extruder should be considered in future work. A single screw extruder was used here in order to get a good representation of the $\mathrm{scCO} 2$ 's role in facilitating exfoliation. A twin screw extruder exposes polymer melts to a much greater level of shear than a single screw extruder can. Many studies have shown that a twin screw extruder is far more effective at causing silicate exfoliation than a single screw extruder. With this in mind, the higher shear levels may be more effective in peeling any silicate layers apart that have been disordered by the $\mathrm{scCO} 2$ treatment.

2) During melt processing of the PET based PLSNs, considerable degradation of the PET matrix occurred. The resulting mechanical properties were likely affected by this drop in matrix molecular weight. Employing a solid state polymerization reaction in the PLSNs in order to increase the molecular weight of the nanocomposites may have a considerable impact on the final mechanical properties. Future work may test this possibility by carrying out solid state polymerization reactions, injection molding tensile samples and measuring the resulting mechanical properties.

3) WAXD analysis on PLSNs produced in this study containing Cloisite 30B showed the occurrence of surfactant degradation during melt processing. This degradation results from the high processing temperatures necessary to melt process PET. The degradation resulted in the collapse of many of the layered silicate galleries and the failure of some of the silicate tactoids to become intercalated. The lack of intercalation is believed to limit the final mechanical properties of the PLSNs. Using 
a syringe pump and the plasticizing capabilities of $\mathrm{CO} 2$, it may be possible to lower the melt temperature of the PET while also injecting treated Cloisite 30B. By dropping the processing temperature of the PET melt, degradation of the Cloisite 30B surface modification should be limited.

4) The type of silicate surfactant used during melt compounding of PET based PLSNs is very important to the final properties of the nanocomposite. An ideal surfactant modification for PET nanocomposites would contain a polar head group that interacts strongly with the silicate surface as well as a long, hydrophobic hydrocarbon chains that interacts strongly with the PET matrix. The polar head group must be thermally stable at temperature of 260 to $280^{\circ} \mathrm{C}$. The hydroxyl modification used in Cloisite 30B is successful at creating strong interactions between the silicate surface and the PET matrix, however, the tendency of the surfactant to degrade at PET melt temperatures makes complete exfoliation with melt compounding methods impossible. In the future, the use of a surfactant with a similar structure to that used in Cloisite 30B but having a higher thermal degradation temperature may be more successful in producing high strength PET based PLSNs. 
Appendix A: WAXD Data 


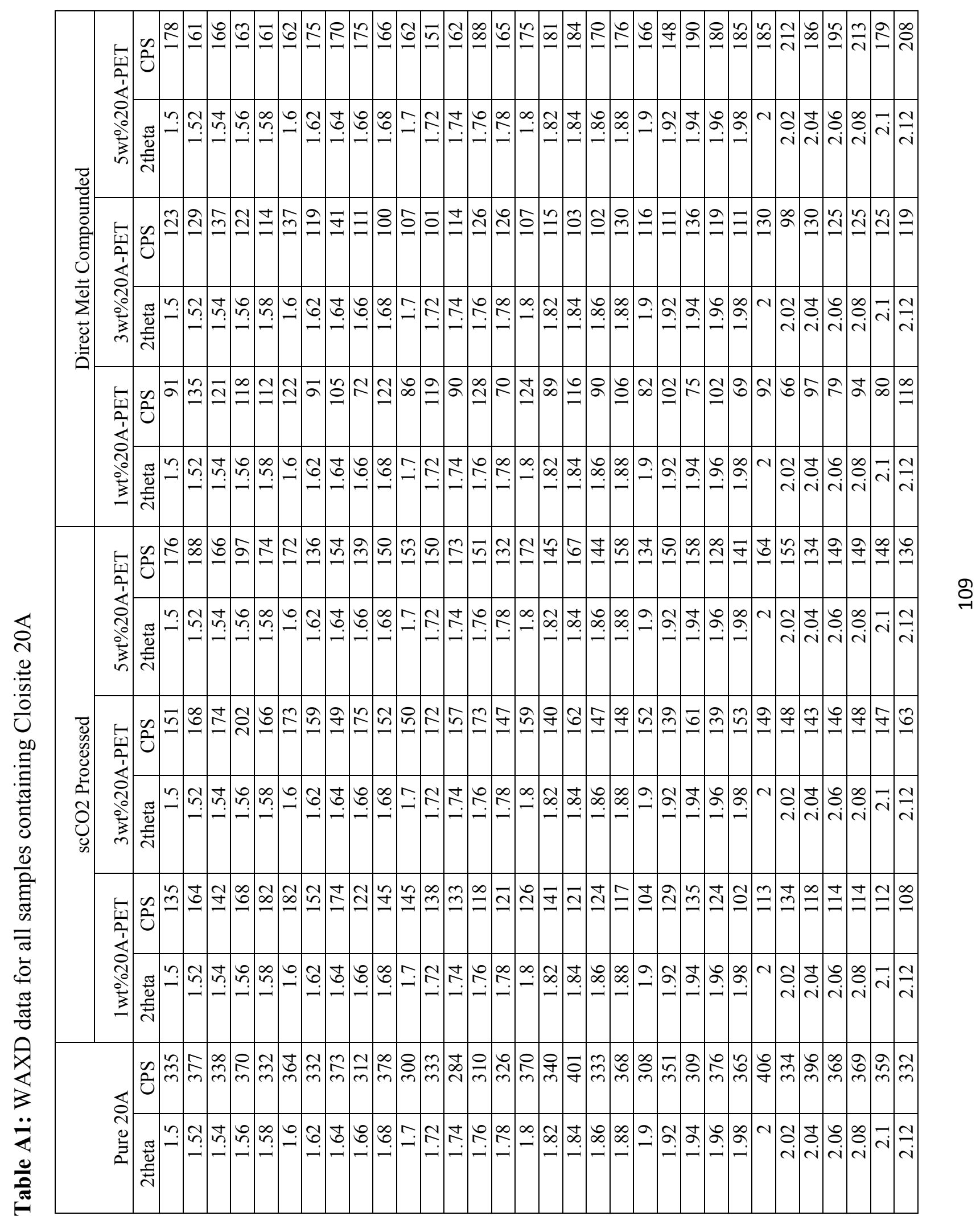




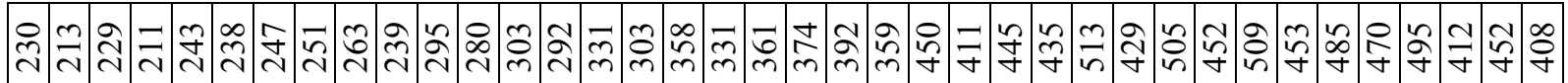
ป

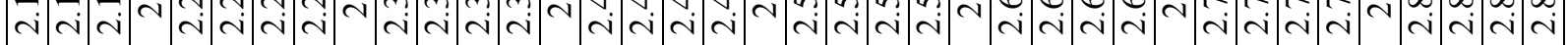

İ

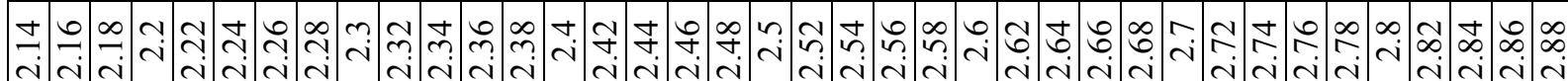

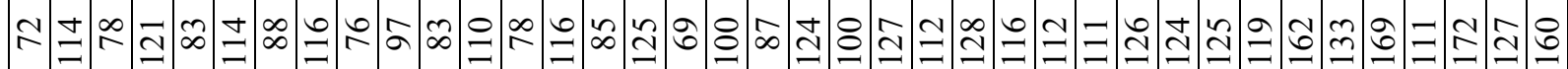

I

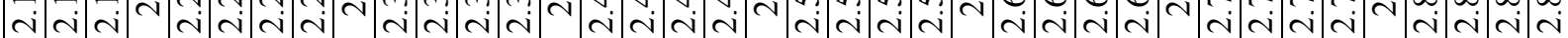

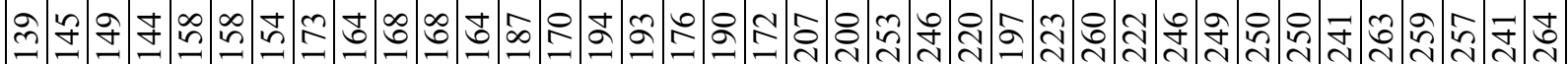

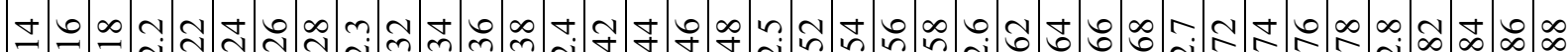

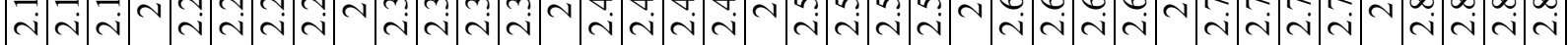

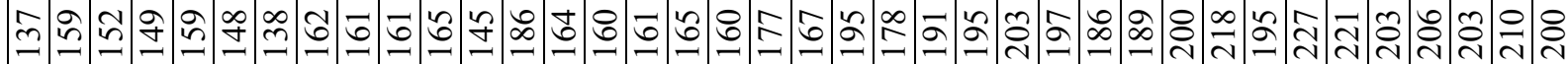

JU

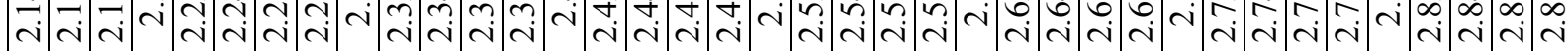

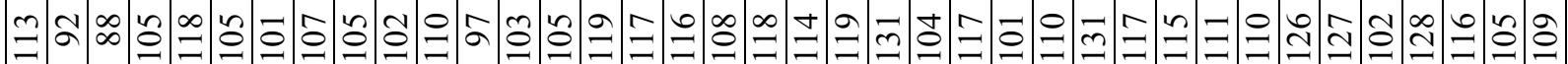

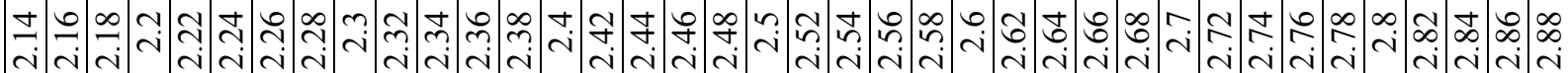



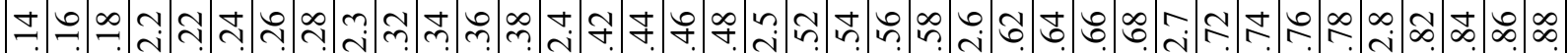

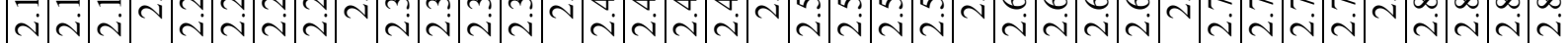




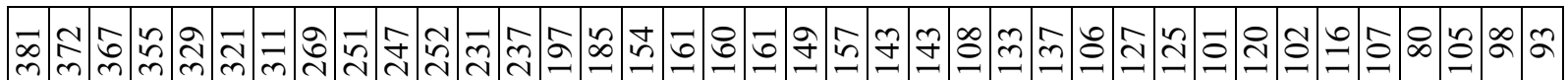

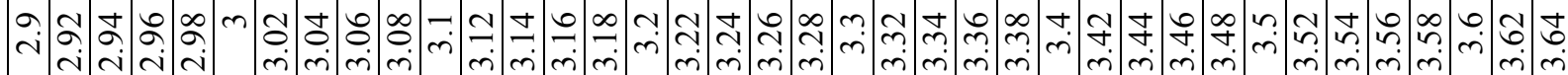

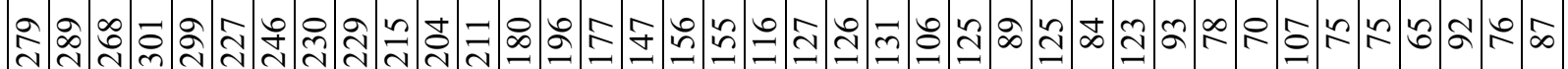

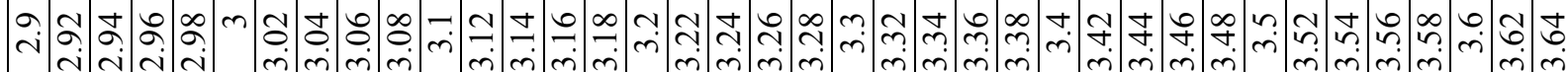

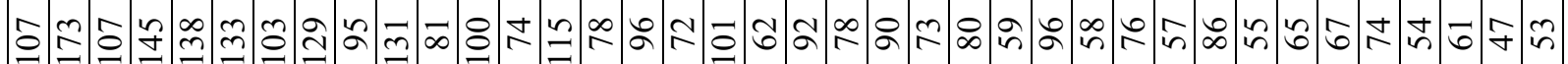

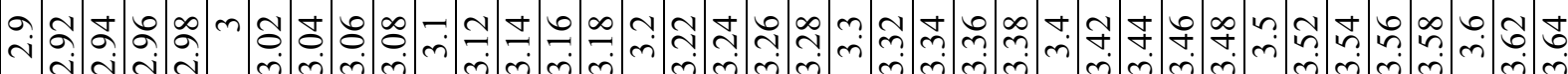

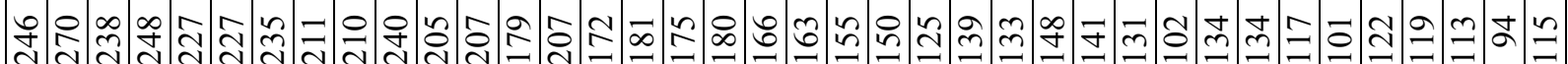

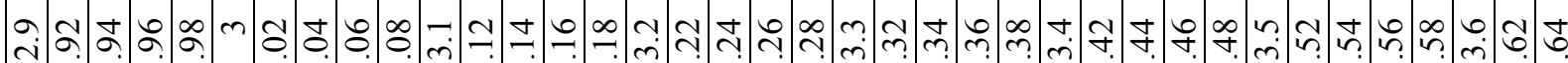

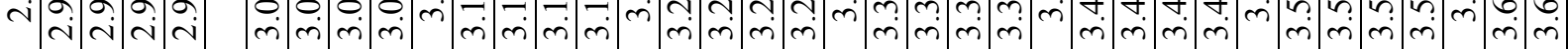

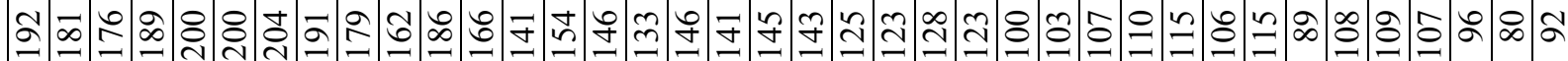

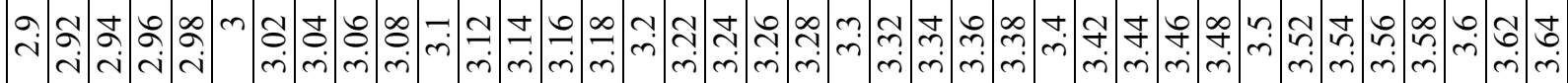

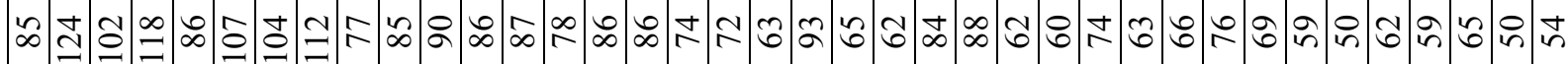

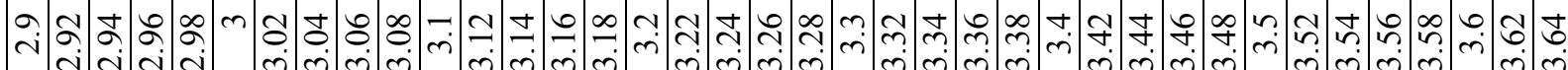

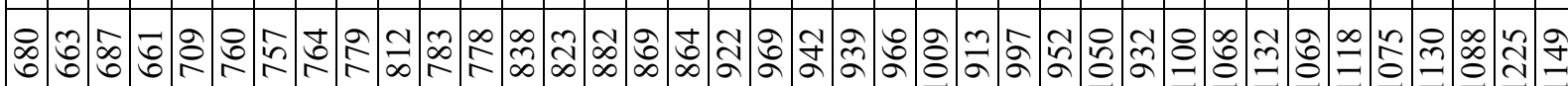

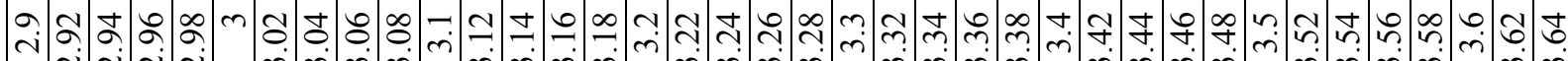

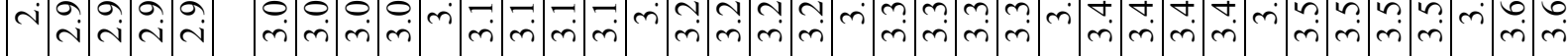




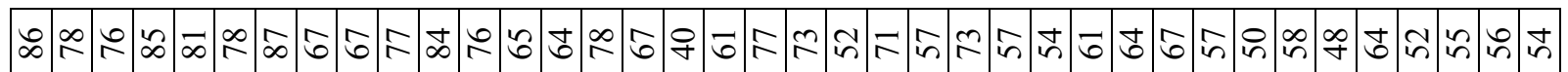

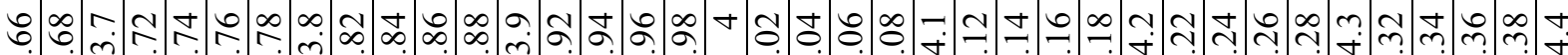

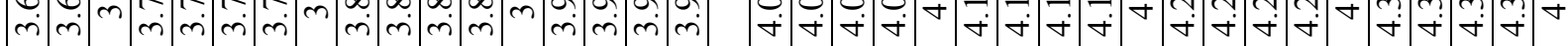

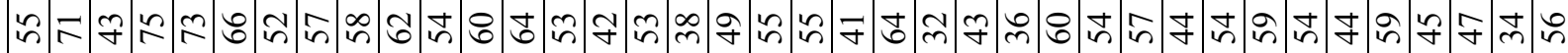

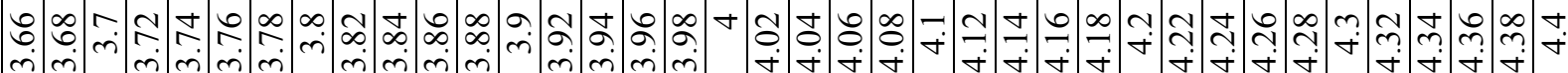

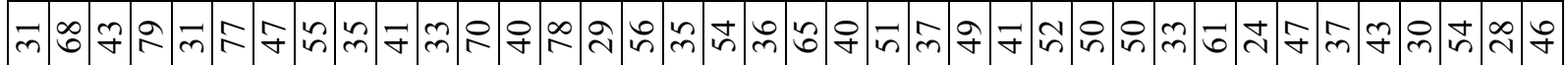

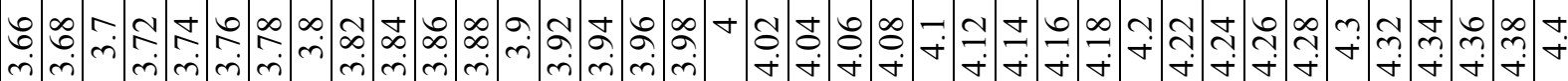
๙

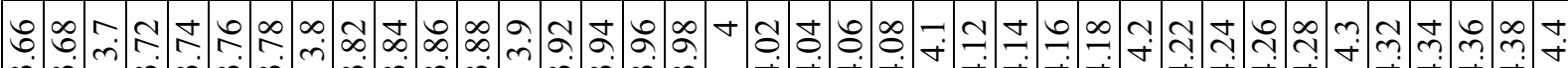

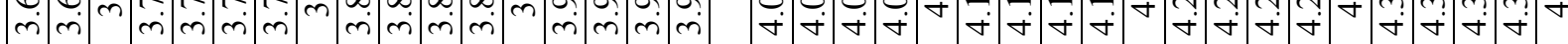

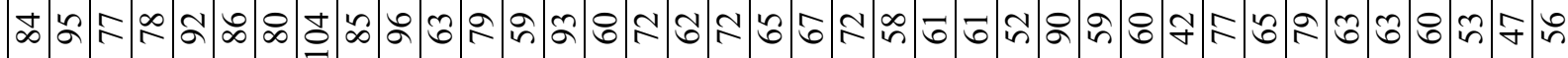

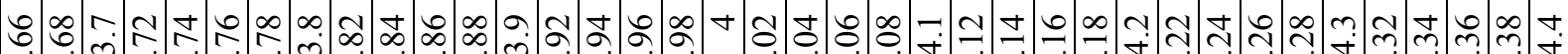

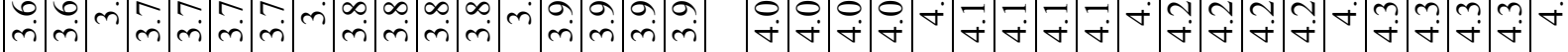

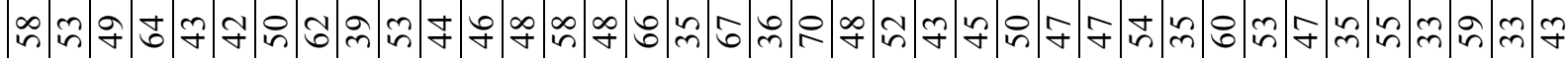

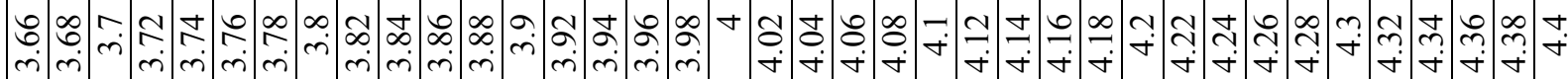

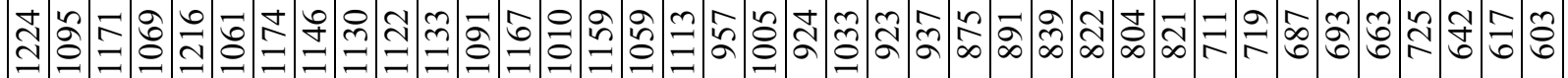
: $\infty$ :

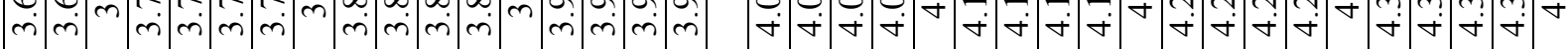


T)

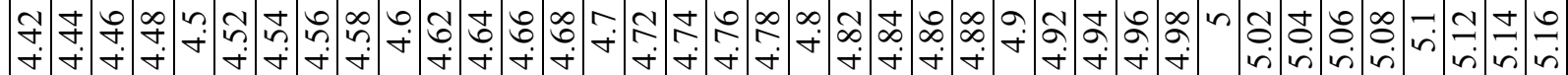

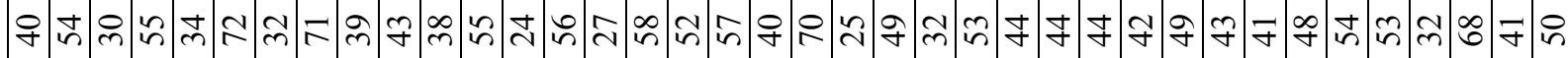

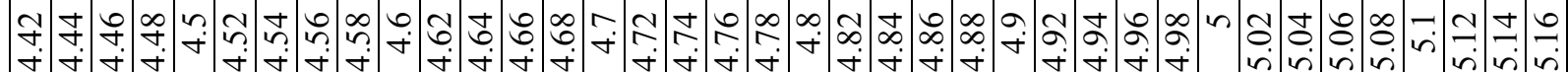

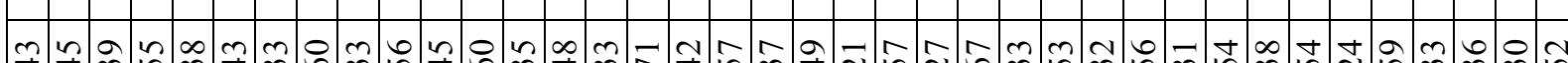
$\forall \forall$ m

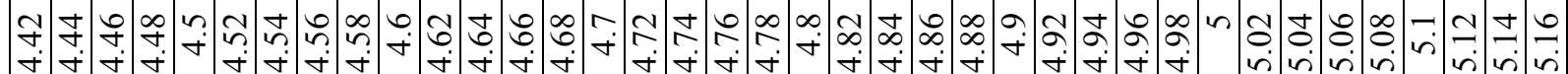



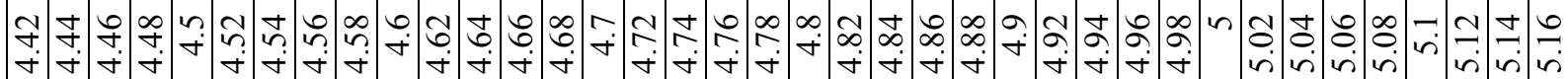

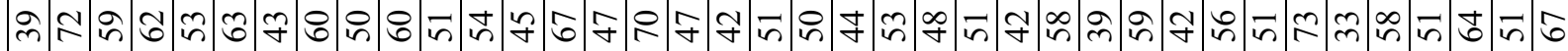

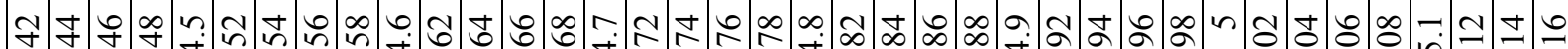

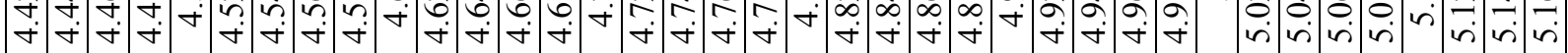

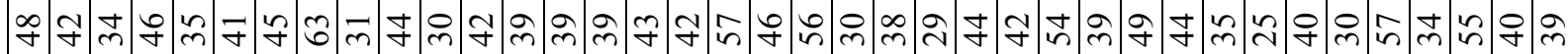

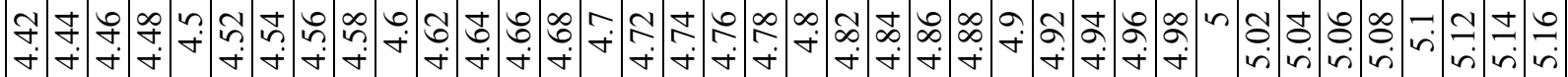

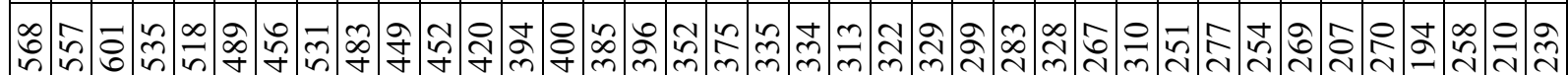

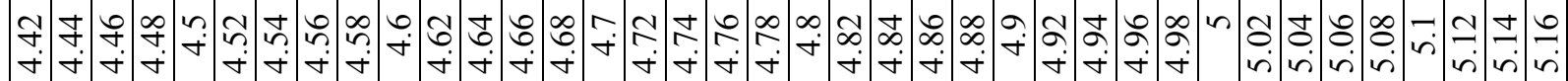




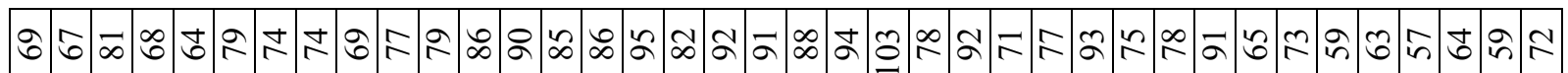

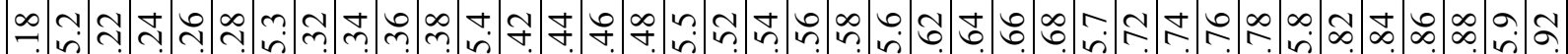



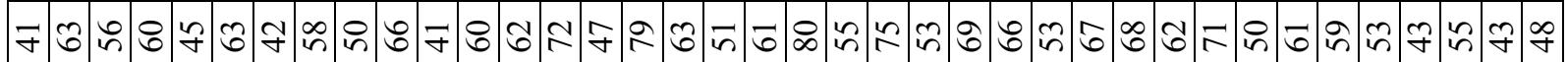

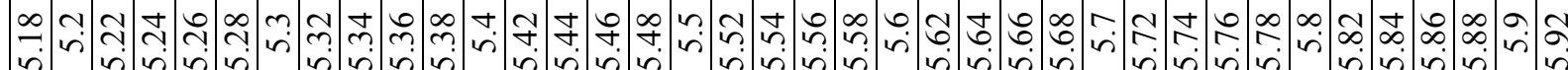

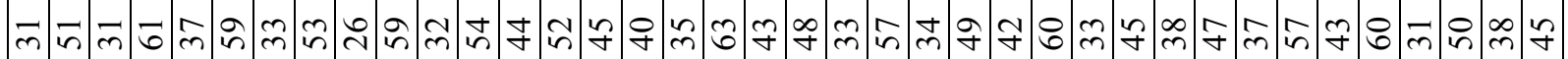

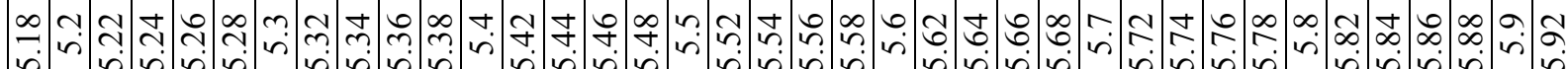

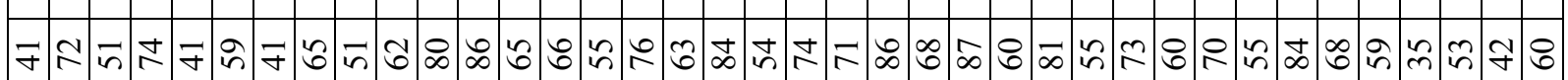

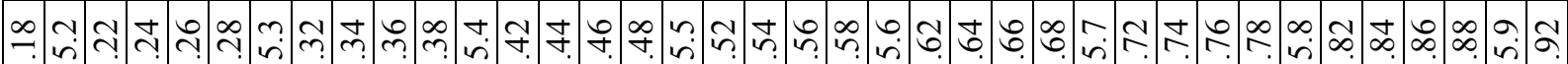

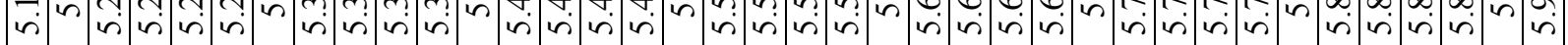

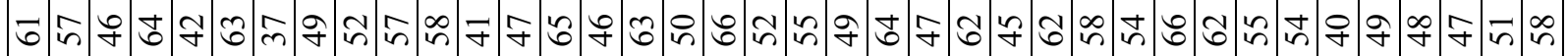

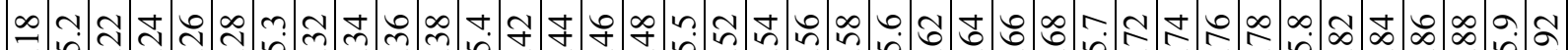

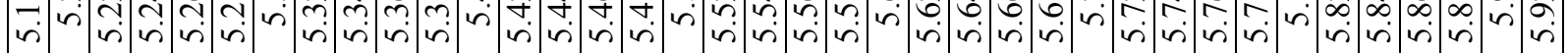

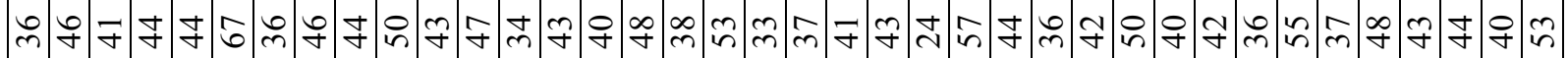

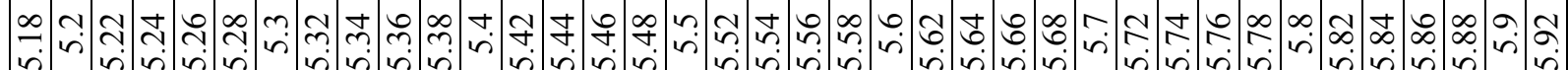

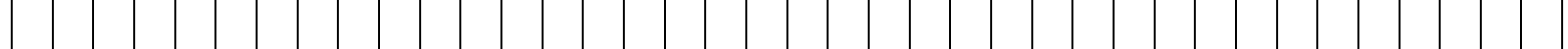




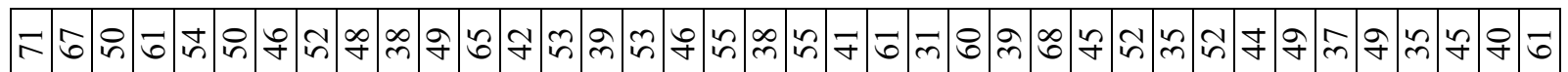

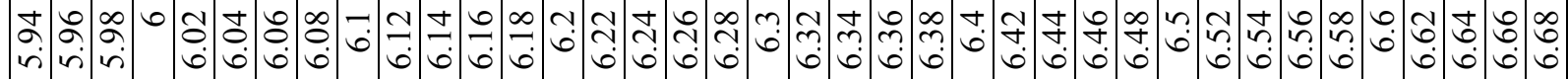

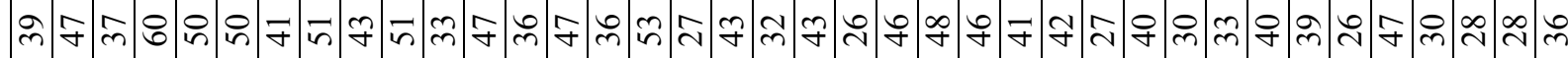

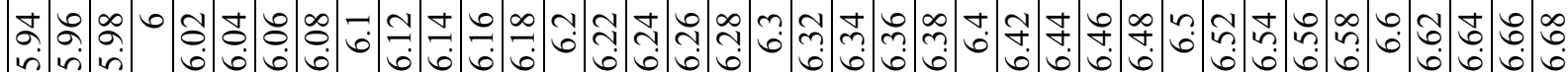

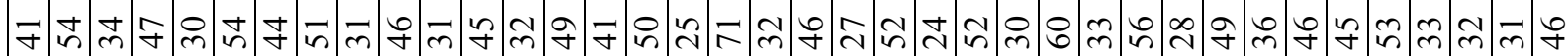

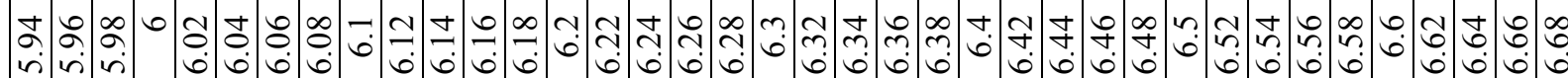

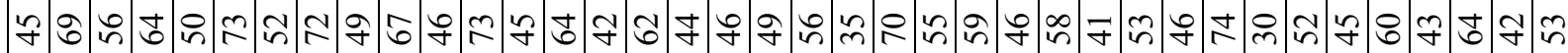

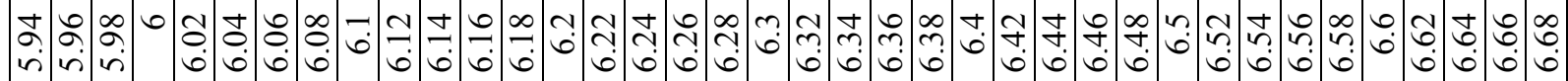

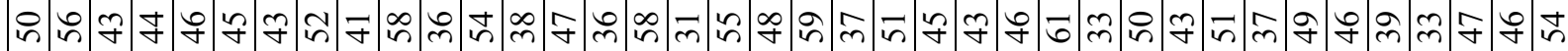

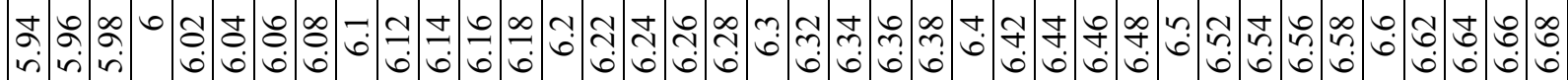

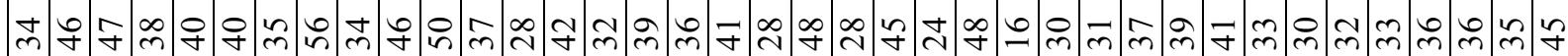

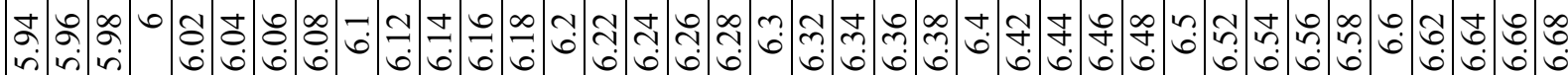

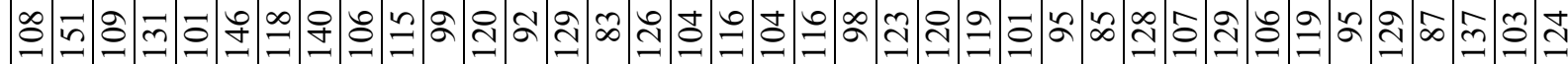

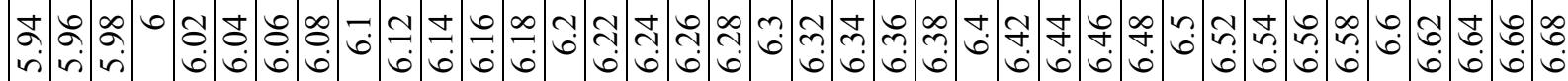




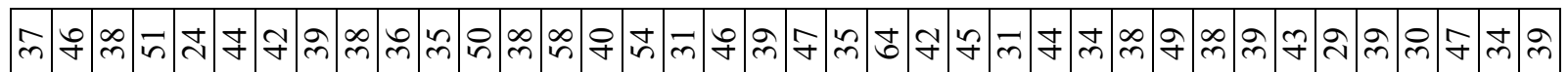
গ.

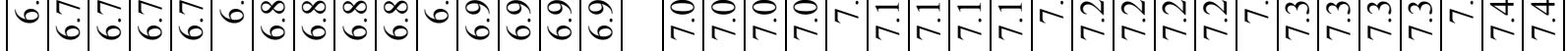

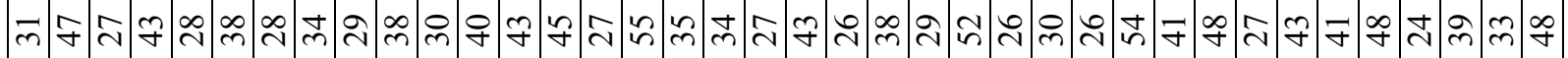

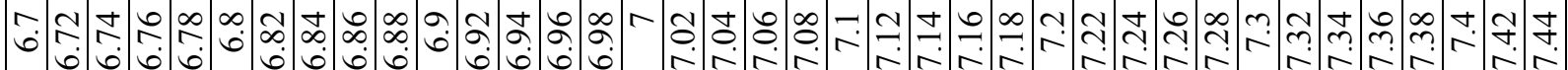

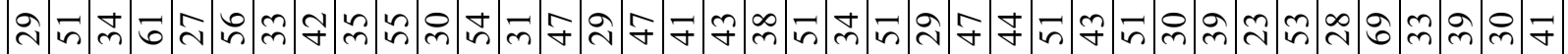

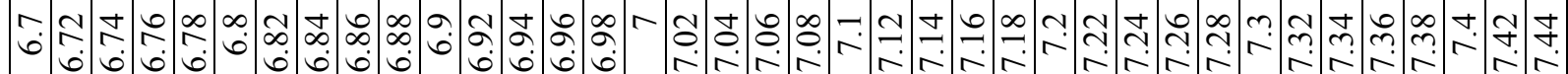
Ұㅇํำ

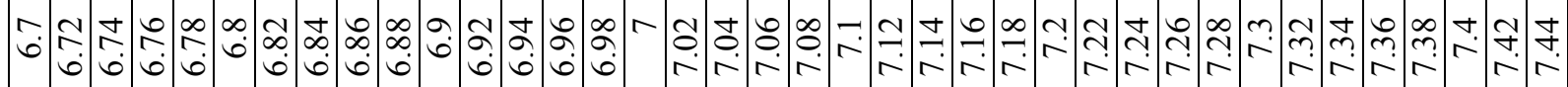

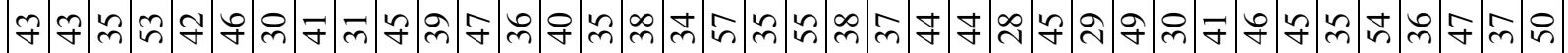

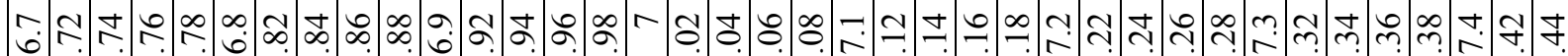

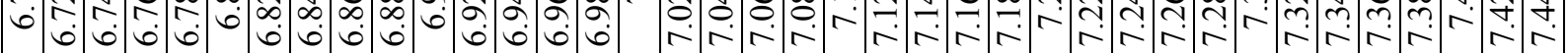

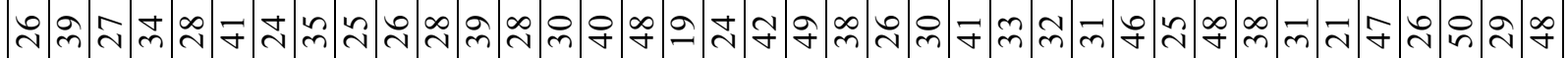

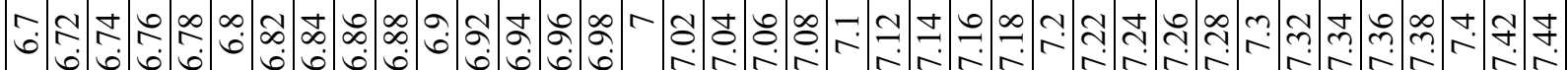

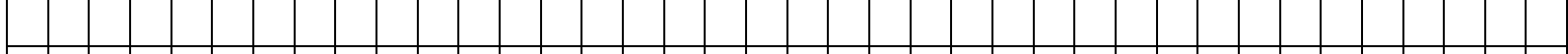
๙

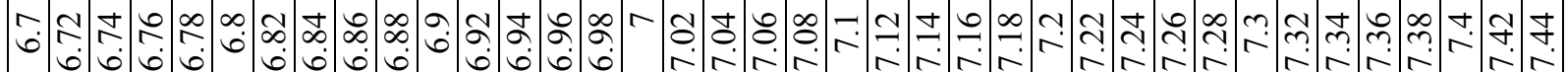




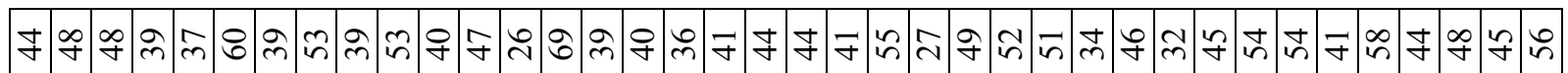

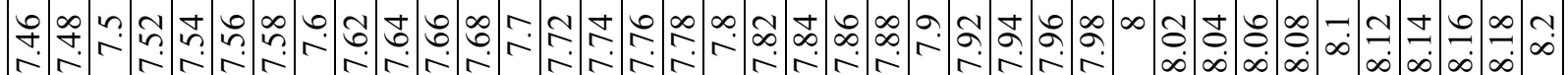

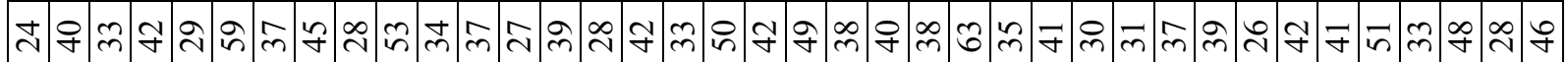

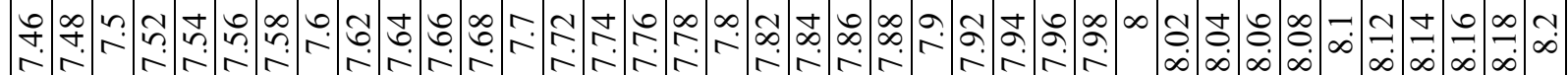

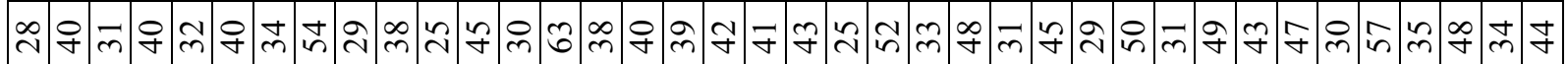

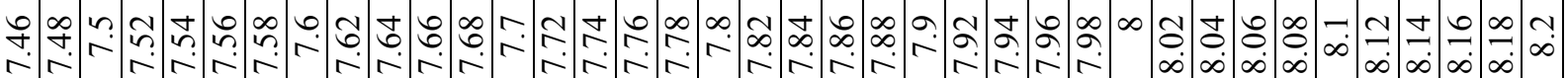

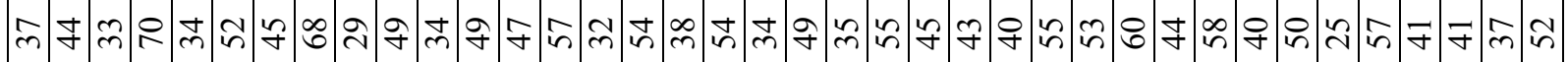

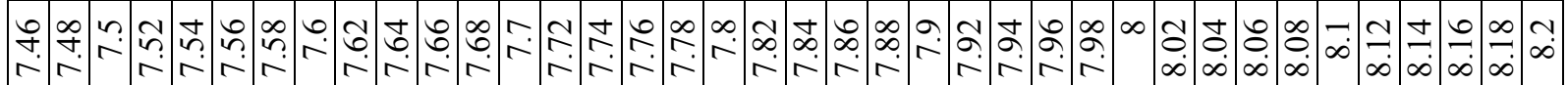

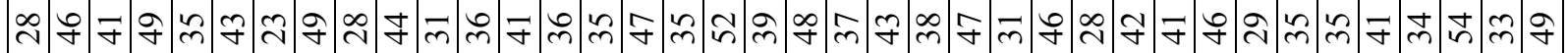

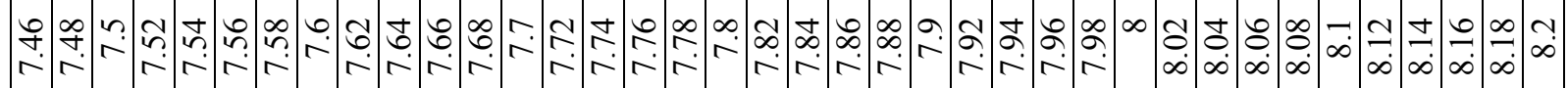

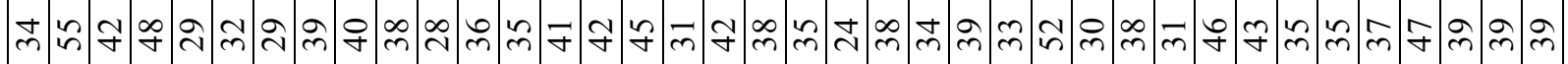

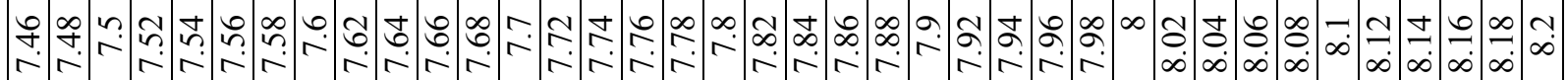

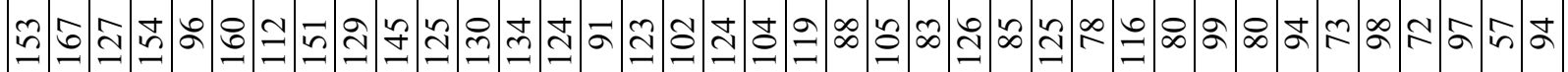

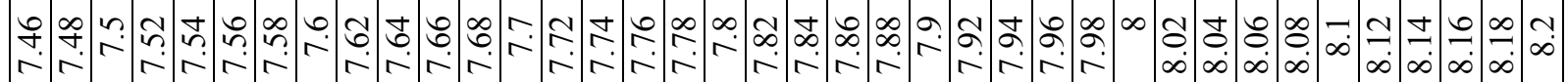


ஸิ

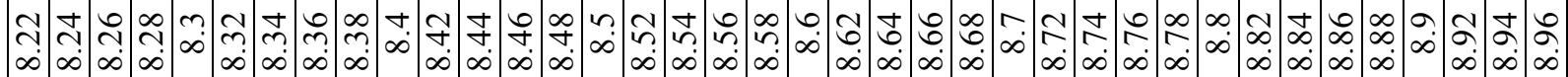

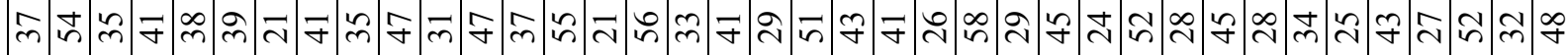

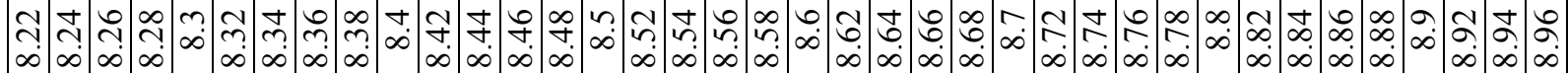

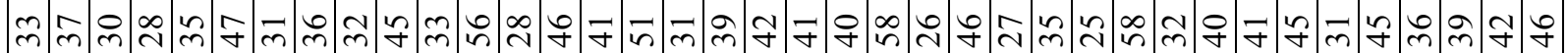

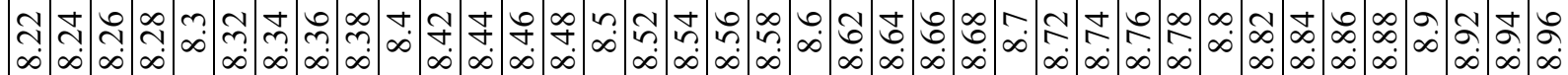

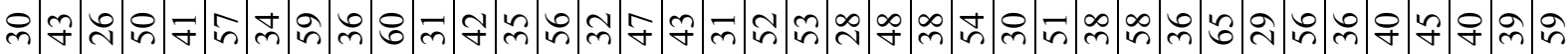

đ̦

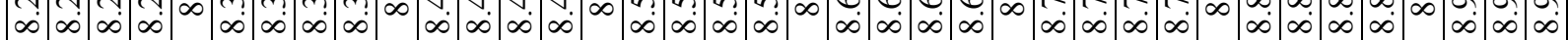

ఫ̛ं

4ป ป

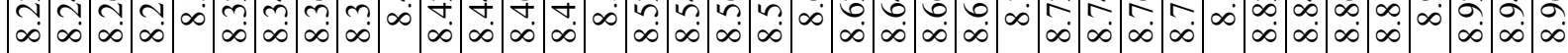

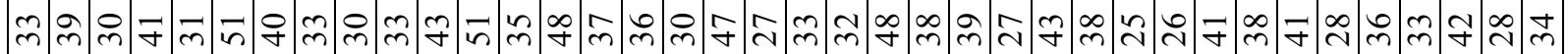

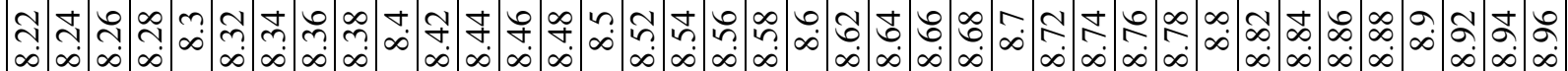

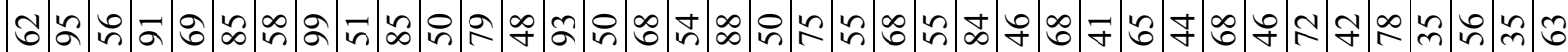

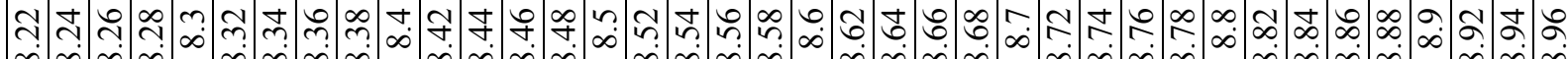

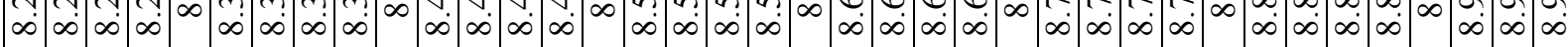




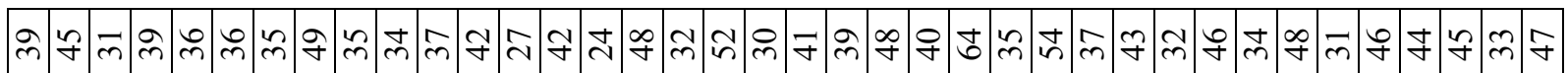

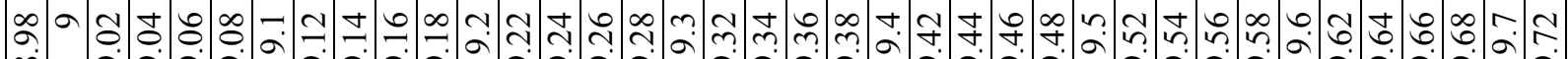

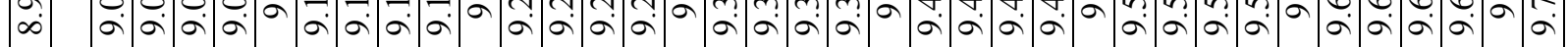

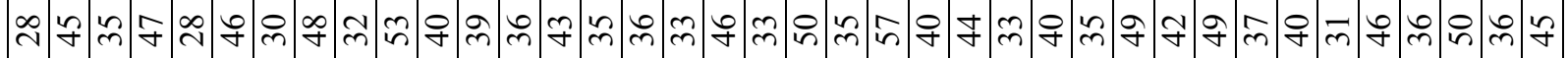

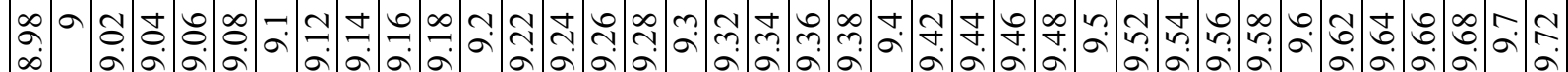

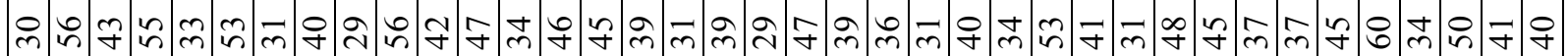

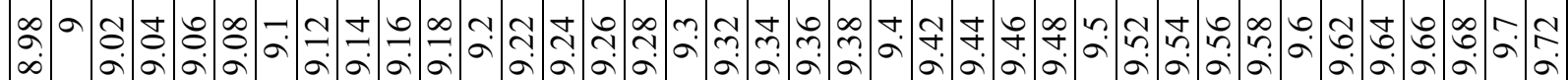

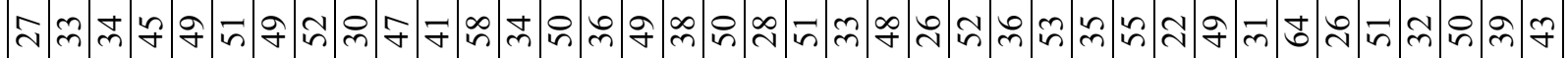

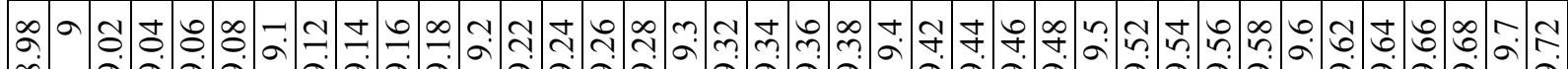

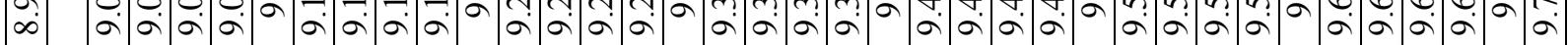

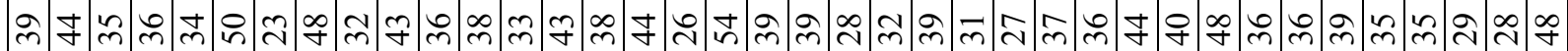

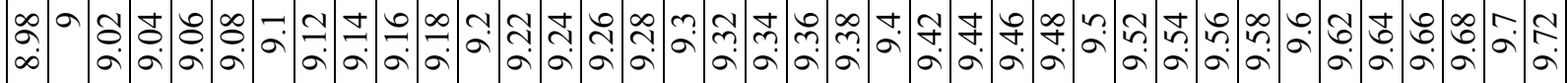

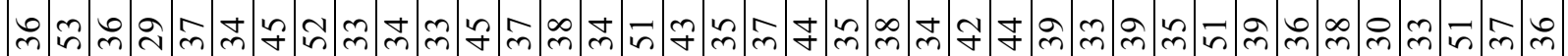

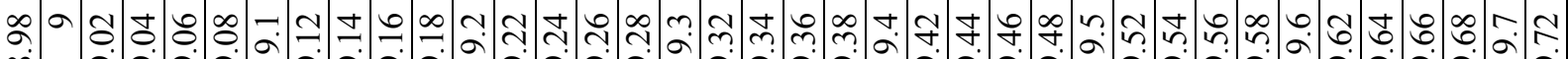

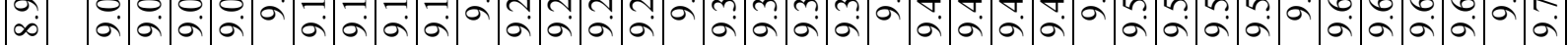

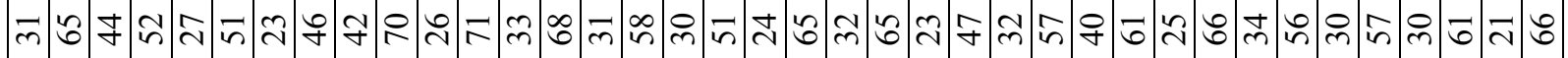

年

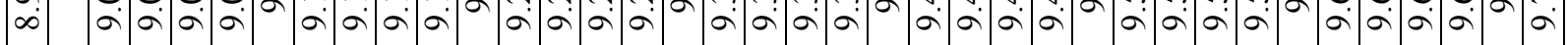


守守守

オ $\div$ ㄴ.

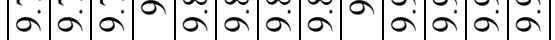

ஸै तิ

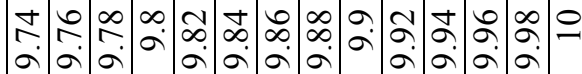

ㄱำ

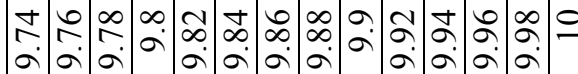

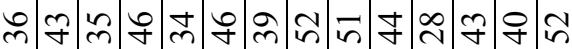

궁․․ aे aे a a

กิษ

구일

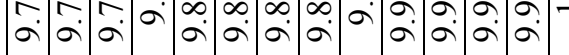

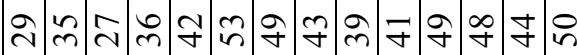

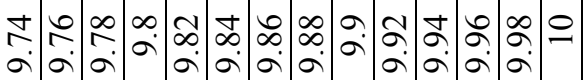

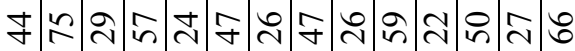

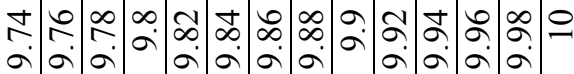

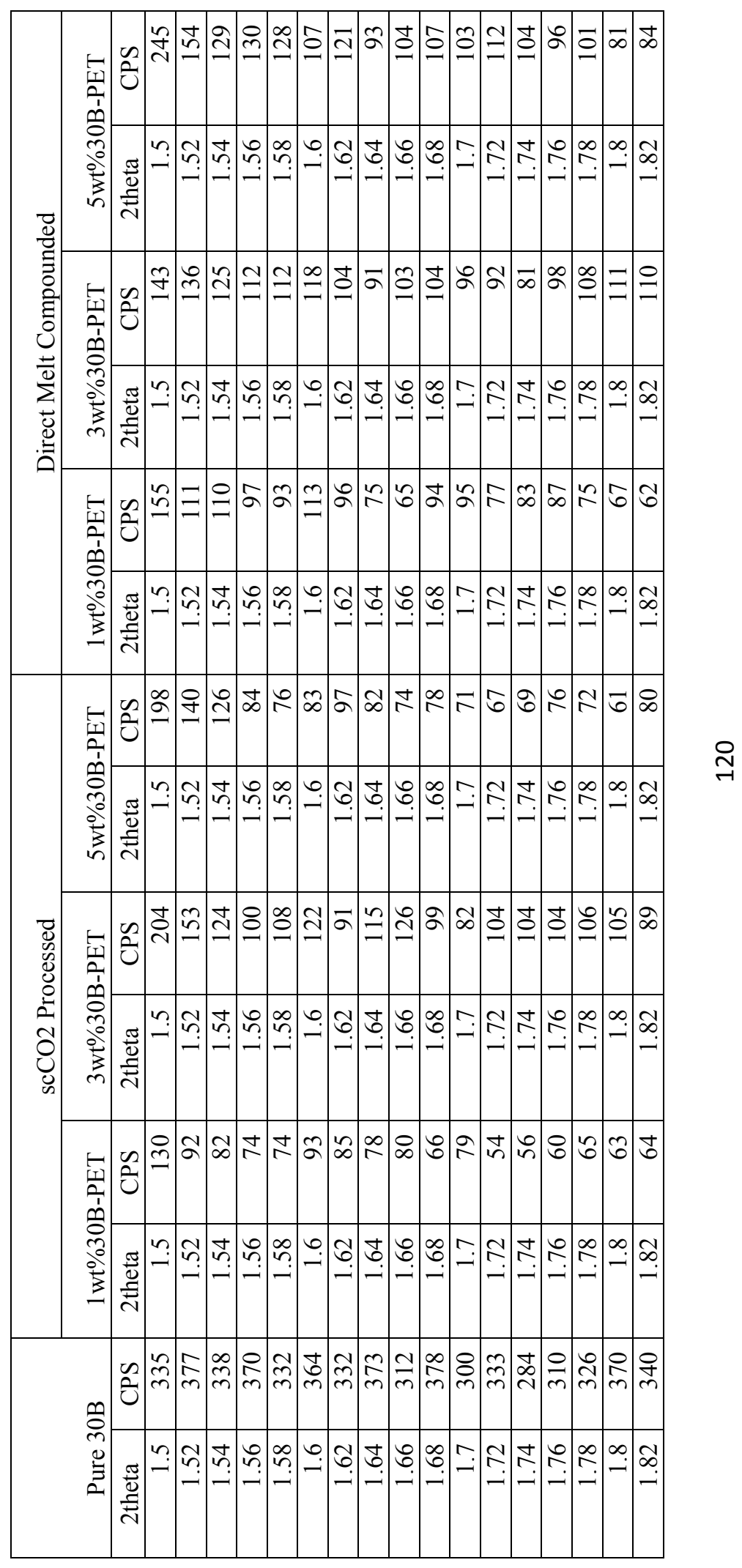


ஓ

म

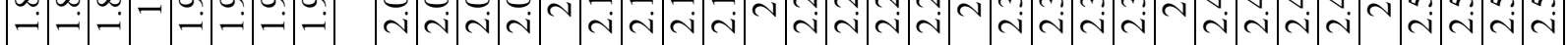

க்

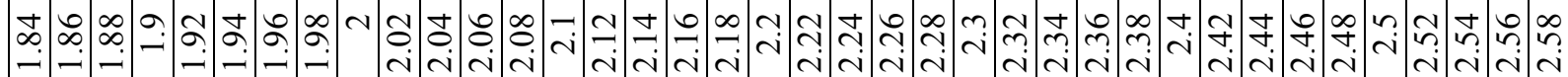



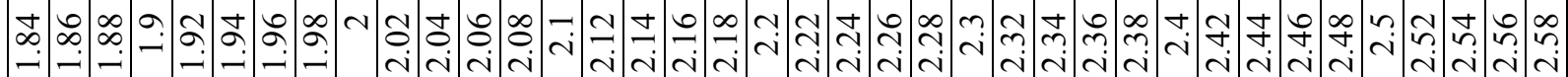

ํำ

ఫ

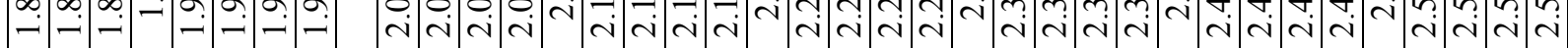

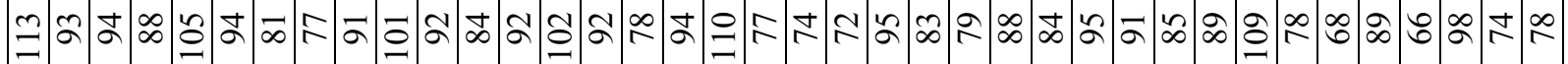

‡.

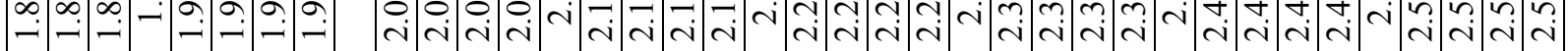

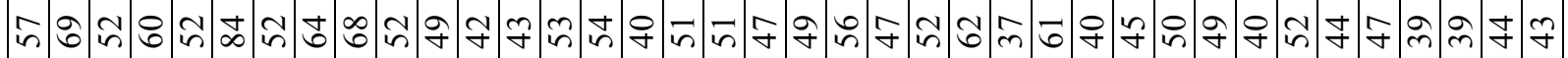



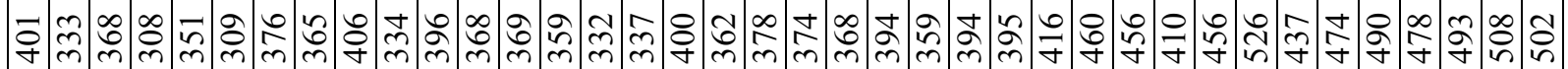

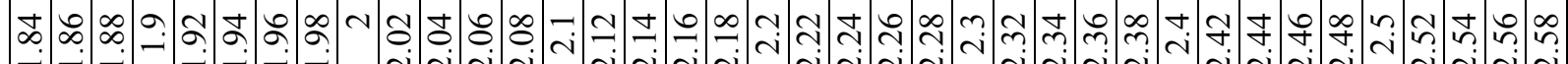

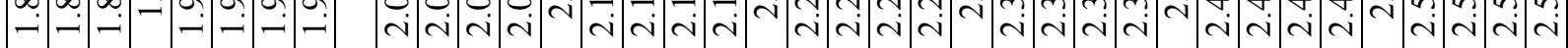




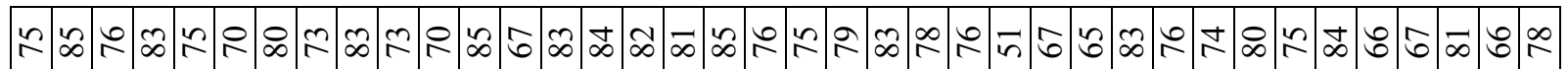

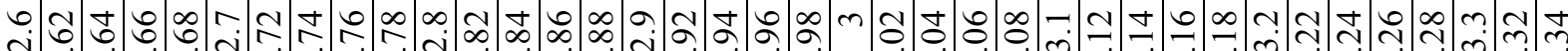

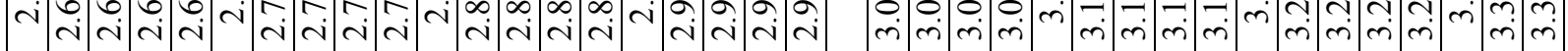

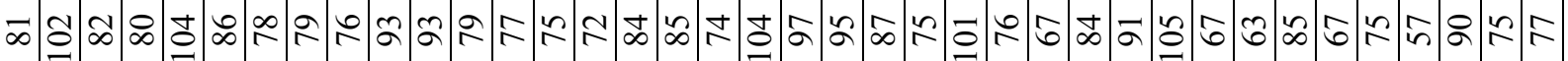

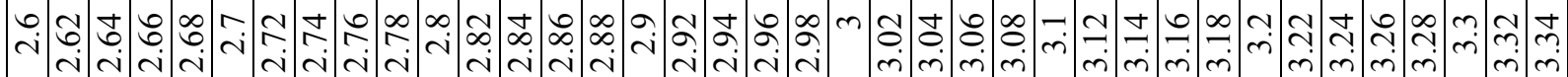

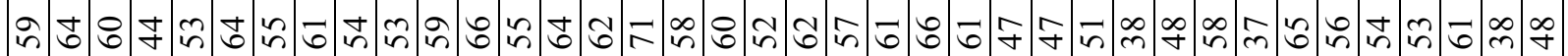

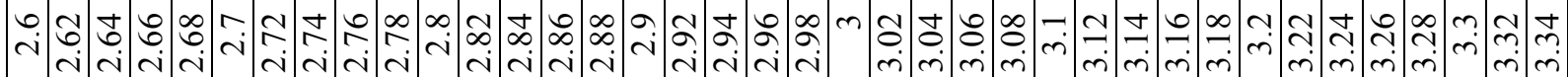

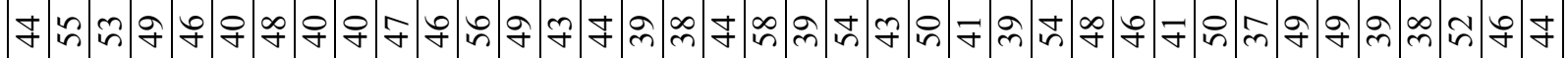

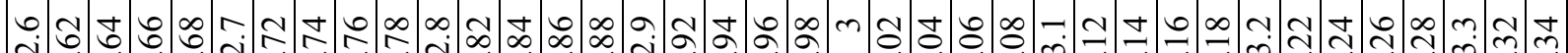

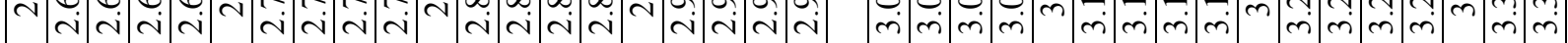

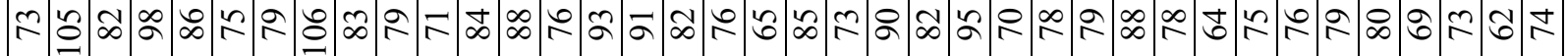

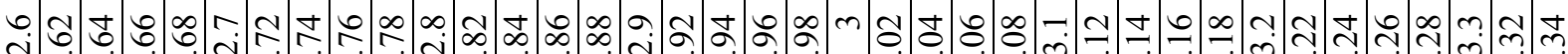

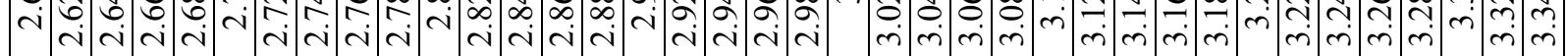

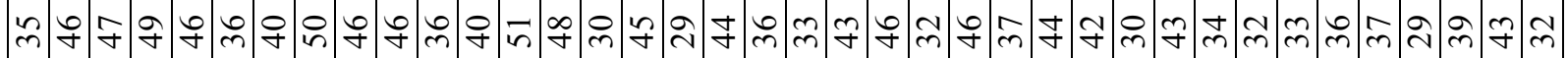

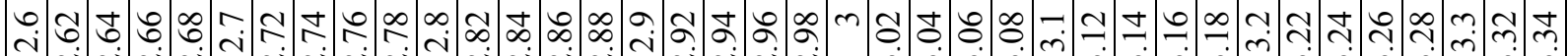

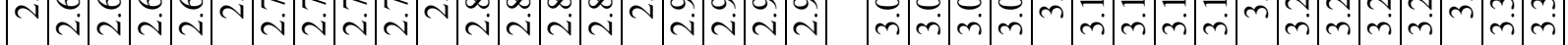

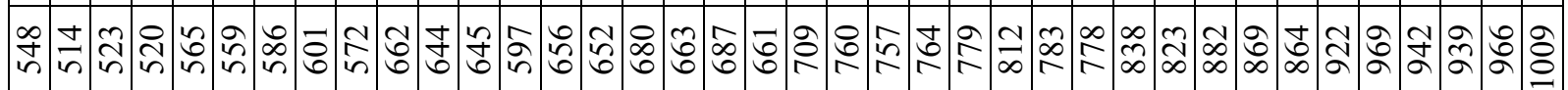

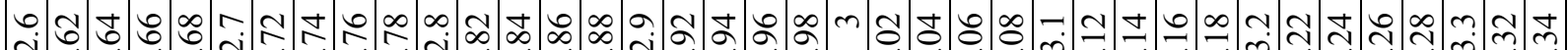

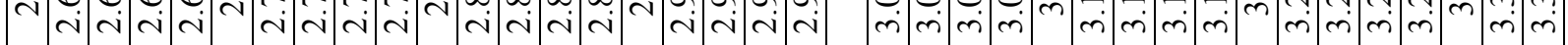




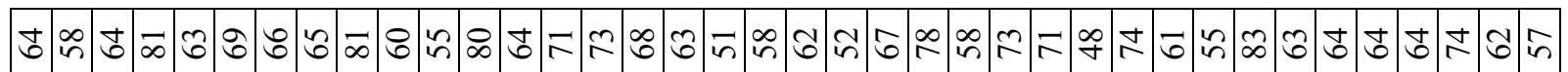

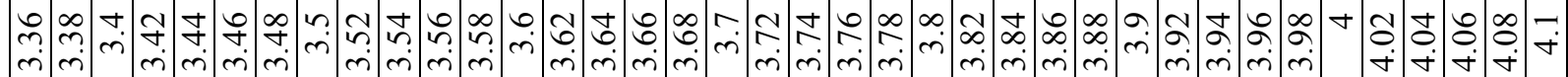

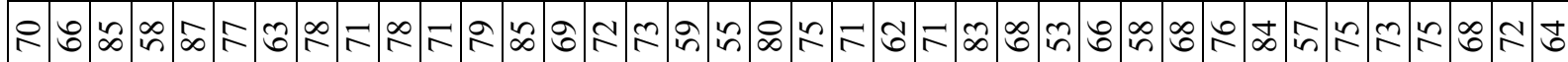

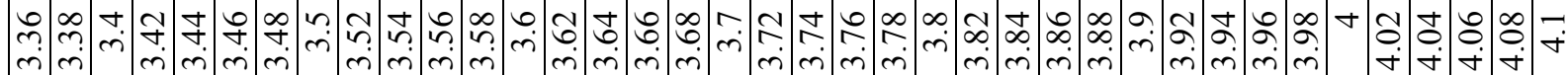

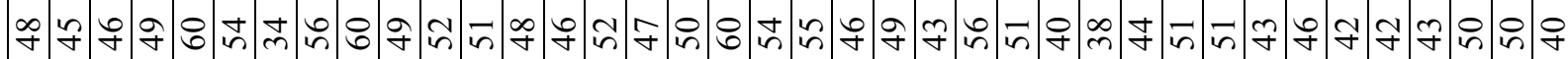

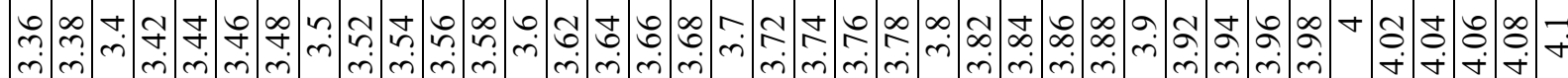

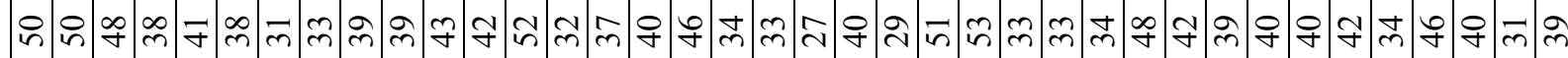

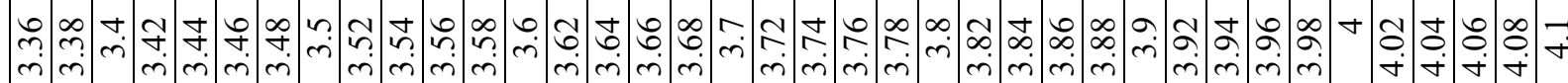

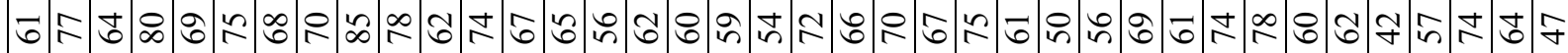

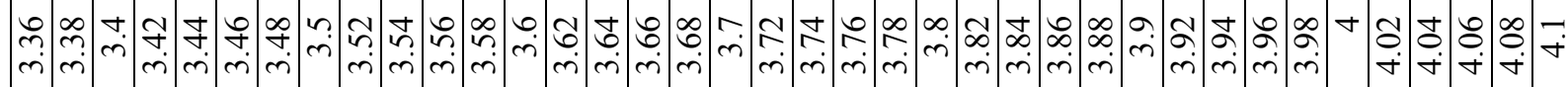

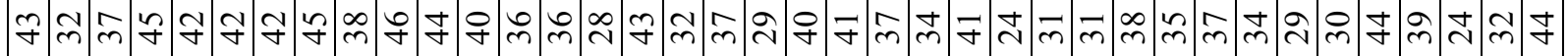

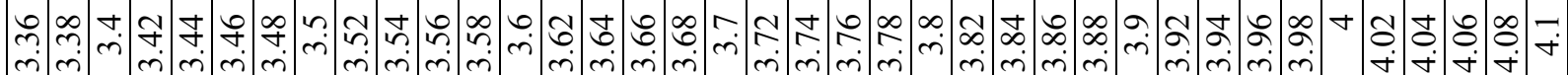
๙a

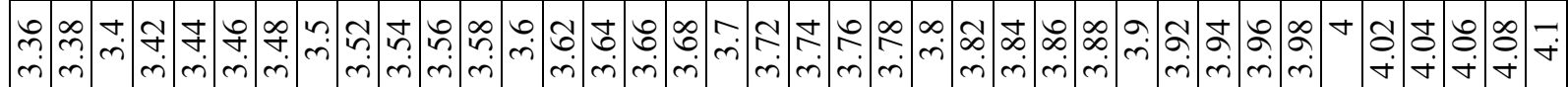




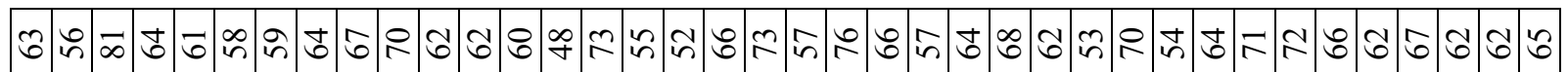

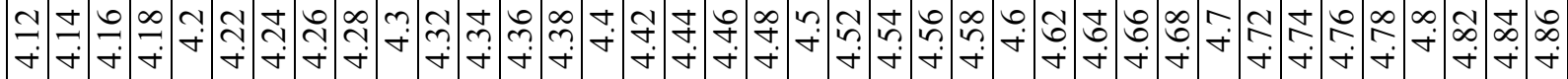

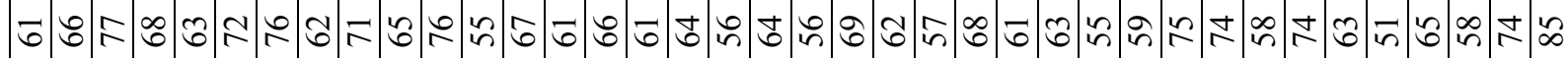

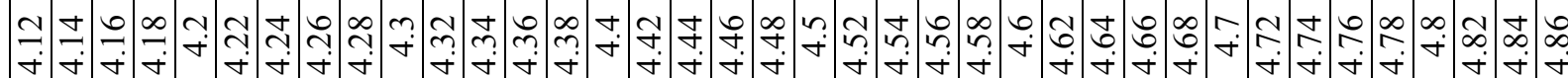

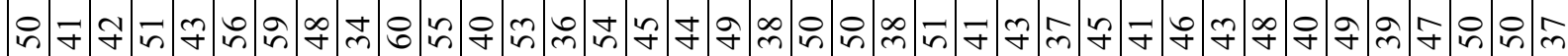

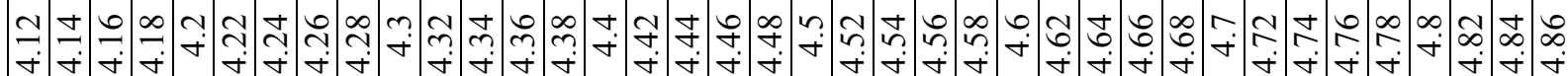

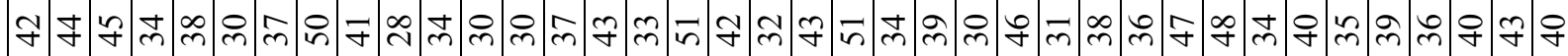

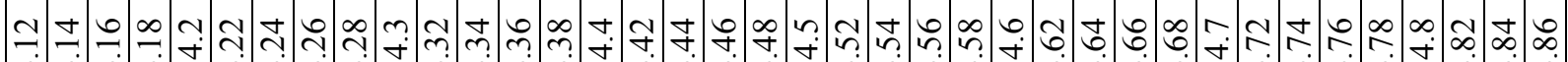

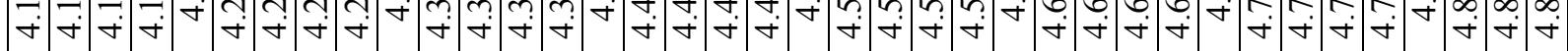

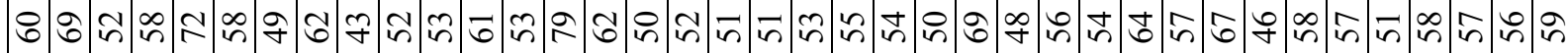
건

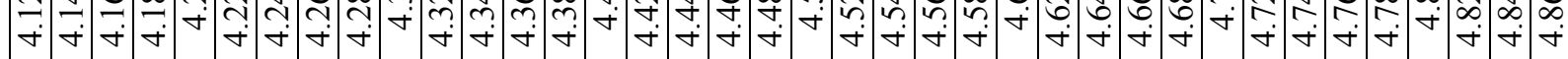

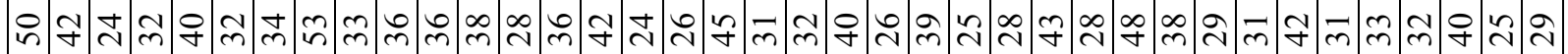

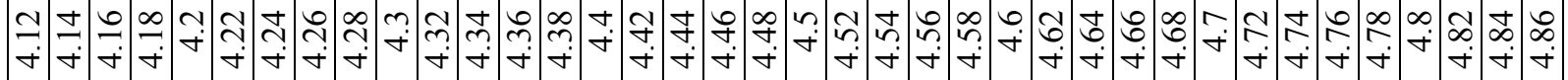

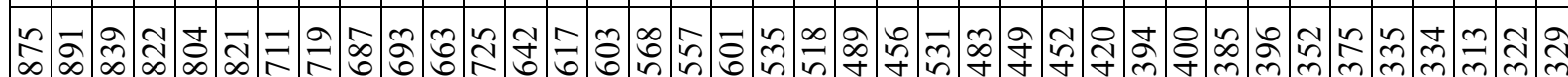

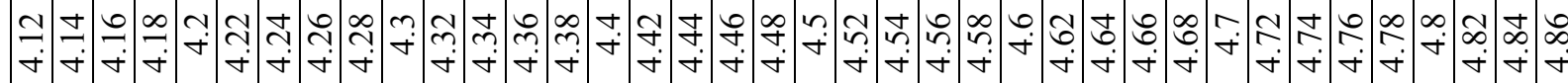




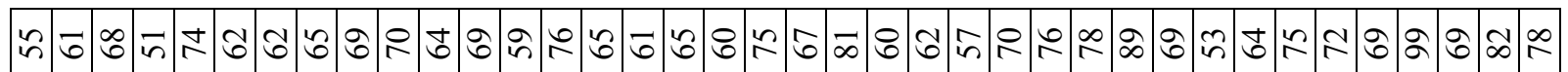

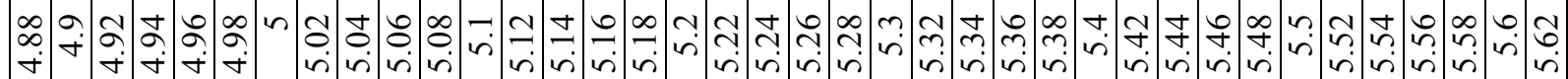

六

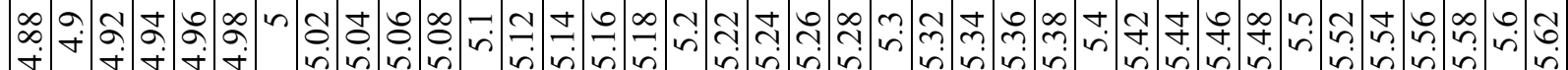

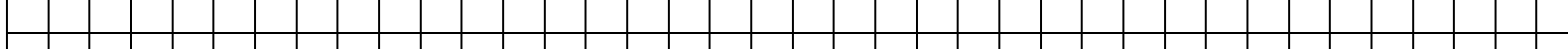

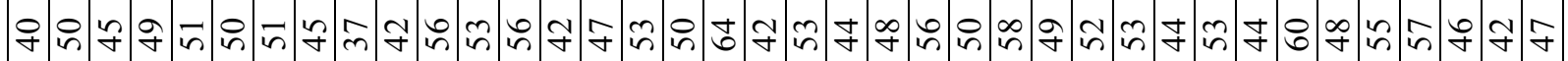

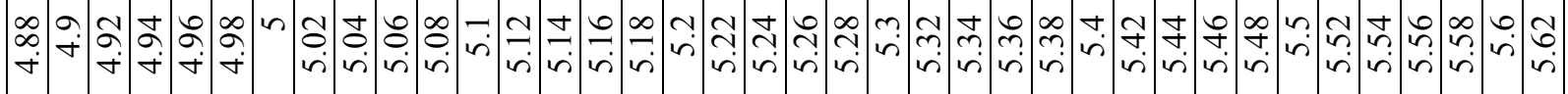

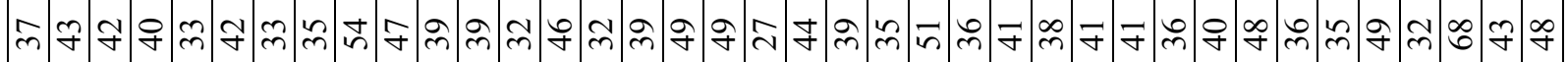

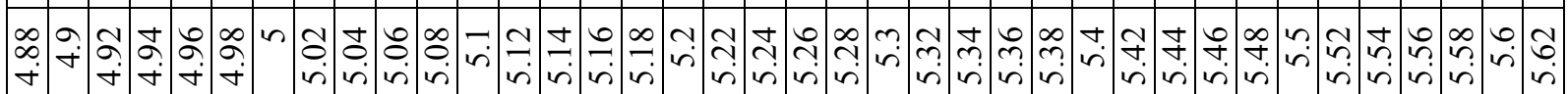

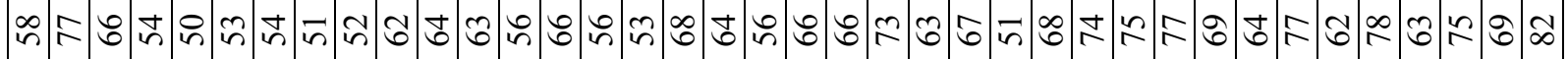

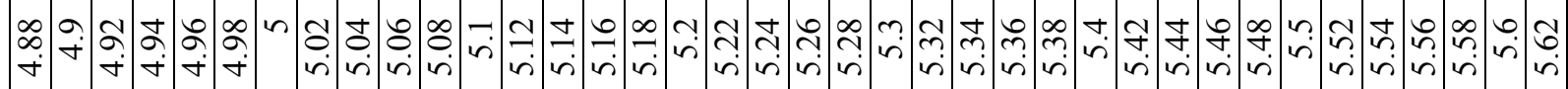

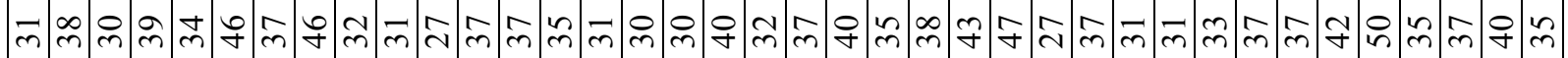

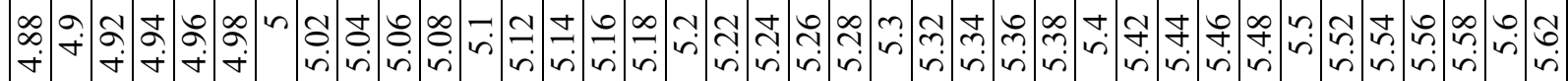

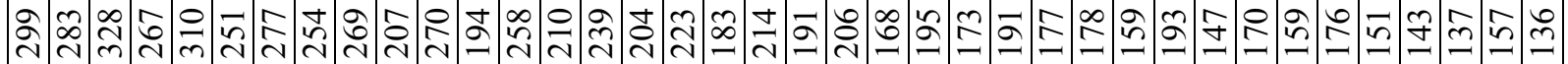

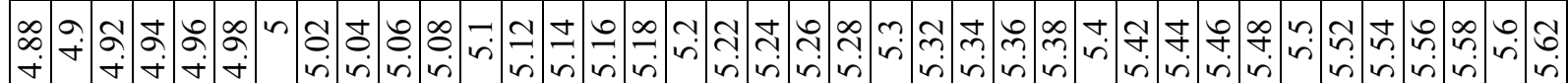


ती

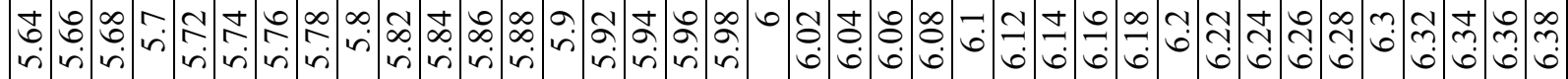

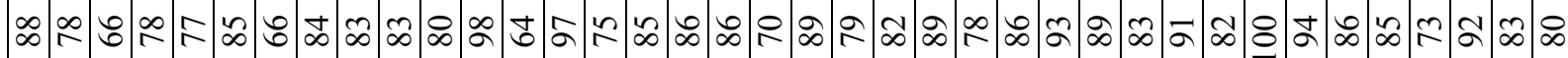

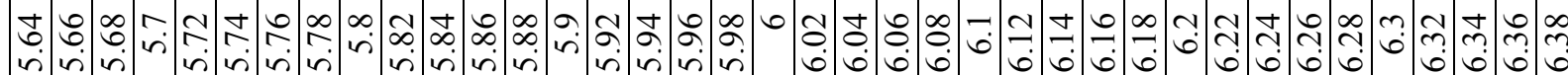

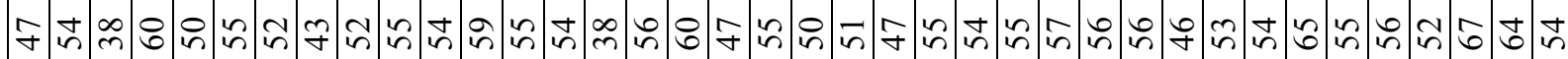

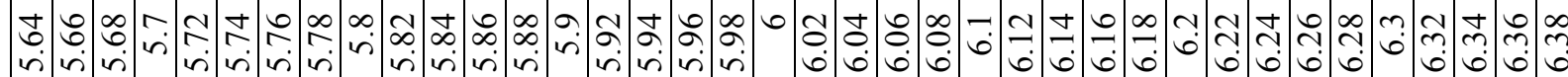

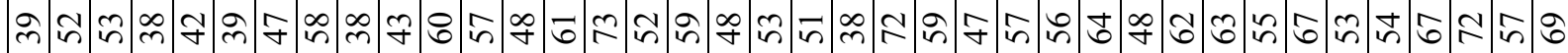

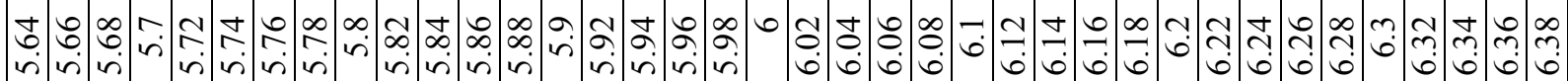

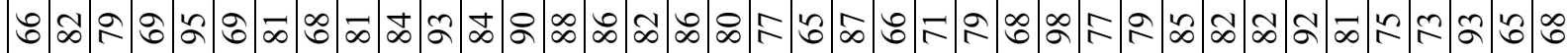
t) ni

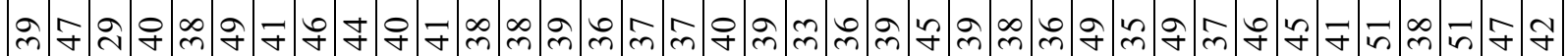

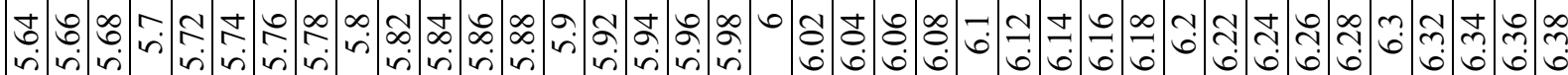
:의

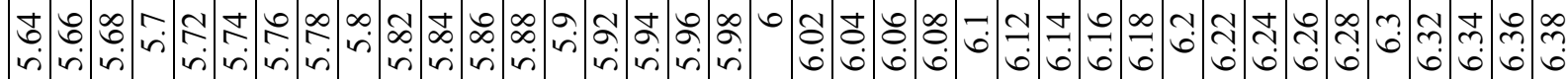




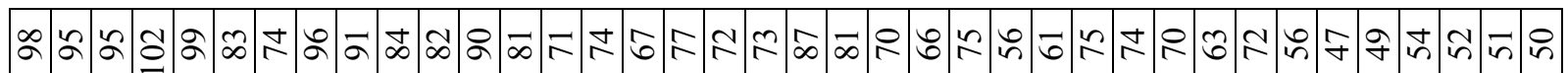

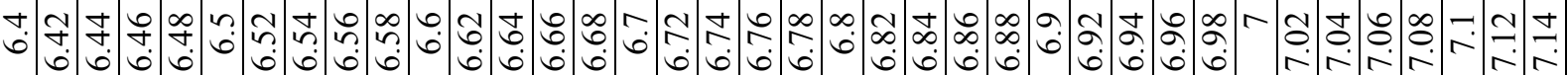

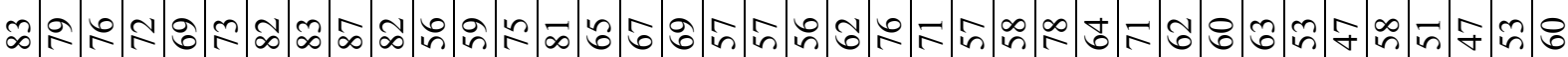

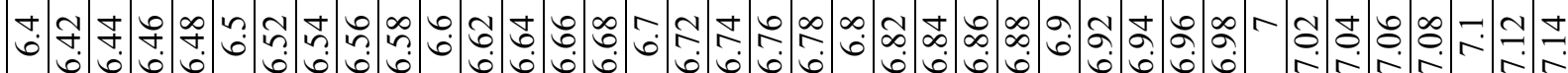

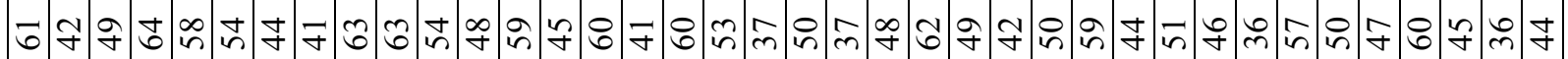

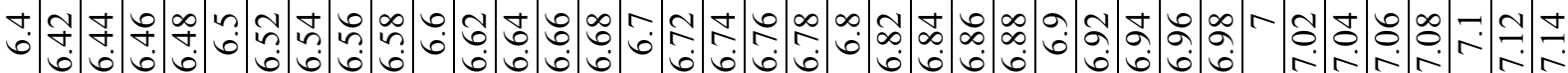

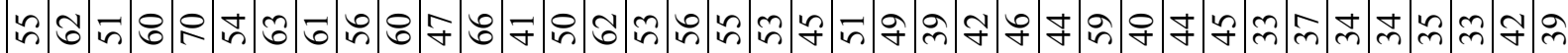

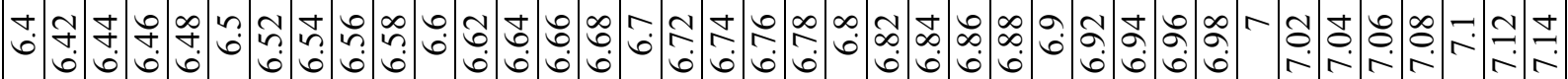

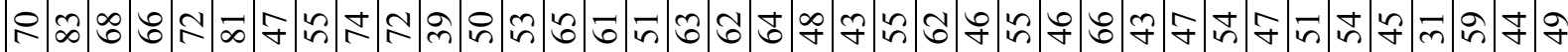

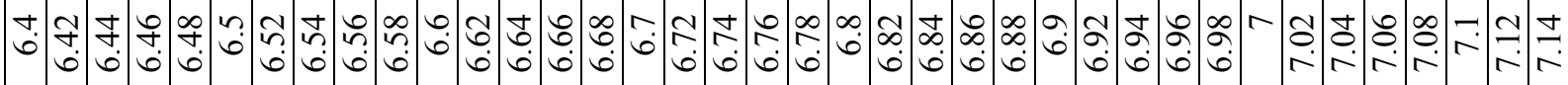

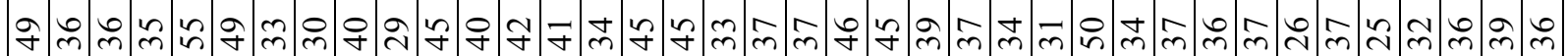



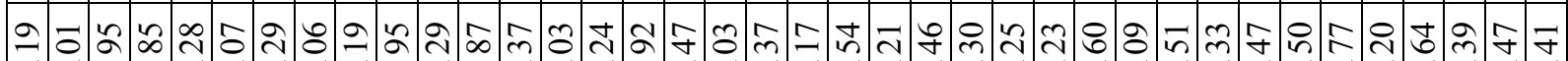

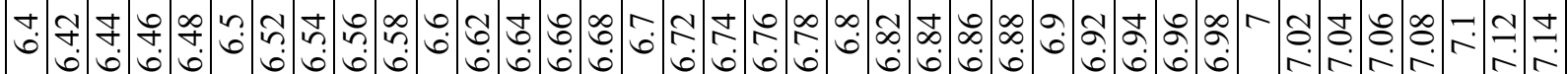




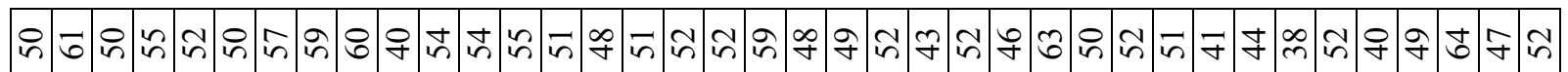

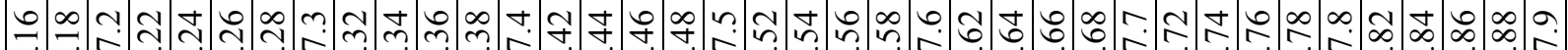

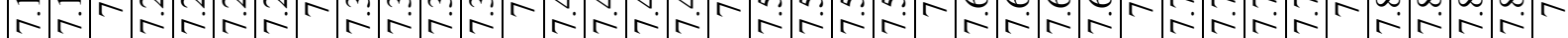



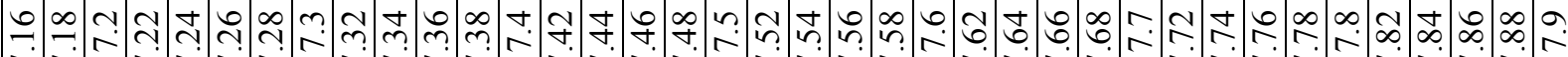

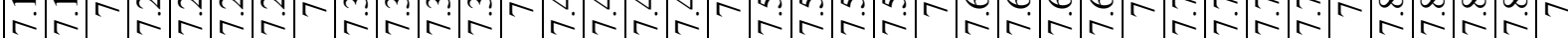

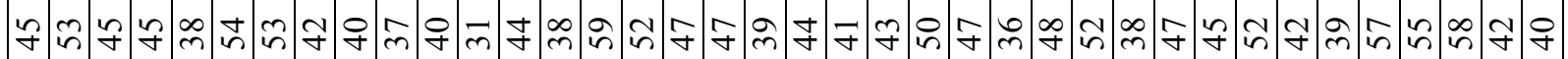

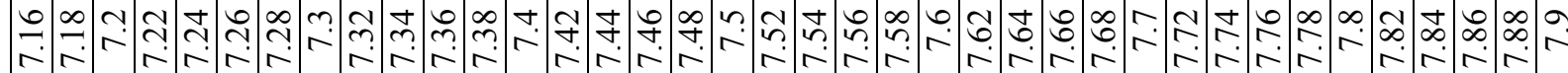

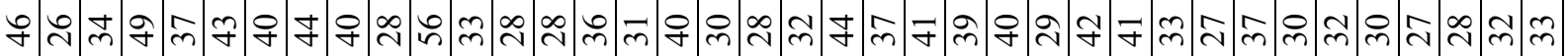

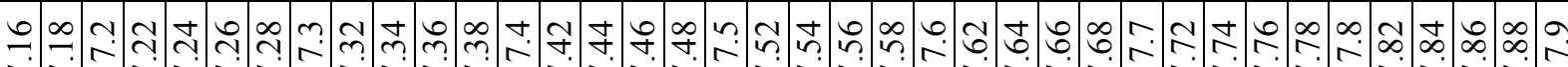

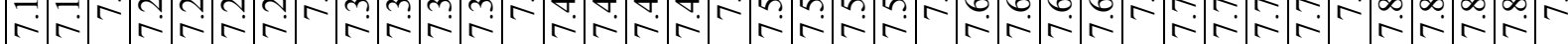

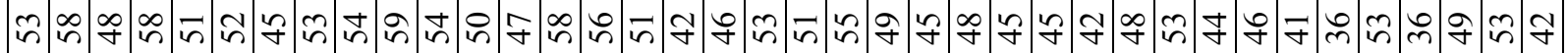

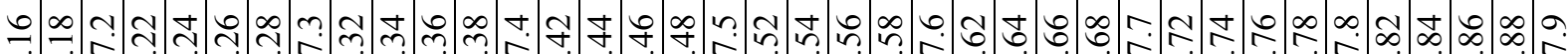

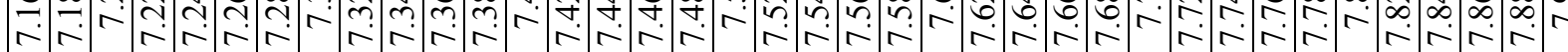

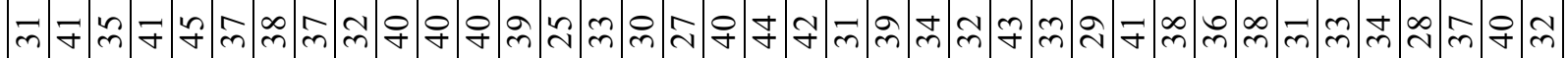

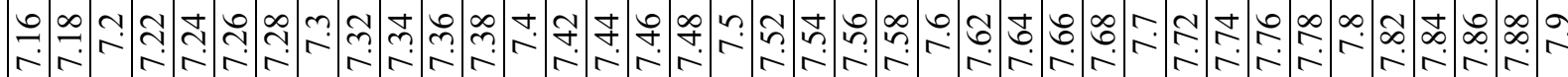

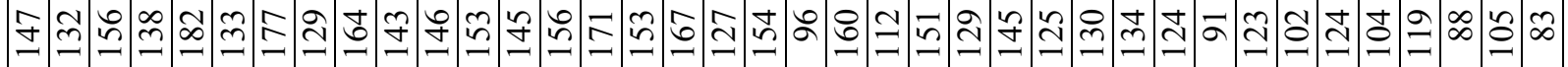

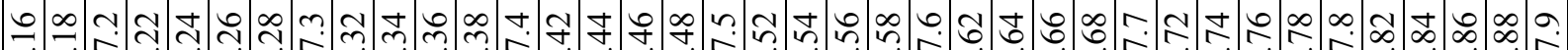

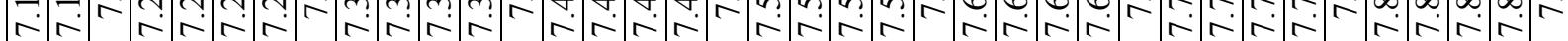




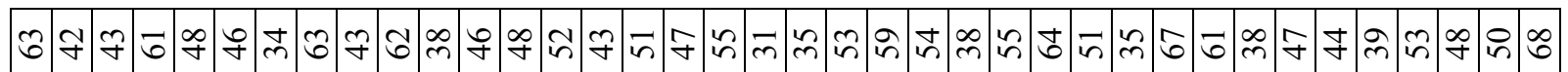

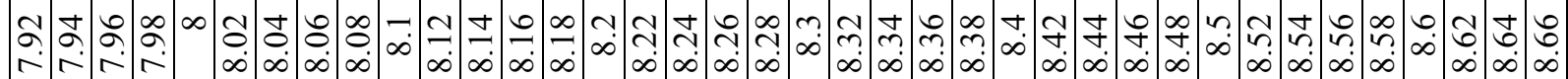

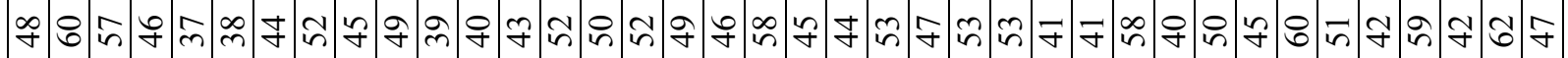

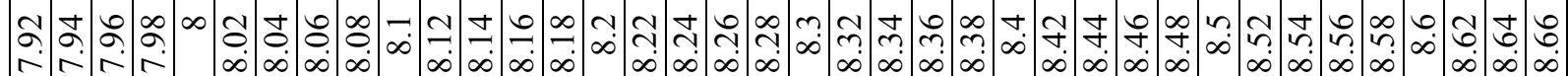

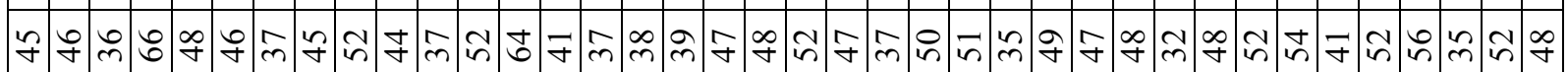

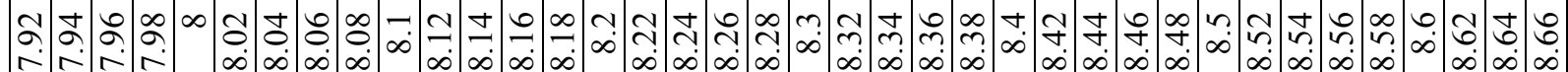

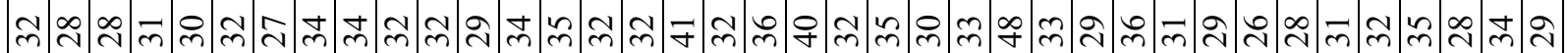
হৃ

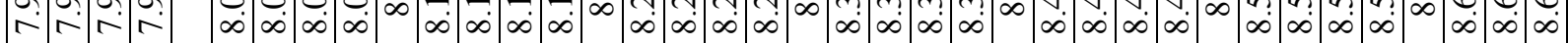

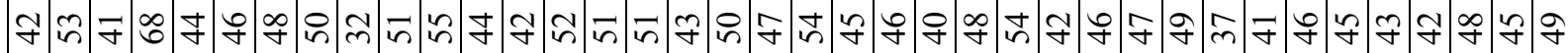

S:

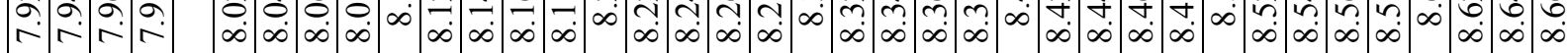

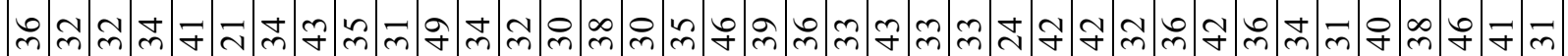

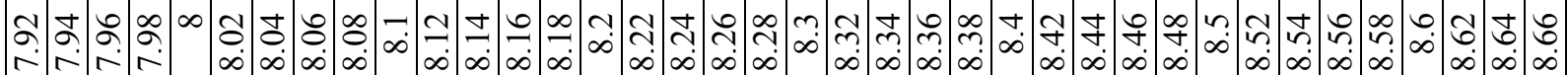

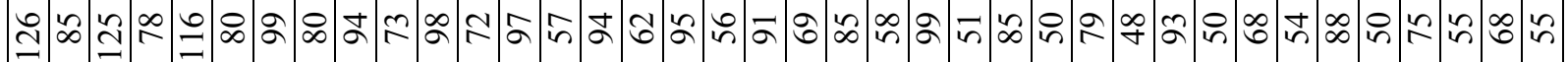

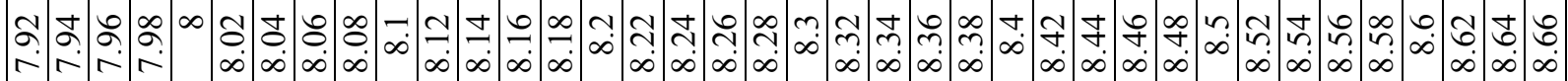


in $m$ m

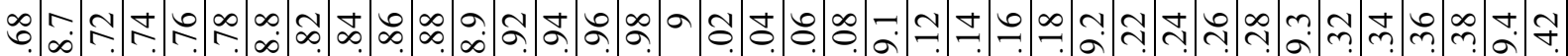

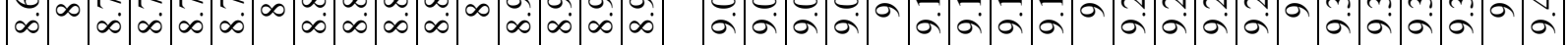

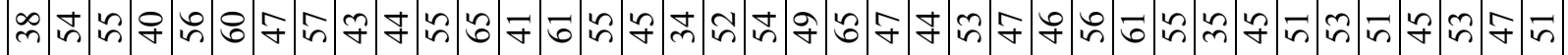

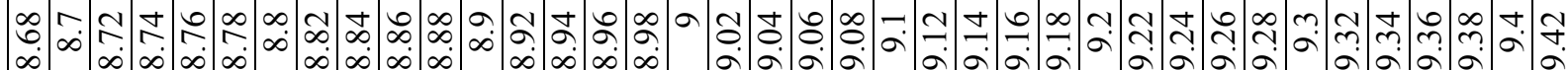



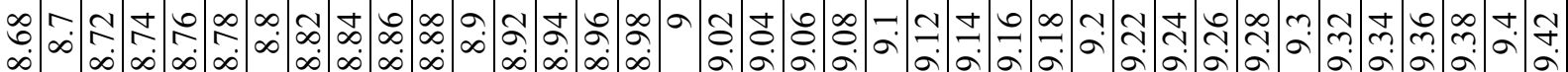

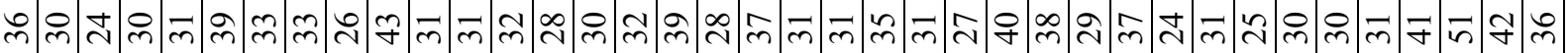

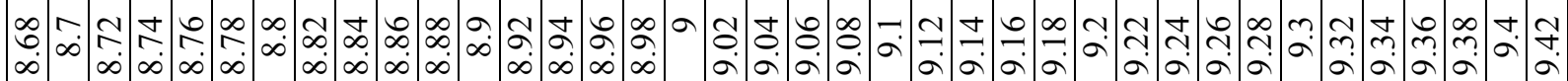

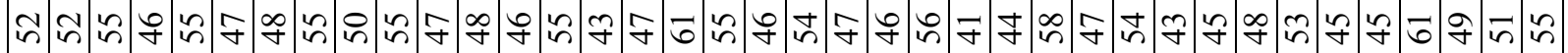

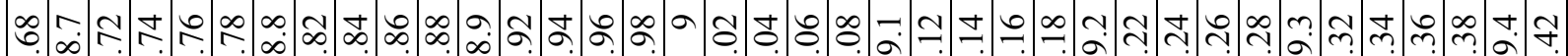

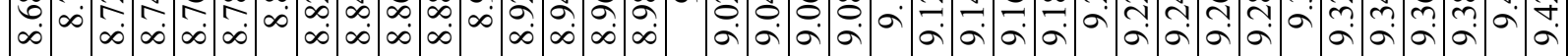

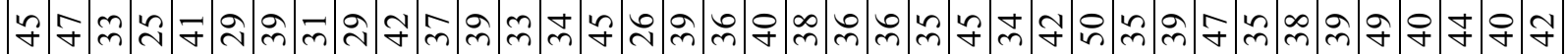

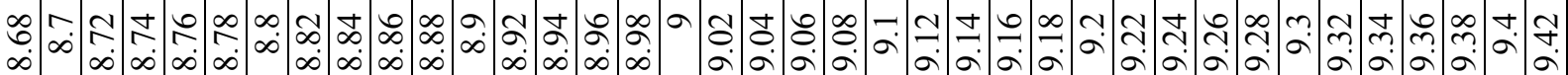



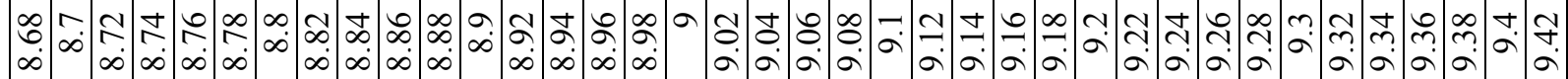




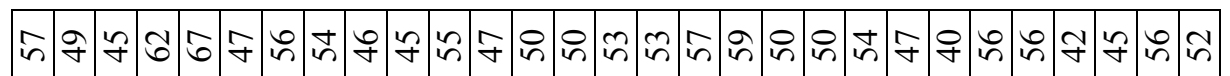

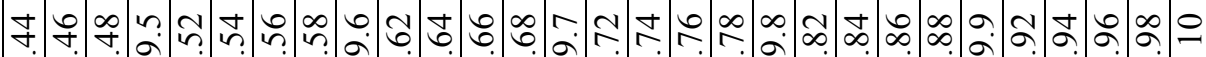

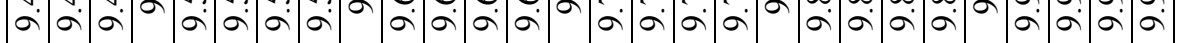

กิ

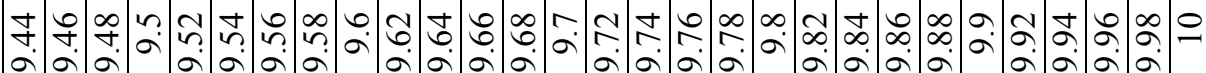

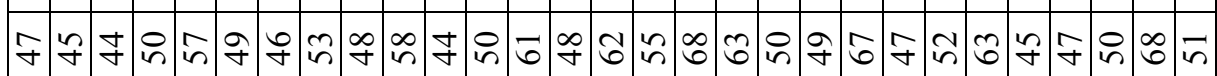

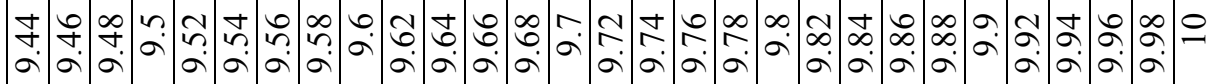

m̄

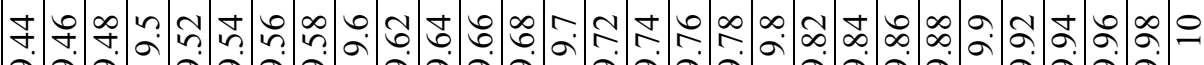



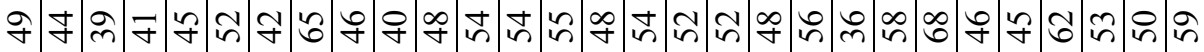

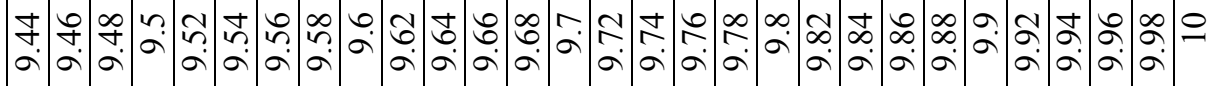

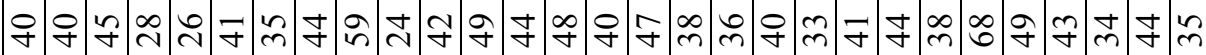

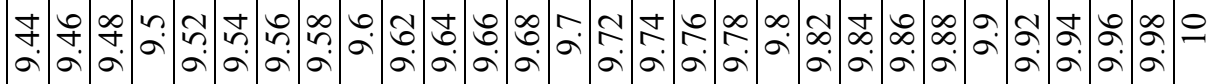

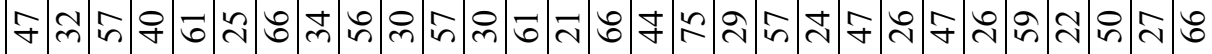






\section{Appendix B: Mechanical Testing Data}




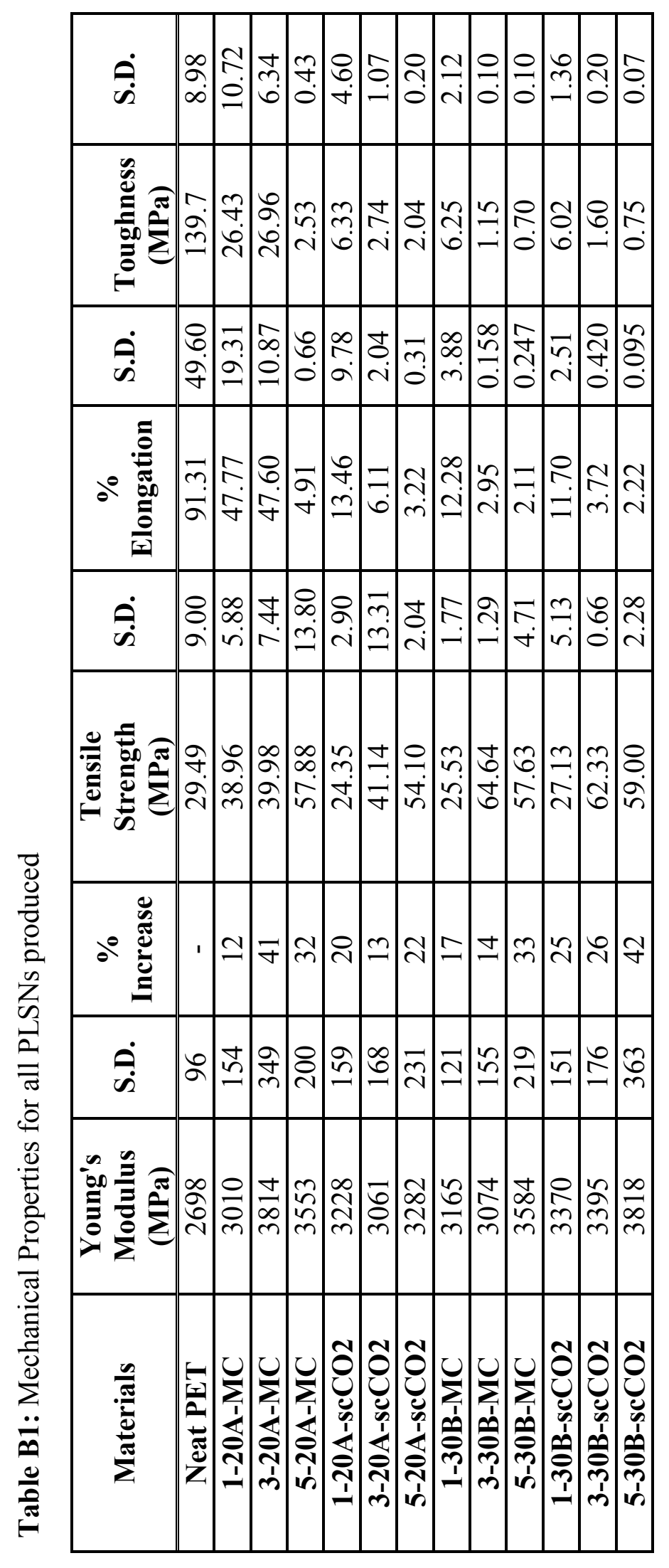


Appendix C: Dynamic Oscillatory Rheological Data 
Table C1: Rheological Data of Neat PET

\begin{tabular}{|c|c|c|c|c|c|c|c|}
\hline frequency & $\mathrm{G}^{\prime}$ & G" & tan delta & Torque & Phase A. & Strain & Eta* \\
\hline $\mathrm{rad} / \mathrm{s}$ & $\mathrm{Pa}$ & $\mathrm{Pa}$ & & $\mathrm{g}-\mathrm{cm}$ & degree & $\%$ & $\mathrm{Pas}$ \\
\hline 0.1 & 0.233588 & 222.261 & 951.5097 & 0.347731 & 89.93978 & 5.00093 & 2222.603 \\
\hline 0.158489 & 1.021882 & 347.3073 & 33.98704 & 0.54359 & 88.31467 & 5.000811 & 2192.311 \\
\hline 0.25119 & 5.378478 & 550.99 & 102.4435 & 0.862156 & 89.44073 & 5.001407 & 2193.622 \\
\hline 0.398109 & 21.88229 & 874.4108 & 39.95975 & 1.368621 & 88.56646 & 5.001526 & 2197.096 \\
\hline 0.630966 & 45.78913 & 1371.693 & 29.95674 & 2.147948 & 88.08809 & 5.002599 & 2175.167 \\
\hline 1.000031 & 91.04624 & 2154.584 & 23.66472 & 3.375095 & 87.58029 & 5.002718 & 2156.441 \\
\hline 1.584961 & 186.8233 & 3371.591 & 18.04695 & 5.285644 & 86.82842 & 5.003433 & 2130.502 \\
\hline 2.512024 & 382.9019 & 5262.87 & 13.74469 & 8.265053 & 85.83876 & 5.006652 & 2100.609 \\
\hline 3.981323 & 738.46 & 8168.137 & 11.06104 & 12.85393 & 84.83408 & 5.009751 & 2059.981 \\
\hline 6.310059 & 1457.455 & 12573.45 & 8.626986 & 19.85972 & 83.38805 & 5.015235 & 2005.946 \\
\hline 10.00073 & 2794.345 & 19191.42 & 6.867948 & 30.4699 & 81.71573 & 5.02203 & 1939.236 \\
\hline 15.8501 & 5270.677 & 29011.79 & 5.504376 & 46.3897 & 79.70317 & 5.028825 & 1860.347 \\
\hline 25.12061 & 9721.315 & 43268.59 & 4.450899 & 69.82847 & 77.33741 & 5.033116 & 1765.372 \\
\hline 39.81348 & 17505.53 & 63413.97 & 3.62251 & 103.3474 & 74.56774 & 5.021553 & 1652.351 \\
\hline 63.10059 & 30539.92 & 90927.99 & 2.977349 & 148.7193 & 71.43438 & 4.955988 & 1520.108 \\
\hline 100 & 51355.85 & 126822.1 & 2.469477 & 203.3502 & 67.95481 & 4.750591 & 1368.257 \\
\hline
\end{tabular}

Table C2: Rheological Data of Extruded PET

\begin{tabular}{|r|c|c|c|c|c|r|r|}
\hline frequency & G' & G" & tan delta & Torque & Phase A. & \multicolumn{1}{c|}{ Strain } & \multicolumn{1}{c|}{ Eta* $^{*}$} \\
\hline rad/s & $\mathrm{Pa}$ & $\mathrm{Pa}$ & & $\mathrm{g}-\mathrm{cm}$ & degree & \multicolumn{1}{c|}{$\%$} & \multicolumn{1}{c|}{ Pa s } \\
\hline & & & & & & & \\
\hline 0.1 & 0.622695 & 128.7847 & 206.8183 & 0.151041 & 89.722969 & 4.998446 & 1287.858 \\
\hline 0.158489 & 3.026331 & 199.9771 & 66.07904 & 0.234533 & 89.132988 & 4.99785 & 1261.915 \\
\hline 0.25119 & 6.803426 & 314.0086 & 46.15448 & 0.368401 & 88.758804 & 4.999042 & 1250.376 \\
\hline 0.398109 & 12.61276 & 490.4873 & 38.88818 & 0.575487 & 88.526978 & 4.998893 & 1232.449 \\
\hline 0.630966 & 26.76509 & 766.4308 & 28.63547 & 0.899636 & 87.999947 & 4.999638 & 1215.434 \\
\hline 1.000031 & 51.97874 & 1197.504 & 23.03835 & 1.406305 & 87.514587 & 5.000382 & 1198.595 \\
\hline 1.584961 & 101.5352 & 1869.591 & 18.41322 & 2.197335 & 86.891388 & 5.001724 & 1181.32 \\
\hline 2.512024 & 186.7202 & 2918.142 & 15.62842 & 3.434315 & 86.338867 & 5.005598 & 1164.045 \\
\hline 3.981323 & 356.3275 & 4516.581 & 12.67537 & 5.326197 & 85.489098 & 5.010366 & 1137.967 \\
\hline 6.310059 & 650.4872 & 6995.15 & 10.75371 & 8.270039 & 84.687279 & 5.017072 & 1113.354 \\
\hline 10.00073 & 1251.665 & 10772.42 & 8.606473 & 12.78946 & 83.372429 & 5.026162 & 1084.41 \\
\hline 15.8501 & 2333.189 & 16451.93 & 7.051261 & 19.63901 & 81.928223 & 5.037189 & 1048.356 \\
\hline 25.12061 & 4352.482 & 24887.69 & 5.718045 & 29.92377 & 80.080147 & 5.047769 & 1005.764 \\
\hline 39.81348 & 7981.639 & 37220.24 & 4.663232 & 45.02909 & 77.896599 & 5.04151 & 956.1191 \\
\hline 63.10059 & 14323.89 & 54720.02 & 3.820192 & 66.10085 & 75.331001 & 4.980564 & 896.4057 \\
\hline 100 & 25112.68 & 78642.01 & 3.131566 & 92.66654 & 72.290207 & 4.784018 & 825.543 \\
\hline
\end{tabular}


Table C3: Rheological Data of $1 \mathrm{wt} \% 20 \mathrm{~A}-\mathrm{PET}$ using scCO2

\begin{tabular}{|c|c|c|c|c|c|c|c|}
\hline frequency & $G^{\prime}$ & G" & tan delta & Torque & Phase A. & Strain & Eta* \\
\hline $\mathrm{rad} / \mathrm{s}$ & $\mathrm{Pa}$ & $\mathrm{Pa}$ & & g-cm & degree & $\%$ & $\mathrm{~Pa} \mathrm{~S}$ \\
\hline 0.1 & 3.5370324 & 54.47984 & 15.4027 & 0.227966 & 86.28536 & 10.01044 & 545.9433 \\
\hline 0.158489 & 2.8638849 & 82.44121 & 28.78649 & 0.344451 & 88.01043 & 10.01044 & 520.4829 \\
\hline 0.25119 & 3.9935124 & 127.5198 & 31.93173 & 0.53271 & 88.20627 & 10.00997 & 507.911 \\
\hline 0.398109 & 5.1724658 & 197.9927 & 38.27819 & 0.827064 & 88.50352 & 10.01092 & 497.5019 \\
\hline 0.630966 & 7.3696742 & 309.5681 & 42.00567 & 1.293129 & 88.63625 & 10.0114 & 490.7645 \\
\hline 1.000031 & 12.058879 & 486.6201 & 40.35368 & 2.032856 & 88.58045 & 10.01187 & 486.7546 \\
\hline 1.584961 & 21.023258 & 765.3652 & 36.40564 & 3.197767 & 88.42658 & 10.01259 & 483.0743 \\
\hline 2.512024 & 37.602974 & 1207.797 & 32.11971 & 5.050073 & 88.21676 & 10.01903 & 481.0392 \\
\hline 3.981323 & 74.705566 & 1890.148 & 25.30129 & 7.90924 & 87.73664 & 10.02379 & 475.1243 \\
\hline 6.310059 & 160.13528 & 2964.321 & 18.51135 & 12.42103 & 86.90784 & 10.03071 & 470.4621 \\
\hline 10.00073 & 323.59094 & 4632.035 & 14.31448 & 19.44696 & 86.00385 & 10.04048 & 464.2984 \\
\hline 15.8501 & 659.52631 & 7193.645 & 10.90729 & 30.2918 & 84.76167 & 10.05288 & 455.7584 \\
\hline 25.12061 & 1347.4882 & 11086.07 & 8.227212 & 46.87407 & 83.06982 & 10.06242 & 444.5619 \\
\hline 39.81348 & 2702.3032 & 16930.39 & 6.265169 & 71.85916 & 80.93137 & 10.04811 & 430.6253 \\
\hline 63.10059 & 5275.2759 & 25526.25 & 4.838846 & 108.3167 & 78.32359 & 9.962282 & 413.0809 \\
\hline 100 & 10105.802 & 37871.52 & 3.747503 & 158.7706 & 75.05908 & 9.710752 & 391.9668 \\
\hline
\end{tabular}

Table C4: Rheological Data of 3wt\%20A-PET using scCO2

\begin{tabular}{|c|c|c|c|c|c|c|c|}
\hline frequency & $\mathrm{G}^{\prime}$ & G" & tan delta & Torque & Phase A. & Strain & Eta* \\
\hline $\mathrm{rad} / \mathrm{s}$ & $\mathrm{Pa}$ & $\mathrm{Pa}$ & & $\mathrm{g}-\mathrm{cm}$ & degree & $\%$ & $\mathrm{Pas}$ \\
\hline 0.1 & 1.993849 & 66.82273 & 33.51444 & 0.279124 & 88.290924 & 10.00949 & 668.5222 \\
\hline 0.158489 & 3.388415 & 100.5473 & 29.67386 & 0.420086 & 88.069878 & 10.01044 & 634.7714 \\
\hline 0.25119 & 5.57107 & 153.0996 & 27.48117 & 0.639709 & 87.916008 & 10.01044 & 609.9 \\
\hline 0.398109 & 9.395045 & 236.9737 & 25.22327 & 0.990337 & 87.729645 & 10.01092 & 595.7154 \\
\hline 0.630966 & 14.8178 & 366.9632 & 24.76503 & 1.533695 & 87.687683 & 10.0114 & 582.0633 \\
\hline 1.000031 & 25.84422 & 571.0994 & 22.09776 & 2.387477 & 87.408936 & 10.01187 & 571.6664 \\
\hline 1.584961 & 44.73873 & 888.8909 & 19.86849 & 3.717168 & 87.118683 & 10.01259 & 561.5382 \\
\hline 2.512024 & 81.5066 & 1382.343 & 16.95989 & 5.786436 & 86.625595 & 10.01783 & 551.2462 \\
\hline 3.981323 & 145.4417 & 2151.405 & 14.79221 & 9.015542 & 86.132507 & 10.02332 & 541.6079 \\
\hline 6.310059 & 273.9054 & 3341.716 & 12.20026 & 14.02855 & 85.314201 & 10.03047 & 531.3616 \\
\hline 10.00073 & 513.1373 & 5156.944 & 10.04983 & 21.70576 & 84.317535 & 10.04096 & 518.2031 \\
\hline 15.8501 & 971.4504 & 7907.696 & 8.140092 & 33.40962 & 82.996376 & 10.05312 & 502.6558 \\
\hline 25.12061 & 1845.877 & 12037.7 & 6.521397 & 51.12249 & 81.282089 & 10.06361 & 484.7972 \\
\hline 39.81348 & 3483.007 & 18144.77 & 5.209514 & 77.45033 & 79.133881 & 10.04954 & 464.0651 \\
\hline 63.10059 & 6477.212 & 26990.14 & 4.166938 & 115.3623 & 76.505112 & 9.963951 & 439.8767 \\
\hline 100 & 11854.23 & 39457.29 & 3.328542 & 166.8834 & 73.278053 & 9.710752 & 411.9952 \\
\hline
\end{tabular}

Table C5: Rheological Data of 5wt\%20A-PET using scCO2

\begin{tabular}{|c|c|c|c|c|c|c|c|}
\hline frequency & $\mathrm{G}^{\prime}$ & $\mathrm{G} "$ & tan delta & Torque & Phase A. & Strain & Eta* $^{*}$ \\
\hline $\mathrm{rad} / \mathrm{s}$ & $\mathrm{Pa}$ & $\mathrm{Pa}$ & & $\mathrm{g}-\mathrm{cm}$ & degree & $\%$ & $\mathrm{~Pa} \mathrm{~s}$ \\
\hline
\end{tabular}




\begin{tabular}{|r|r|r|r|r|r|r|r|}
\hline & & & & & & & \\
\hline 0.1 & 3.188443 & 49.25011 & 15.44645 & 0.206075 & 86.295853 & 10.0102 & 493.5302 \\
\hline 0.158489 & 3.497991 & 70.24706 & 20.08212 & 0.293689 & 87.149277 & 10.01044 & 443.7784 \\
\hline 0.25119 & 5.650909 & 102.4343 & 18.12706 & 0.428398 & 86.842415 & 10.01092 & 408.416 \\
\hline 0.398109 & 8.313377 & 153.9428 & 18.51748 & 0.64379 & 86.908859 & 10.01116 & 387.2481 \\
\hline 0.630966 & 11.70235 & 233.5608 & 19.95846 & 0.976602 & 87.131645 & 10.01164 & 370.6281 \\
\hline 1.000031 & 16.89058 & 359.6337 & 21.29197 & 1.503637 & 87.31102 & 10.01235 & 360.0192 \\
\hline 1.584961 & 25.43273 & 557.4857 & 21.92001 & 2.330826 & 87.387955 & 10.01283 & 352.1005 \\
\hline 2.512024 & 39.22966 & 870.9581 & 22.20152 & 3.643341 & 87.421028 & 10.01831 & 347.0672 \\
\hline 3.981323 & 64.03479 & 1354.605 & 21.15421 & 5.66992 & 87.293533 & 10.02332 & 340.6199 \\
\hline 6.310059 & 120.5011 & 2111.676 & 17.52412 & 8.850209 & 86.734001 & 10.03119 & 335.1968 \\
\hline 10.00073 & 224.8512 & 3280.546 & 14.58985 & 13.77101 & 86.079033 & 10.04001 & 328.8001 \\
\hline 15.8501 & 430.6804 & 5082.752 & 11.80168 & 21.38595 & 85.156685 & 10.05097 & 321.8255 \\
\hline 25.12061 & 841.9021 & 7828.604 & 9.298711 & 33.03596 & 83.8619 & 10.0586 & 313.4377 \\
\hline 39.81348 & 1632.714 & 11981.75 & 7.33855 & 50.64517 & 82.240288 & 10.04048 & 303.7284 \\
\hline 63.10059 & 3148.96 & 18173.85 & 5.771381 & 76.53909 & 80.170029 & 9.948216 & 292.3053 \\
\hline 100 & 5998.053 & 27224.55 & 4.538897 & 112.7073 & 77.575211 & 9.692393 & 278.7746 \\
\hline
\end{tabular}

Table C6: Rheological Data of 1wt\%20A-PET using direct melt compounding

\begin{tabular}{|c|c|c|c|c|c|c|c|}
\hline frequency & $\mathrm{G}^{\prime}$ & G" & tan delta & Torque & Phase A. & Strain & Eta* \\
\hline $\mathrm{rad} / \mathrm{s}$ & $\mathrm{Pa}$ & $\mathrm{Pa}$ & & $\mathrm{g}-\mathrm{cm}$ & degree & $\%$ & $\mathrm{Pas}$ \\
\hline 0.1 & 2.208456 & 106.3379 & 48.15035 & 0.249217 & 88.81023 & 9.9863 & 1063.605 \\
\hline 0.158489 & 3.889975 & 142.2499 & 36.56833 & 0.333484 & 88.43358 & 9.987801 & 897.8721 \\
\hline 0.25119 & 5.818778 & 203.9927 & 35.05765 & 0.480177 & 88.36611 & 10.02813 & 812.4347 \\
\hline 0.398109 & 9.55541 & 309.3463 & 32.37394 & 0.726619 & 88.23075 & 10.00609 & 777.4089 \\
\hline 0.630966 & 14.73635 & 476.7995 & 32.35534 & 1.119409 & 88.22974 & 10.00127 & 756.0265 \\
\hline 1.000031 & 24.0876 & 740.2808 & 30.73286 & 1.737498 & 88.13635 & 9.997869 & 740.6501 \\
\hline 1.584961 & 42.01114 & 1154.934 & 27.49115 & 2.714577 & 87.91676 & 10.01076 & 729.1651 \\
\hline 2.512024 & 68.63101 & 1798.495 & 26.20528 & 4.229839 & 87.81464 & 10.01632 & 716.4757 \\
\hline 3.981323 & 136.6804 & 2818.492 & 20.62104 & 6.634995 & 87.22366 & 10.02128 & 708.7603 \\
\hline 6.310059 & 267.6709 & 4390.257 & 16.4017 & 10.35026 & 86.51103 & 10.02917 & 697.0473 \\
\hline 10.00073 & 518.523 & 6806.887 & 13.12746 & 16.08446 & 85.64384 & 10.04179 & 682.6108 \\
\hline 15.8501 & 1003.662 & 10491.34 & 10.45306 & 24.86938 & 84.53539 & 10.05692 & 664.9321 \\
\hline 25.12061 & 1954.643 & 16080.72 & 8.226934 & 38.27115 & 83.06959 & 10.0691 & 644.8522 \\
\hline 39.81348 & 3760.482 & 24438.38 & 6.498736 & 58.33203 & 81.25216 & 10.05455 & 621.0462 \\
\hline 63.10059 & 7102.212 & 36635.25 & 5.158289 & 87.19269 & 79.02858 & 9.958158 & 591.3944 \\
\hline 100 & 13038.97 & 53830.83 & 4.128458 & 125.7507 & 76.384 & 9.676277 & 553.8748 \\
\hline
\end{tabular}

Table C7: Rheological Data of 3wt\%20A-PET using direct melt compounding

\begin{tabular}{|r|c|c|c|c|c|c|c|}
\hline frequency & G' & G" & tan delta & Torque & Phase A. & Strain & Eta* $^{*}$ \\
\hline $\mathrm{rad} / \mathrm{s}$ & $\mathrm{Pa}$ & $\mathrm{Pa}$ & & $\mathrm{g}-\mathrm{cm}$ & degree & $\%$ & Pa s \\
\hline & & & & & & & \\
\hline 0.1 & 3.082079 & 42.60327 & 13.8229 & 0.100133 & 85.86222 & 9.990999 & 427.1444 \\
\hline 0.158489 & 4.407233 & 56.92622 & 12.91655 & 0.133846 & 85.57299 & 9.990913 & 360.2552 \\
\hline 0.25119 & 6.310593 & 79.10826 & 12.53579 & 0.186467 & 85.43908 & 10.01409 & 315.9342 \\
\hline
\end{tabular}




\begin{tabular}{|r|r|r|r|r|r|r|r|}
\hline 0.398109 & 8.444192 & 114.8046 & 13.59569 & 0.270197 & 85.79331 & 10.00367 & 289.1534 \\
\hline 0.630966 & 10.88831 & 170.1196 & 15.62406 & 0.400179 & 86.33785 & 10.00511 & 270.1693 \\
\hline 1.000031 & 14.88554 & 259.1912 & 17.41227 & 0.609538 & 86.71307 & 10.00633 & 259.6103 \\
\hline 1.584961 & 20.44434 & 397.8451 & 19.45991 & 0.935344 & 87.05829 & 10.00677 & 251.3438 \\
\hline 2.512024 & 31.66944 & 606.1883 & 19.14111 & 1.426244 & 87.00938 & 10.01391 & 241.6438 \\
\hline 3.981323 & 50.39443 & 955.998 & 18.97031 & 2.250571 & 86.98251 & 10.01942 & 240.4541 \\
\hline 6.310059 & 85.02304 & 1478.54 & 17.38987 & 3.484638 & 86.70885 & 10.02807 & 234.7018 \\
\hline 10.00073 & 131.5464 & 2295.771 & 17.45218 & 5.4173 & 86.72057 & 10.04043 & 229.9368 \\
\hline 15.8501 & 258.1375 & 3544.927 & 13.73271 & 8.385752 & 85.83514 & 10.05532 & 224.2455 \\
\hline 25.12061 & 459.2636 & 5454.386 & 11.87637 & 12.92848 & 85.187 & 10.06646 & 217.8963 \\
\hline 39.81348 & 856.2181 & 8364.797 & 9.76947 & 19.83066 & 84.15558 & 10.05143 & 211.1974 \\
\hline 63.10059 & 1590.452 & 12746.58 & 8.014442 & 29.99529 & 82.88769 & 9.952086 & 203.5706 \\
\hline 100 & 2952.215 & 19165.72 & 6.491977 & 43.99893 & 81.2432 & 9.670177 & 193.9176 \\
\hline
\end{tabular}

Table C8: Rheological Data of 5wt\%20A-PET using direct melt compounding

\begin{tabular}{|r|r|r|r|r|r|r|r|}
\hline \multicolumn{1}{|c|}{ frequency } & \multicolumn{1}{c|}{$\mathrm{G}^{\prime}$} & \multicolumn{1}{c|}{ G" } & \multicolumn{1}{c|}{ tan delta } & \multicolumn{1}{c|}{ Torque } & \multicolumn{1}{c|}{ Phase A. } & \multicolumn{1}{c|}{ Strain } & \multicolumn{1}{c|}{ Eta* } \\
\hline \multicolumn{1}{|c|}{$\mathrm{rad} / \mathrm{s}$} & \multicolumn{1}{c|}{$\mathrm{Pa}$} & $\mathrm{Pa}$ & & \multicolumn{1}{c|}{$\mathrm{g}$-cm } & \multicolumn{1}{c|}{ degree } & \multicolumn{1}{c|}{$\%$} & Pa s \\
\hline & & & & & & & \\
\hline 0.1 & 4.755786 & 38.44111 & 8.083019 & 0.136222 & 82.94743 & 14.98868 & 387.3403 \\
\hline 0.25119 & 9.627059 & 68.55212 & 7.120776 & 0.244069 & 82.006 & 15.02658 & 275.5872 \\
\hline 0.398109 & 12.78666 & 97.12194 & 7.595566 & 0.345167 & 82.49982 & 15.01722 & 246.0631 \\
\hline 0.630966 & 17.355 & 140.7927 & 8.112515 & 0.499952 & 82.97281 & 15.02047 & 224.8271 \\
\hline 1.000031 & 22.39096 & 211.2765 & 9.435792 & 0.74814 & 83.95041 & 15.00775 & 212.4532 \\
\hline 1.584961 & 29.29586 & 319.3302 & 10.90018 & 1.129178 & 84.75827 & 15.00762 & 202.3212 \\
\hline 2.512024 & 37.82909 & 486.3244 & 12.85583 & 1.718564 & 85.55216 & 15.01548 & 194.1835 \\
\hline 3.981323 & 53.53461 & 743.3882 & 13.88612 & 2.627089 & 85.881 & 15.02261 & 187.2024 \\
\hline 6.310059 & 81.51878 & 1146.886 & 14.06898 & 4.054965 & 85.93435 & 15.0308 & 182.2137 \\
\hline 10.00073 & 122.3822 & 1758.008 & 14.36491 & 6.220459 & 86.01783 & 15.04393 & 176.2134 \\
\hline 15.8501 & 195.5806 & 2697.4 & 13.79176 & 9.553124 & 85.85291 & 15.05466 & 170.6287 \\
\hline 25.12061 & 335.512 & 4145.414 & 12.35549 & 14.6935 & 85.37281 & 15.05736 & 165.5601 \\
\hline 39.81348 & 586.6469 & 6337.698 & 10.80326 & 22.42776 & 84.7115 & 15.01797 & 159.8652 \\
\hline 63.10059 & 1052.445 & 9657.637 & 9.176385 & 33.87166 & 83.78072 & 14.85975 & 153.9576 \\
\hline 100 & 1901.94 & 14516.64 & 7.632543 & 49.66644 & 82.53574 & 14.45808 & 146.407 \\
\hline
\end{tabular}

Table C9: Rheological Data of 1wt\%30B-PET using scCO2

\begin{tabular}{|r|r|r|r|r|r|r|r|}
\hline frequency & \multicolumn{1}{|c|}{$\mathrm{G}^{\prime}$} & \multicolumn{1}{c|}{$\mathrm{G} "$} & \multicolumn{1}{c|}{ tan delta } & \multicolumn{1}{c|}{ torque } & Phase A. & \multicolumn{1}{c|}{ strain } & \multicolumn{1}{c|}{ eta* } \\
\hline $\mathrm{rad} / \mathrm{s}$ & \multicolumn{1}{c}{$\mathrm{Pa}$} & \multicolumn{1}{c|}{$\mathrm{Pa}$} & & $\mathrm{g} \mathrm{cm}$ & & \multicolumn{1}{c|}{$\%$} & $\mathrm{~Pa} \mathrm{~s}$ \\
\hline 0.1 & 1.41833 & 62.00345 & 43.71581 & 0.207105 & 88.68958 & 8.005589 & 620.1943 \\
\hline 0.158489 & 1.68974 & 94.5005 & 55.92606 & 0.31563 & 88.97562 & 8.005827 & 596.3535 \\
\hline 0.25119 & 2.718166 & 145.8929 & 53.67329 & 0.487271 & 88.93263 & 8.005589 & 580.9074 \\
\hline 0.398109 & 3.911247 & 228.9012 & 58.52385 & 0.764537 & 89.02108 & 8.006065 & 575.0545 \\
\hline 0.630966 & 6.98985 & 359.8381 & 51.48009 & 1.202101 & 88.88717 & 8.007258 & 570.4045 \\
\hline 1.000031 & 11.8132 & 565.967 & 47.9097 & 1.890877 & 88.80426 & 8.007734 & 566.073 \\
\hline 1.584961 & 22.22431 & 889.6151 & 40.02892 & 2.97272 & 88.56894 & 8.00845 & 561.4603 \\
\hline 2.512024 & 47.8106 & 1407.769 & 29.44471 & 4.70836 & 88.05487 & 8.013456 & 560.7354 \\
\hline
\end{tabular}




\begin{tabular}{|r|r|r|r|r|r|r|r|}
\hline 3.981323 & 87.35986 & 2201.098 & 25.19576 & 7.367842 & 87.72717 & 8.018463 & 553.2912 \\
\hline 6.310059 & 178.8524 & 3454.815 & 19.31657 & 11.58151 & 87.0365 & 8.025854 & 548.2423 \\
\hline 10.00073 & 386.2986 & 5399.482 & 13.97749 & 18.14519 & 85.90782 & 8.035868 & 541.2887 \\
\hline 15.8501 & 792.8237 & 8388.448 & 10.58047 & 28.29094 & 84.6008 & 8.049458 & 531.5949 \\
\hline 25.12061 & 1633.847 & 12932.89 & 7.91561 & 43.83661 & 82.79981 & 8.061855 & 518.9241 \\
\hline 39.81348 & 3292.949 & 19739.69 & 5.994533 & 67.2644 & 80.52921 & 8.057802 & 502.6557 \\
\hline 63.10059 & 6480.58 & 29707.96 & 4.584151 & 101.4141 & 77.69412 & 7.995813 & 481.8749 \\
\hline 100 & 12430.37 & 43919.39 & 3.533232 & 148.4465 & 74.19705 & 7.796735 & 456.4457 \\
\hline
\end{tabular}

Table C10: Rheological Data of 3wt\%30B-PET using scCO2

\begin{tabular}{|c|c|c|c|c|c|c|c|}
\hline frequency & $\mathrm{G}^{\prime}$ & G" & tan delta & Torque & Phase A. & Strain & Eta* \\
\hline $\mathrm{rad} / \mathrm{s}$ & $\mathrm{Pa}$ & $\mathrm{Pa}$ & & g-cm & degree & $\%$ & $\mathrm{Pas}$ \\
\hline 0.1 & 0.465607 & 21.53278 & 46.24667 & 0.089936 & 88.76128 & 10.01068 & 215.3774 \\
\hline 0.158489 & 0.449295 & 32.90813 & 73.24392 & 0.137418 & 89.21779 & 10.00997 & 207.6557 \\
\hline 0.25119 & 1.199613 & 49.75767 & 41.47811 & 0.20784 & 88.61892 & 10.01092 & 198.1452 \\
\hline 0.398109 & 1.907072 & 77.09187 & 40.42422 & 0.32202 & 88.58292 & 10.01092 & 193.7042 \\
\hline 0.630966 & 3.436514 & 119.6431 & 34.81525 & 0.499814 & 88.35474 & 10.01092 & 189.6971 \\
\hline 1.000031 & 5.623183 & 186.848 & 33.22816 & 0.780709 & 88.27621 & 10.01235 & 186.9269 \\
\hline 1.584961 & 9.790231 & 293.1718 & 29.94534 & 1.225178 & 88.08736 & 10.01307 & 185.0741 \\
\hline 2.512024 & 21.12393 & 459.3161 & 21.74388 & 1.921513 & 87.36682 & 10.01855 & 183.0403 \\
\hline 3.981323 & 28.33146 & 712.963 & 25.16506 & 2.983317 & 87.7244 & 10.02356 & 179.2182 \\
\hline 6.310059 & 58.86222 & 1115.262 & 18.94699 & 4.672501 & 86.9788 & 10.02999 & 176.9894 \\
\hline 10.00073 & 108.7503 & 1736.163 & 15.96467 & 7.284874 & 86.41577 & 10.03953 & 173.9438 \\
\hline 15.8501 & 202.3273 & 2696.763 & 13.32872 & 11.33723 & 85.70937 & 10.05026 & 170.6199 \\
\hline 25.12061 & 376.6836 & 4178.719 & 11.09345 & 17.59837 & 84.84909 & 10.0555 & 167.0208 \\
\hline 39.81348 & 711.6852 & 6444.878 & 9.055799 & 27.13622 & 83.69856 & 10.03309 & 162.8608 \\
\hline 63.10059 & 1359.877 & 9899.161 & 7.279452 & 41.39941 & 82.17807 & 9.932718 & 158.3524 \\
\hline 100 & 2612.25 & 15126.83 & 5.790726 & 61.88216 & 80.20223 & 9.66426 & 153.5072 \\
\hline
\end{tabular}

Table C11: Rheological Data of 5wt\%30B-PET using scCO2

\begin{tabular}{|r|c|c|c|c|c|c|r|}
\hline frequency & $\mathrm{G}^{\prime}$ & \multicolumn{1}{c|}{$\mathrm{G}^{\prime \prime}$} & \multicolumn{1}{c|}{ tan delta } & \multicolumn{1}{c|}{ torque } & Phase A. & \multicolumn{1}{c|}{ strain } & eta* $^{*}$ \\
\hline $\mathrm{rad} / \mathrm{s}$ & $\mathrm{Pa}$ & $\mathrm{Pa}$ & & $\mathrm{g} \mathrm{cm}$ & & $\%$ & $\mathrm{~Pa} \mathrm{~s}$ \\
\hline & & & & & & & \\
\hline 0.1 & 0.608057 & 17.47947 & 28.74645 & 0.058409 & 88.00766 & 8.006065 & 174.8998 \\
\hline 0.158489 & 1.028572 & 25.47261 & 24.76503 & 0.085141 & 87.68768 & 8.006542 & 160.8523 \\
\hline 0.398109 & 2.480341 & 37.53762 & 22.33929 & 0.125484 & 87.43691 & 8.006065 & 149.5887 \\
\hline 0.630966 & 3.410112 & 56.36639 & 23.48489 & 0.188425 & 87.56178 & 8.006781 & 141.7135 \\
\hline 1.000031 & 5.308966 & 133.3953 & 25.12641 & 0.445938 & 87.7209 & 8.007973 & 133.4968 \\
\hline 1.584961 & 6.825323 & 207.0384 & 30.33386 & 0.692016 & 88.11185 & 8.008688 & 130.6978 \\
\hline 2.512024 & 14.69116 & 322.3092 & 21.939 & 1.078478 & 87.39021 & 8.013456 & 128.4398 \\
\hline 3.981323 & 13.47167 & 509.958 & 37.85411 & 1.706259 & 88.48676 & 8.018463 & 128.1323 \\
\hline 6.310059 & 20.26485 & 798.092 & 39.38306 & 2.672791 & 88.54548 & 8.026093 & 126.5201 \\
\hline 10.00073 & 33.72159 & 1252.727 & 37.14911 & 4.200007 & 88.45805 & 8.034676 & 125.3089 \\
\hline 15.8501 & 71.77454 & 1965.845 & 27.38917 & 6.602853 & 87.90901 & 8.046835 & 124.11 \\
\hline
\end{tabular}




\begin{tabular}{|r|r|r|r|r|r|r|r|}
\hline 25.12061 & 142.627 & 3068.784 & 21.51615 & 10.32173 & 87.339 & 8.054703 & 122.2939 \\
\hline 39.81348 & 296.5938 & 4811.302 & 16.22186 & 16.17044 & 86.47245 & 8.042067 & 121.0755 \\
\hline 63.10059 & 616.9677 & 7504.662 & 12.16378 & 25.01041 & 85.30021 & 7.962673 & 119.333 \\
\hline 100 & 1290.455 & 11679.57 & 9.050735 & 37.96741 & 83.69506 & 7.746071 & 117.5064 \\
\hline
\end{tabular}

Table C12: Rheological Data of 1wt\%30B-PET using direct melt compounding

\begin{tabular}{|c|c|c|c|c|c|c|c|}
\hline freq & $G^{\prime}$ & G" & tan delta & torque & Phase A. & strain & eta* \\
\hline $\mathrm{rad} / \mathrm{s}$ & $\mathrm{Pa}$ & $\mathrm{Pa}$ & & $\mathrm{g} \mathrm{cm}$ & & $\%$ & $\mathrm{Pas}$ \\
\hline 0.1 & 1.891883 & 59.10896 & 31.24345 & 0.01975 & 88.16678 & 8.006304 & 591.39 \\
\hline 0.158489 & 0.50349 & 89.73517 & 178.2265 & 0.029968 & 89.67853 & 8.006065 & 566.1999 \\
\hline 0.25119 & 1.643292 & 139.3365 & 84.79107 & 0.046537 & 89.3243 & 8.006304 & 554.7436 \\
\hline 0.398109 & 1.296853 & 219.2102 & 169.0324 & 0.073212 & 89.66104 & 8.006542 & 550.6377 \\
\hline 0.630966 & 4.252629 & 347.1102 & 81.62249 & 0.115945 & 89.29807 & 8.007258 & 550.1662 \\
\hline 1.000031 & 10.36996 & 542.8766 & 52.35089 & 0.181372 & 88.90568 & 8.007973 & 542.9591 \\
\hline 1.584961 & 18.00832 & 858.2739 & 47.65986 & 0.286764 & 88.798 & 8.008211 & 541.6302 \\
\hline 2.512024 & 32.01997 & 1349.191 & 42.13592 & 0.451111 & 88.64047 & 8.013456 & 537.2443 \\
\hline 3.981323 & 74.95343 & 2124.018 & 28.33784 & 0.710887 & 87.97896 & 8.018702 & 533.8277 \\
\hline 6.310059 & 166.4536 & 3335.568 & 20.03902 & 1.118104 & 87.14316 & 8.026093 & 529.2691 \\
\hline 10.00073 & 358.293 & 5210.155 & 14.54161 & 1.750556 & 86.06606 & 8.035868 & 522.2078 \\
\hline 15.8501 & 747.2783 & 8107.239 & 10.84902 & 2.733661 & 84.73369 & 8.049458 & 513.6628 \\
\hline 25.12061 & 1545.723 & 12506.64 & 8.091121 & 4.237875 & 82.95441 & 8.062094 & 501.6517 \\
\hline 39.81348 & 3124.006 & 19102.4 & 6.114714 & 6.506425 & 80.71207 & 8.058518 & 486.1712 \\
\hline 63.10059 & 6161.347 & 28779.76 & 4.671017 & 9.817494 & 77.91618 & 7.996767 & 466.4283 \\
\hline 100 & 11852.07 & 42624.33 & 3.59636 & 14.39096 & 74.46094 & 7.798165 & 442.4144 \\
\hline
\end{tabular}

Table C13: Rheological Data of 3wt\%30B-PET using direct melt compounding

\begin{tabular}{|r|c|r|r|r|r|r|r|}
\hline frequency & \multicolumn{1}{|c|}{$\mathrm{G}^{\prime}$} & \multicolumn{1}{c|}{$\mathrm{G}^{\prime \prime}$} & \multicolumn{1}{c|}{ tan delta } & \multicolumn{1}{c|}{ Torque } & \multicolumn{1}{c|}{ Phase A. } & \multicolumn{1}{c|}{ Strain } & Eta $^{*}$ \\
\hline $\mathrm{rad} / \mathrm{s}$ & $\mathrm{Pa}$ & \multicolumn{1}{c|}{$\mathrm{Pa}$} & & \multicolumn{1}{c|}{ g-cm } & \multicolumn{1}{c|}{ degree } & \multicolumn{1}{c|}{$\%$} & $\mathrm{~Pa} \mathrm{~s}$ \\
\hline & & & & & & & \\
\hline 1.000031 & 2.772179 & 166.4138 & 60.02996 & 0.195306 & 89.04563 & 5.001213 & 166.4318 \\
\hline 1.584961 & 4.409408 & 260.8846 & 59.16546 & 0.306257 & 89.03169 & 5.002472 & 164.6236 \\
\hline 2.512024 & 5.282933 & 436.8509 & -82.691 & 0.513186 & 90.69286 & 5.006328 & 173.9167 \\
\hline 3.981323 & 10.03603 & 657.3256 & 65.49654 & 0.773 & 89.12528 & 5.011383 & 165.1215 \\
\hline 6.310059 & 32.66844 & 1021.521 & 31.26934 & 1.203306 & 88.1683 & 5.017836 & 161.9704 \\
\hline 10.00073 & 58.87999 & 1581.515 & 26.85996 & 1.867122 & 87.86786 & 5.02815 & 158.2494 \\
\hline 15.8501 & 80.64922 & 2513.31 & 31.16348 & 2.973674 & 88.16208 & 5.040032 & 158.6491 \\
\hline 25.12061 & 186.2006 & 3907.551 & 20.98571 & 4.635235 & 87.27184 & 5.049915 & 155.7281 \\
\hline 39.81348 & 431.2731 & 6124.73 & 14.20151 & 7.263178 & 85.97216 & 5.041679 & 154.2165 \\
\hline 63.10059 & 736.7045 & 9565.056 & 12.98357 & 11.20424 & 85.59575 & 4.9776 & 152.0332 \\
\hline 100 & 1511.562 & 14738.49 & 9.7505 & 16.65378 & 84.14429 & 4.790683 & 148.1579 \\
\hline
\end{tabular}

Table C14: Rheological Data of 5wt\%30B-PET using direct melt compounding

\begin{tabular}{|c|c|c|c|c|c|c|c|}
\hline frequency & G' & G" & tan delta & torque & Phase $\mathrm{A}$. & strain & eta* $^{*}$ \\
\hline $\mathrm{rad} / \mathrm{s}$ & $\mathrm{Pa}$ & $\mathrm{Pa}$ & & $\mathrm{g} \mathrm{cm}$ & & $\%$ & Pa s \\
\hline
\end{tabular}




\begin{tabular}{|r|r|r|r|r|r|r|r|}
\hline & & & & & & & \\
\hline 0.1 & 0.608975 & 8.091776 & 13.28753 & 0.025339 & 9.981295 & 85.69612 & 81.14629 \\
\hline 0.158489 & 1.047903 & 11.60114 & 11.07082 & 0.036456 & 10.00403 & 84.83862 & 73.49631 \\
\hline 0.25119 & 1.0121 & 17.05895 & 16.85501 & 0.053506 & 10.00821 & 86.60465 & 68.03191 \\
\hline 0.398109 & 1.345219 & 25.15888 & 18.70245 & 0.078885 & 10.00821 & 86.93937 & 63.28616 \\
\hline 0.630966 & 2.069697 & 39.21578 & 18.94759 & 0.122976 & 10.00983 & 86.9789 & 62.23846 \\
\hline 1.000031 & 2.844826 & 59.85115 & 21.0386 & 0.187638 & 10.00986 & 87.27869 & 59.91689 \\
\hline 1.584961 & 4.086642 & 92.9529 & 22.74555 & 0.291385 & 10.01049 & 87.48264 & 58.70347 \\
\hline 2.512024 & 2.029292 & 145.9371 & 71.91528 & 0.457351 & 10.01643 & 89.20334 & 58.10104 \\
\hline 3.981323 & 12.54381 & 218.9746 & 17.45679 & 0.687709 & 10.02237 & 86.72144 & 55.09063 \\
\hline 6.310059 & 15.92905 & 354.539 & 22.25738 & 1.113684 & 10.03069 & 87.42749 & 56.24301 \\
\hline 10.00073 & 16.84293 & 547.9777 & 32.53457 & 1.722331 & 10.04198 & 88.23948 & 54.81963 \\
\hline 15.8501 & 35.57129 & 856.6691 & 24.08316 & 2.6974 & 10.05609 & 87.62228 & 54.09476 \\
\hline 25.12061 & 61.18284 & 1336.641 & 21.84667 & 4.213266 & 10.06515 & 87.3792 & 53.26466 \\
\hline 39.81348 & 115.5441 & 2087.687 & 18.06831 & 6.571414 & 10.04616 & 86.83217 & 52.51693 \\
\hline 63.10059 & 212.6664 & 3244.527 & 15.25641 & 10.113 & 9.941883 & 86.24984 & 51.52866 \\
\hline 100 & 408.7553 & 4996.086 & 12.22268 & 15.14269 & 9.655952 & 85.32276 & 50.1278 \\
\hline
\end{tabular}

Table C15: Time Sweep of 5wt\%30B-PET using direct melt compounding

\begin{tabular}{|r|r|r|r|r|r|r|}
\hline \multicolumn{1}{|c|}{ Time } & \multicolumn{1}{c|}{$\mathrm{G}^{\prime}$} & \multicolumn{1}{c|}{$\mathrm{G}^{\prime \prime}$} & tan delta & \multicolumn{1}{c|}{ eta } & \multicolumn{1}{c|}{ Strain } & Freq \\
\hline sec & \multicolumn{1}{c|}{$\mathrm{Pa}$} & \multicolumn{1}{c|}{$\mathrm{Pa}$} & & $\mathrm{Pa} \mathrm{s}$ & $\%$ & $\mathrm{rad} / \mathrm{s}$ \\
\hline 6 & & & & & 8 & 1 \\
\hline 18 & 1181.3099 & 446.9035 & 2.336019 & 486.1298 & 8 & 1 \\
\hline 30 & 96.98 & 319.3886 & 3.293345 & 333.7876 & 8 & 1 \\
\hline 43 & 89.01975 & 306.9352 & 3.447944 & 319.5837 & 8 & 1 \\
\hline 56 & 82.95817 & 297.8221 & 3.590028 & 309.1603 & 8 & 1 \\
\hline 68 & 79.84798 & 291.3985 & 3.649416 & 302.1404 & 8 & 1 \\
\hline 81 & 77.26474 & 280.2924 & 3.627689 & 290.7468 & 8 & 1 \\
\hline 93 & 75.03131 & 275.2039 & 3.667854 & 285.2488 & 8 & 1 \\
\hline 106 & 71.36089 & 267.3406 & 3.746317 & 276.7008 & 8 & 1 \\
\hline 119 & 67.70045 & 259.582 & 3.834274 & 268.2651 & 8 & 1 \\
\hline 132 & 66.11732 & 256.8474 & 3.884722 & 265.2208 & 8 & 1 \\
\hline 145 & 64.72115 & 249.606 & 3.856637 & 257.8604 & 8 & 1 \\
\hline 157 & 63.27168 & 246.5407 & 3.896541 & 254.5302 & 8 & 1 \\
\hline 170 & 59.90483 & 240.7307 & 4.018553 & 248.0723 & 8 & 1 \\
\hline 182 & 56.44561 & 234.871 & 4.161015 & 241.5585 & 8 & 1 \\
\hline 195 & 58.80237 & 233.2604 & 3.966853 & 240.5579 & 8 & 1 \\
\hline 207 & 52.74791 & 225.1319 & 4.268072 & 231.2287 & 8 & 1 \\
\hline 220 & 53.52376 & 223.7648 & 4.180664 & 230.0772 & 8 & 1 \\
\hline 232 & 53.40081 & 222.04 & 4.15799 & 228.3712 & 8 & 1 \\
\hline 243 & 51.93164 & 218.8075 & 4.213376 & 224.8858 & 8 & 1 \\
\hline 256 & 50.7131 & 215.7233 & 4.253799 & 221.6041 & 8 & 1 \\
\hline 268 & 49.42908 & 210.9548 & 4.267828 & 216.6684 & 8 & 1 \\
\hline 281 & 50.37007 & 210.4549 & 4.178175 & 216.3988 & 8 & 1 \\
\hline 294 & 49.72667 & 206.8185 & 4.159106 & 212.7126 & 8 & 1 \\
\hline 306 & 50.22848 & 205.2642 & 4.086609 & 211.3203 & 8 & 1 \\
\hline & & & & & & 8 \\
\hline
\end{tabular}




\begin{tabular}{|r|r|r|r|r|r|r|}
\hline 319 & 49.73188 & 203.1811 & 4.085529 & 209.1789 & 8 & 1 \\
\hline 331 & 47.95652 & 199.1354 & 4.152415 & 204.8285 & 8 & 1 \\
\hline 344 & 51.117 & 201.5794 & 3.94349 & 207.9596 & 8 & 1 \\
\hline 357 & 51.40433 & 200.4007 & 3.898517 & 206.8885 & 8 & 1 \\
\hline 370 & 52.1053 & 199.0396 & 3.819948 & 205.7467 & 8 & 1 \\
\hline 382 & 52.48972 & 198.6756 & 3.785038 & 205.4925 & 8 & 1 \\
\hline 395 & 50.9199 & 195.0458 & 3.830444 & 201.583 & 8 & 1 \\
\hline 407 & 51.70895 & 194.5658 & 3.762711 & 201.3199 & 8 & 1 \\
\hline 420 & 51.84563 & 193.1319 & 3.725133 & 199.9697 & 8 & 1 \\
\hline 432 & 50.16413 & 188.846 & 3.764562 & 195.3951 & 8 & 1 \\
\hline 445 & 50.94099 & 190.6913 & 3.743376 & 197.3782 & 8 & 1 \\
\hline 458 & 49.85695 & 187.2749 & 3.756245 & 193.7979 & 8 & 1 \\
\hline 470 & 50.11567 & 186.3242 & 3.717882 & 192.9463 & 8 & 1 \\
\hline 483 & 49.99794 & 183.297 & 3.666091 & 189.9936 & 8 & 1 \\
\hline 495 & 47.58511 & 179.6231 & 3.774774 & 185.8192 & 8 & 1 \\
\hline 508 & 46.72905 & 179.0824 & 3.832358 & 185.0787 & 8 & 1 \\
\hline 520 & 43.61864 & 174.5562 & 4.001872 & 179.9235 & 8 & 1 \\
\hline 533 & 42.61552 & 170.1885 & 3.99358 & 175.4429 & 8 & 1 \\
\hline 545 & 42.45139 & 169.1824 & 3.985321 & 174.4271 & 8 & 1 \\
\hline 558 & 38.34694 & 165.6598 & 4.320028 & 170.0402 & 8 & 1 \\
\hline 570 & 40.81431 & 165.2189 & 4.048063 & 170.1855 & 8 & 1 \\
\hline 583 & 40.14841 & 163.8975 & 4.082293 & 168.7433 & 8 & 1 \\
\hline 595 & 38.27077 & 161.3368 & 4.215666 & 165.8138 & 8 & 1 \\
\hline 608 & 38.5597 & 160.5463 & 4.163578 & 165.112 & 8 & 1 \\
\hline & & & & & & 8 \\
\hline
\end{tabular}


Appendix D: Actual Silicate Loading Calculations 
Actual silicate loadings were obtained by burn off. A known amount of sample was placed in an ashing oven at $600^{\circ} \mathrm{C}$ for over 3 hours. The silicate layers remained intact while the polymer matrix and the silicate surface modification was burned off. The layered silicate remaining was weighed and used to calculate the actual silicate loading of the sample. For Cloisite 20A, a 38\% weight loss upon ignition occurred due to burn off of the surface modification. For Cloisite 30B, a 30\% weight loss upon ignition occurred. Burning neat PET left no residue. The following equations were used to calculate actual silicate loadings as a weight fraction:

$$
\begin{gathered}
\frac{\left(m_{\text {silicate }}\right)}{(1-\alpha)}=M_{\text {silicate }} \\
X_{\text {silicate }}=\frac{M_{\text {silicate }}}{M_{\text {total }}}=\text { Actual wt frac. nanoclay loading }
\end{gathered}
$$

where $\mathrm{m}_{\text {silicate }}$ is the mass of the silicate after burn off, $\alpha$ is the silicate weight loss on ignition, $\mathrm{M}_{\text {silicate }}$ is the mass of the silicate prior to burn off and $\mathrm{M}_{\text {total }}$ is the weight of the sample prior to burn off.

Volume fractions of layered silicate in the PLSNs were calculated using the following equation:

$$
\phi_{\text {silicate }}=\frac{\rho_{\text {sample } \times X_{\text {silicate }}}}{\rho_{\text {nanoclay }}}
$$

where $\rho_{\text {sample }}$ is the density of the PLSN sample calculated in lab and $\rho_{\text {nanoclay }}$ is the density of the nanoclay as reported by Southern Clay Products Inc.. The results of the burn off tests are shown in Table D1. 
Table D1: Actual silicate loadings in weight and volume percent

\begin{tabular}{|c|c|c|}
\hline Material Description & $\begin{array}{c}\text { Silicate Loading } \\
(\mathrm{wt} \%)\end{array}$ & $\begin{array}{c}\text { Silicate Loading } \\
\text { (vol\%) }\end{array}$ \\
\hline Neat PET & 0 & 0 \\
\hline 1wt\% Cloisite 20A/PET Melt Compounded & 1.27 & 0.99 \\
\hline 3wt\% Cloisite 20A/PET Melt Compounded & 3.32 & 2.59 \\
\hline 5wt\% Cloisite 20A/PET Melt Compounded & 5.80 & 4.55 \\
\hline 1wt\% Cloisite 20A/PET scCO2 & 1.09 & 0.85 \\
\hline 3wt\% Cloisite 20A/PET scCO2 & 2.60 & 2.02 \\
\hline 5wt\% Cloisite 20A/PET scCO2 & 4.78 & 3.74 \\
\hline 1wt\% Cloisite 30B/PET Melt Compounded & 1.21 & 0.84 \\
\hline 3wt\% Cloisite 30B/PET Melt Compounded & 2.85 & 1.99 \\
\hline 5wt\% Cloisite 30B/PET Melt Compounded & 5.21 & 3.66 \\
\hline 1wt\% Cloisite 30B/PET scCO2 & 1.14 & 0.79 \\
\hline 3wt\% Cloisite 30B/PET scCO2 & 2.84 & 1.98 \\
\hline 5wt\% Cloisite 30B/PET scCO2 & 4.93 & 3.46 \\
\hline
\end{tabular}

